Illinois State University

ISU ReD: Research and eData

Theses and Dissertations

6-2-2016

\title{
A Quantitative Analysis of Sex Trafficking Law on the Decriminalization of Youth Involved in Commercialized Sex
}

Nay Petrucelli

Illinois State University, rpetruc@ilstu.edu

Follow this and additional works at: https://ir.library.illinoisstate.edu/etd

Part of the Criminology Commons, Criminology and Criminal Justice Commons, and the Political Science Commons

\section{Recommended Citation}

Petrucelli, Nay, "A Quantitative Analysis of Sex Trafficking Law on the Decriminalization of Youth Involved in Commercialized Sex" (2016). Theses and Dissertations. 593.

https://ir.library.illinoisstate.edu/etd/593

This Thesis is brought to you for free and open access by ISU ReD: Research and eData. It has been accepted for inclusion in Theses and Dissertations by an authorized administrator of ISU ReD: Research and eData. For more information, please contact ISUReD@ilstu.edu. 


\section{A QUANTITATIVE ANALYSIS OF SEX TRAFFICKING LAW ON THE DECRIMINALIZATION OF YOUTH INVOLVED IN \\ COMMERCIALIZED SEX}

Nay Petrucelli

\section{Pages}

Legislators have been responding to the growing push to treat youth in the sex industry as victims of a crime instead of perpetrators. Recent legislative changes have occurred in every state and nationally as part of anti-trafficking legislation, not prostitution law directly. While the content of these laws has been studied, its outcomes for youth have not. This study uses a cross-sectional time-series model to test the impact that changes to state trafficking law has had on juvenile prostitution arrest rates. Findings support the hypothesis that legislation passed with a juvenile protection component decreases the juvenile prostitution arrest rate. It also found that higher child poverty rates in a state resulted in lower arrest rates, opposite the anticipated direction. The author concludes by making a case for youth decriminalization and access to services, as well as for a reframing of the prostitution-consent law paradox and the implicit definition of prostitution victimhood in the current literature. 
KEYWORDS: Child Prostitution, Child Sex Trafficking, FBI Data, Trafficking Law Analysis, Victims of Trafficking and Violence Protection Act 
A QUANTITATIVE ANALYSIS OF SEX TRAFFICKING LAW ON THE DECRIMINALIZATION OF YOUTH INVOLVED IN COMMERCIALIZED SEX

NAY PETRUCELLI

A Thesis Submitted in Partial Fulfillment of the Requirements for the Degree of

MASTER OF SCIENCE

Department of Politics and Government

ILLINOIS STATE UNIVERSITY 
(C) 2016 Nay Petrucelli 
A QUANTITATIVE ANALYSIS OF SEX TRAFFICKING LAW ON THE DECRIMINALIZATION OF YOUTH INVOLVED IN

COMMERCIALIZED SEX

NAY PETRUCELLI

COMMITTEE MEMBERS:

T.Y. Wang, Chair

Meghan Leonard

Michael Gizzi 


\section{ACKNOWLEDGMENTS}

I am indebted to the following people:

My committee, Dr. T.Y. Wang, Dr. Meghan Leonard, and Dr. Michael Gizzi, for helping me stumble through rewrites, modeling errors, fast-approaching deadlines, and my own self-doubt;

My thesis accountability partner, Ramya Kumaran, for our accountability video conferencing, showing me tough love, and letting me know when it was time to relax and have a beer;

Mary Taylor, Cherie Valentine, Dr. Frank Beck, Dr. Osaore Aideyan, Dr. Kerri Milita, Grace Allbaugh, Dr. Kam Shapiro, and Dr. Carl Palmer for supporting me at various stages throughout this process. From buying me coffee and asking me how I am really doing, to helping me work through administrative hurdles, to providing initial feedback on parts of my project, each of you have helped me cross the finish line;

My family by choice, who have each contributed in their own ways: my "pops", John Panganiban, who sends me emergency clothing care packages when my fashion sense is lacking; Katie Raynor for giving me a place to stay in Normal; Katie Simpson and Shikshya Adhikari for their empathy and advice; Danielle Shaubah who reminds me of brighter beaches at the end of the tunnel; and Bibian Guevara, Christina Davila, and Xayden Zebbera for prying me away from my computer every so often;

Nicole Ersland, and my TLEG family for their love, community, and for giving me a sense of purpose on campus; 
All of the Wifi-enabled coffee shops (with outlets) and breweries that fueled me; And to my partner, Kellen Carter, for formatting my entire thesis, doing the dinner dishes, and having my best interests at heart. Te quiero mon coco.

This paper is dedicated to the students I have had over the years, who have shared their stories with me, who have challenged me to do better, and who have inspired me to be proactive in creating the kind of world I want to live in through their own tenacity and grit.

My thesis is especially dedicated to you, knucklehead. You still owe me that tattoo design for my forehead.

N. P. 


\section{CONTENTS}

Page

ACKNOWLEDGMENTS

CONTENTS

TABLES

FIGURES

CHAPTER

i

iii

$\mathrm{V}$

vi
I. INTRODUCTION 1

Study Overview $\quad 2$

Existent Research 3

An Exploratory Look at Existing Data 5

II. LEGISLATIVE HISTORY 9

Defining Trafficking in Federal Policy $\quad 9$

A Brief History of Children as a Protected Class 11

History of Laws and Policies Regulating Juvenile

Commercialized Sex

13

$\begin{array}{ll}\text { The TVPA and State Law } & 17\end{array}$

III. LITERATURE REVIEW 26

Characteristics of Commercially Sexually Exploited Children (CSEC)

Dysfunctional Home Life

28

Insufficient or Ineffective Services for Youth

30

Entrance by Choice

31

33

Characteristics of CSEC Susceptible to Arrest

35

The 3P Index and Defining a 'Strong' Anti-Trafficking Law

The 3P Index: Protection, Prevention and Prosecution

1

2

5

9

9

1


Compliance Decision Making and International Trafficking Policy

Compliance Decisions for the Protection Component of Trafficking Law

Domestic Measures of 'Strong' Anti-Trafficking Laws

IV. METHODOLOGY

Dependent Variable: Juvenile Prostitution Arrest Data

Measuring Juvenile Protections in State Trafficking Legislation

Police Response to Victimless Crimes

Socio-Economic Factors Contributing to Sex Industry Participation

Race as a Factor Contributing to Arrest

Model

Data Limitations of the CIUS

V. ANALYSIS OF THE DATA 63

$\begin{array}{ll}\text { VI. CONCLUSIONS } & 70\end{array}$

$\begin{array}{ll}\text { Study Implications } & 70\end{array}$

Broader Implications $\quad 73$

Arresting Youth Furthers the Paradox between Prostitution and Consent Law

Perceptions of Culpability Are Non-Random, Historically Consistent, and Suggest Bias

REFERENCES

APPENDIX A: Level of Compliance with Protection and Prosecution Elements of Domestic Anti-Trafficking Law

APPENDIX B: State Legislation

APPENDIX C: Discussion of CIUS Dataset and Potential Limitations 


\section{TABLES}

Table $\quad$ Page

1. Cho et al. (2011) 3P Index Sub-Categories 38

2. Classification of Trafficking Metric Sub-Components Using the 3Ps 45

3. Explanation of Variables, Data Sources 58

4. Variable Descriptives 64

$\begin{array}{lll}\text { 5. } & \text { Model Descriptions } & 67\end{array}$

6. Model Parameter Coefficients and (Standard Errors) 69 


\section{FIGURES}

Figure $\quad$ Page

1. Rate of Juvenile Arrest for Prostitution and Commercialized Vice 6

2. Rate of Arrest for Prostitution and Commercialized Vice by Age 7

3. Selected Maps of Juvenile Prostitution Arrest by State 47

4. Juvenile Prostitution Arrest Rate by State and Year, Nevada Highlighted 60

5. Juvenile Prostitution Arrest Rates by State, 2001-2014 66 


\section{CHAPTER I}

\section{INTRODUCTION}

‘.... a child cannot [legally] consent to sex with an adult' and, therefore, 'prosecution' of a thirteen-year-old juvenile for the offense of prostitution leads to an absurd result, violates due process of law, and 'offends public policy notions that children [suffering] sexual exploitation must be protected as victims.",

-In re B.W. (Court of Appeals of Texas), 2008

It may be somewhat jarring to hear that teenagers in the United States, who cannot legally buy pornography or even enter a sex toy store, are commonly considered culpable for the crime of prostitution. How can youth — not yet deemed sophisticated enough to equip themselves with tools for their own sexual pleasure — be arrested for using their wiles to seduce grown adults into the sex economy? Even more baffling are prostitution laws in some states that are explicitly paradoxical. Cases such as In re B.W. illustrate how children have been arrested for commercial sex when they were not legally old enough to give permission to have sex under the state's own age of consent laws (see Dysart 2014). The Federal Advisory Committee on Juvenile Justice (FACJJ), in its annual report to the Office of Juvenile Justice and Delinquency Prevention, recommended that states redefine youth sex work as an act of child exploitation, not juvenile delinquency. In defense of this recommendation the authors write: "In many instances, the crime of prostitution, as applied to juveniles, purports to hold juveniles accountable for conduct to which they are legally unable to consent" ("Federal Advisory Committee" 2007). 
In the past fifteen years there has been a great deal of momentum from advocacy organizations, academia, and legislators to increasingly treat these youth as victims of a crime instead of perpetrators. Recent legislative changes have occurred in every state and nationally as part of anti-trafficking legislation, not prostitution law directly. This relationship between human trafficking efforts and juvenile prostitution will be discussed thoroughly in Chapter 2. The current chapter will introduce the study and some of the underlying themes from the existent literature, as well as provide some justification for conducting this type of analysis.

\section{Study Overview}

In this study, human trafficking laws that allege to provide protections for youth engaged in sex work are put to the test. Specifically, this paper asks the following research question: Can the decline in state arrests for juvenile prostitution be explained, in part, by changes in state sex trafficking law? The present study will employ a crosssectional time series analysis considering juvenile arrest for prostitution by state as the dependent variable. The explanatory variable of interest is the year in which a state adopted anti-trafficking legislation that provided protections for juveniles engaged in prostitution. In addition to changes to state trafficking law, the study will also consider factors that make a state's youth population more vulnerable to entrance into the sex economy, as well as what makes this population more susceptible to arrest. It will also consider how police response to so-called 'victimless crime' may have changed over the course of the study. Data was collected from the year 2001, prior to the influence of federal trafficking law on state trafficking legislation, until the most recent year for which data was available (2014). 


\section{Existent Research}

Human trafficking legislation in the United States hit a major turning point in 2000 when Congress passed the Victims of Trafficking Violence Protection Act, or TVPA. Following the passage of this law, states began to pass their own anti-trafficking statutes. Many of these laws adopted some of the language from the TVPA, but only a couple of states consider all youth trafficking victims as the federal law does. A large body of legal research has emerged comparing different state models to each other or against the standard presented in the TVPA (for example, see Dess 2013; Dysart 2014; Heiges 2010; Kara 2007; and Sager 2012). These articles commonly identify the jurisdictions or models that create the strongest stated protections for juveniles engaged in the sex industry.

All of the scholarship debating the best framework to protect juveniles is predicated on the assumption that the policies created will be implemented as designed. However, interviews with police and prosecutors show that there are many professionals who view new anti-trafficking laws as political stunts rather than the directives for procedural change that they are intended to be (Farrell et al. 2013). Existent research on law enforcement attitudes towards trafficking shows that officers (who may express sympathy towards trafficking victims) are not likely to perceive trafficking as a problem in their own neighborhoods and are likely to perceive populations of youth who would be classified as trafficking victims under the TVPA (and some state laws) as willingly engaging in an illegal sexual act (Halter 2010). A low emphasis on officer training, combined with the difficulty that states and the federal government face in attaching 
funding to the stipulations presented in their trafficking laws, add credence to the notion that policies are enacted with a preference for ideas over substantive change.

Even though there is some evidence to suggest that these laws have not been utilized to their full potential, there are no studies that attempt to measure the impact that these laws have had on states, institutional policies, or people. This is alarming, given the amount of advocacy for these laws and academic research published about them. The most relevant literature looks at the impact that the U.N. anti-trafficking protocol has had on the policies of nations who have signed on to it. Researchers in this field have developed an index that considers three different elements of anti-trafficking legislation and looks at how these elements fair differently when they are adopted by individual nations. Although the focus of the research in this thesis is state-level legislation, the 3P Index is pertinent for two primary reasons. First, it validates the importance of this study's research question despite the lack of domestic studies with a similar focus. Both domestic and international anti-trafficking literature have been dominated by studies that narrowly focus on the language used in the laws or policies themselves. Researchers using the 3P Index (Cho and Vadlamannati 2012) made a similar observation about the lack of empirical data measuring any tangible impacts of the Protocol as this project makes about the dearth of data regarding the effectiveness of state-level trafficking policy changes in the United States. Both studies shift the focus away from the semantics and structure of a few overarching policies towards a discussion of their outcomes. Data of this kind are critical in determining whether anti-trafficking directives are successful in creating the type of changes that they espouse. 
While this research does not consider domestic law directly, the highly politicized nature of this area of policy and evidence of low buy-in from implementing populations (Farrell et al. 2013) demonstrate that the conditions to foster similar discrepancies exist domestically. It is especially pertinent to consider in this thesis because the lowest levels of compliance have been found with respect to the protection aspects of anti-trafficking legislation, the sub-component that is measured here. To further illustrate this point, a crude test using a 2014 domestic state-level metric of juvenile trafficking law found that on average, states received more than 10 percentage points closer to full compliance for their prosecution related policies than their protection ones (see Appendix A). This provides additional support for the relevance of the 3P index research in a domestic context. Some of the most prominent theories from this emerging body of literature will be discussed in Chapter 3 and be used to guide the model and an analysis of the findings.

\section{An Exploratory Look at Existing Data}

This thesis applies the more critical type of analysis found in international research to the study of domestic law by asking whether changes in state anti-trafficking legislation have impacted the degree to which youth are criminalized, as measured by arrest data. To test the plausibility of this idea, the national arrest rate for this population was graphed in Figure 1 below. A quick analysis of the data available on the Bureau of Justice Statistics website shows a decline in the national rate of juvenile arrests beginning in 2005 for the crime category Prostitution and Commercialized Vice. This consistent decline followed a relatively stable arrest rate lasting from 1993 until 2004, where it had a brief spike. This portion of the graph reveals a story consistent with what one may expect to see following the passage of the TVPA in 2000. 
It would be unrealistic to expect that the passage of the TVPA would bring about an immediate, drastic reduction of juvenile prostitution arrests for several reasons: the TVPA's jurisdiction only rarely covers juvenile cases of this type, and a federal recognition of a domestic problem regarding children in the sex industry did not reveal itself in policy until the 2005 reauthorization of the TVPA. Instead, it is expected that a lag would exist between the passage of the TVPA and state-level mechanisms designed to manage these types of cases in an alternate way.

\section{Figure 1}

\section{Rate of Juvenile Arrest for Prostitution and Commercialized Vice}

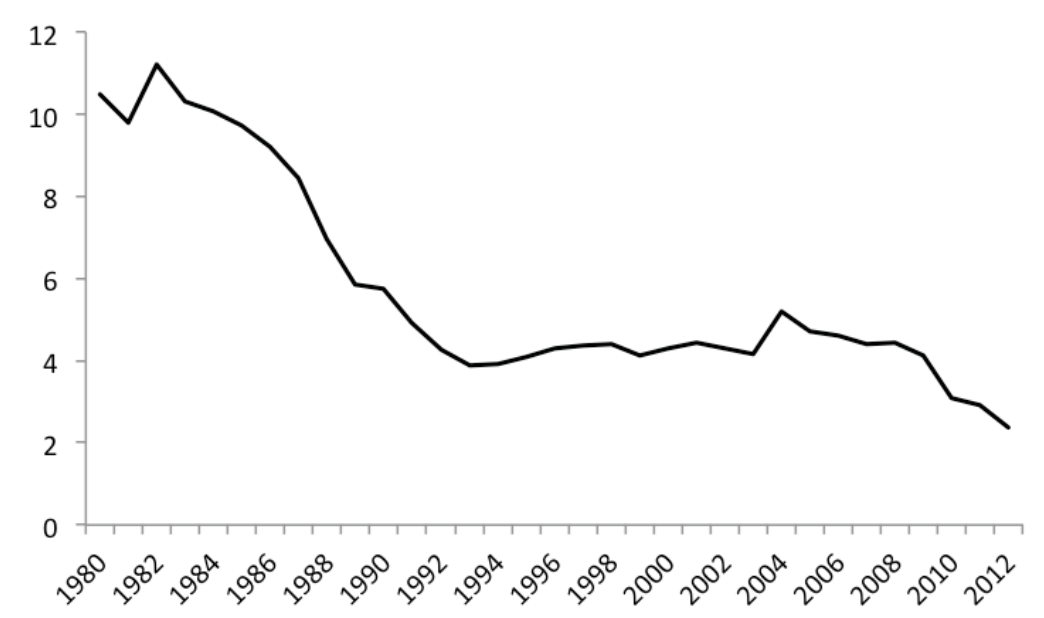

Source: Bureau of Justice Statistics; rate out of 100,000 juveniles

However, the data also reveal that sharp declines in juvenile arrests for prostitution occurred in the 1980s, decades before the federal recognition of youth as trafficking victims emerged. While this does not eliminate the possibility that post-TVPA legislative changes have sparked the recent reductions in juvenile arrests, it is clear that other factors have contributed to sharp declines in the past. If new policies were having an impact on juvenile arrests, could this be seen through a change in the rate at which youth were 
arrested? Seventeen and 18 year-olds have very similar levels of growth, maturity, and experience, but are separated by an artificial legal marker of adulthood. Figure 2 below graphs the rates at which teenagers have been arrested for prostitution, separated into 18, 17, and below 17 age brackets.

\section{Figure 2}

Rate of Arrest for Prostitution and Commercialized Vice by Age

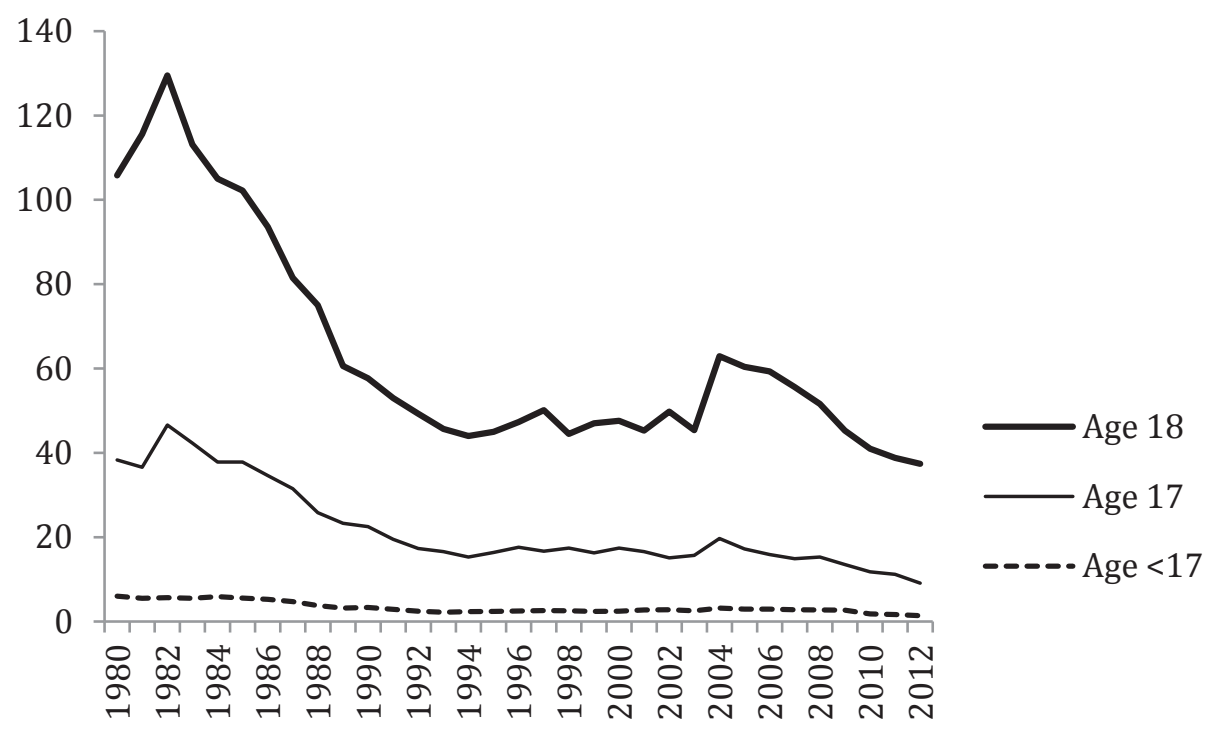

Source: Bureau of Justice Statistics; rate out of 100,000 juveniles

The figure shows that age is clearly important when considering arrest rates:

juveniles are less likely to get arrested than 18 year-olds and the combined arrest rate for juveniles 16 and under is much lower than 17 year-olds alone. If the data for the dashed line were disaggregated to show each year in age, the rates would continue to get progressively lower as children get younger. Intuitively, it is plausible that an officer would be more reluctant to arrest an 11 year-old for prostitution than a 17 year-old based on appearance alone. However, older teens are very similar in appearance and maturity, and drastically lower rates of 17 year-olds have been arrested for prostitution than 18 
year-olds, at least since 1980. One likely explanation is that officers are reluctant to arrest 17 year-olds because they are still perceived as more vulnerable than 18 year-olds. Evidence consistently suggests that law enforcement and the public are more likely to find youth who appear less vulnerable and more autonomous as more culpable for prostitution (Halter 2010; Menaker and Franklin 2013; Menaker and Miller 2012). Although the arrest rates between the graphs differ, the rates of change of these graphs appear fairly consistent. This is not surprising, given that previous prostitution law did not provide a legal distinction between juveniles and adults (Crile 2012). However, the anticipated steeper decline of recent arrests for 17 year-olds is not visible in the figure above. This suggests that if legislative changes have been responsible for some of the reduction in juvenile prostitution arrests, they have not likely been affecting juveniles in a drastically different way than adults.

In order to study the nuance in these variables, the model is designed to consider the relationship between individual legislative changes in each state and the juvenile prostitution arrest rates of those states. This thesis will proceed as followed: the second chapter will provide a comprehensive overview of relevant trafficking legislation, as well as provide some pertinent historical context for juvenile treatment under the law. The third chapter will introduce the literature on juveniles in sex work and existing ways trafficking policy has been studied quantitatively. The methodology used will be discussed in Chapter 4, including a review of the nuances and challenges in using FBI crime data. Chapter 5 will provide an analysis of the data and the final chapter will consider the implications of these results. 


\section{CHAPTER II}

\section{LEGISLATIVE HISTORY}

The relationship that human trafficking has to commercialized sex, child protection, and the criminal justice system is complex and has been shifting rapidly in the past fifteen years. The changes in trafficking law and juvenile arrest rates that are discussed in this paper are best understood as part of a recent movement towards creating policies and protections for youth that are separate from those pertaining to adults, as well as a Congressional push to broaden the scope of who is considered a victim of coercion. This chapter will begin with the current federal definition of trafficking before giving some brief historical context for juvenile treatment under the law and in institutions. It will conclude by retracing the recent history of trafficking legislation and how youth have been classified under these laws.

\section{Defining Trafficking in Federal Policy}

Defining human trafficking has proven difficult, especially as it is often entangled with other concepts, such as smuggling, prostitution, and forced migration. Federal prosecutor of human trafficking cases Victor Boutros decouples smuggling and trafficking with the distinction that while smuggling is centrally about movement, trafficking is instead centrally about coercion. While smuggling can be voluntary, trafficking as characterized by coercion cannot be (Boutros 2014).

This distinction by Boutros implies something else that may be puzzling: trafficking is not centrally about movement. The common image of trafficking is the 
young, foreign victim tricked into entering the United States and forcibly held in hidden rooms, kitchens, or fields where they are exploited. Stories of forced farm labor or brothel raids sometimes make it to mainstream media. While these situations certainly exist, there are many other legally defined cases of trafficking where no movement of the victim or perpetrator has occurred. Defining trafficking is further complicated by its changing definition depending on the level of government and jurisdiction. This is particularly apparent when looking at the inconsistent ways youth involved in commercialized sex have been characterized under the law.

At the federal level, the current law explicitly protects all youth as sex trafficking victims, preventing them from being legally classified as consensually engaging in prostitution. This statute is called the Victims of Trafficking and Violence Protection Act of 2000 (TVPA) and it is the most broad-reaching anti-trafficking legislation in the United States. The federal definition of sex trafficking as outlined in the TVPA (2000) is "the recruitment, harboring, transportation, provision, or obtaining of a person for the purpose of a commercial sex act", which is broad enough to encompass a range of behaviors including all pimp and john activities. The expansiveness of this framing is the result of strong politicized debates around how trafficking and prostitution should be defined. Because this thesis is concerned specifically with minor sex trafficking, a detailed discussion of these broader debates will be left for other scholarship. At this point, the most pertinent part of the TVPA is the definition applied to youth involvement, more stringently classified as a Severe Form of Trafficking in Persons. One of two stipulations must be met for this severe classification and youth sex trafficking falls under the first: 
(A) sex trafficking in which a commercial sex act is induced by force, fraud, or coercion, or in which the person induced to perform such act has not attained 18 years of age; or

(B) the recruitment, harboring, transportation, provision, or obtaining of a person for labor or services, through the use of force, fraud, or coercion for the purpose of subjection to involuntary servitude, peonage, debt bondage, or slavery.

By the use of the word 'or' in the middle of definition (A), the term sex trafficking applies regardless of whether force, fraud, or coercion is present, giving youth a legal classification distinct from adults. This is particularly significant given that prostitution law has historically been exclusively regulated by the state and states rarely created separate policies for youth. Although this federal law does not protect all youth in the United States from prosecution, its influence has stretched beyond the scope of its jurisdiction into individual state policies. Before discussing the relationship between state law and the TVPA, it is prudent to lay the historical groundwork on which these recent policies lie.

\section{A Brief History of Children as a Protected Class}

While the idea of an inherent difference in the needs, abilities, and constitution of youth is widely accepted by today's society, it has only been about a century that juveniles in the United States have had social service agencies and correctional systems existing separately from those available to adults. The first formal organization devoted entirely to child protection was called the New York Society for the Prevention of Cruelty to Children (NYSPCC) and did not come into existence until 1875. If this 
group's name seems reminiscent of a modern organization, it is not coincidental. The organization was created after the animal protection advocate and founder of the American Society for the Prevention of Cruelty to Animals, Henry Bergh, was convinced by a woman named Etta Wheeler of the need (Myers 2008). By the early 1920s, hundreds of non-governmental agencies sprung up, along with departments of social services and juvenile courts at the state level, which addressed abuse and neglect cases (Myers 2008). Around the same time, special facilities were also being created to house juveniles who broke the law. These facilities sprang from a growing sentiment for the differing needs of children who were seen as more amenable to reform and would benefit from a more personal form of care (Benekos et al. 2013).

Not all youth benefited in the same way from this changing tide, however. It was common for black youth to be excluded from many social services and forms of protection, even those supported by progressive Northerners. Historian Thomas Philpott states that whether due to racism or conformity, reformers at settlement houses often failed to serve black youth or segregated their services (Muhammad 2010). Jane Addams, one of the most famous reformers of this era and supporter of the NAACP, also used language supporting the superiority of the European immigrant child over the black child. Her Hull House was critiqued for its guise of "exuding interracial good" but serving very few black youth and segregating services when they were admitted (Muhammad 2010). The nineteenth century rhetoric around distinguishing juveniles who are victims from their more culpable peers is nearly identical to the language used today in news media, political debate, and journal articles. As later discussed, today's research suggests that those whom the public and the criminal justice system deem worthy or capable of being 
'saved' from prostitution disproportionately falls along the same racial divide as it did 200 years ago.

A second way in which social service experiences of the past resonate with the present is in the sheer inability of existing institutions to meet demand. By the late 1960s, social services were being institutionalized at the state level. Federal law created new mandates that states were to create child protective services, and states began adopting child abuse reporting laws (Myers 2008). As governments were taking on the responsibility of child protection, the number of non-governmental agencies plummeted. While a 1967 study notes that no state or community agency was sufficiently equipped to meet area need, jurisdictions outside of the purview of existing agencies appeared to fare worse, with no services other than the police (Myers 2008). The criminalization of those with unmet needs remains a common refrain today, which is discussed in context of gaps in a variety of services for areas such as poverty, mental illness, homelessness, as well as youth crime. Prostitution is one area of law that has often been charged with criminalizing vulnerable segments of the population, whereas new human trafficking laws are commonly heralded as the solution to protecting victims. However, the history of human trafficking law is not so straightforward and uncertainty about its commitment to victim protection persists.

\section{History of Laws and Policies Regulating Juvenile Commercialized Sex}

When considering the timeline of this schism in treatment between adults and children, the recent flurry of attention given to children involved in commercialized sex seems to have arrived predictably as the next logical step in the growing concern for child protection. Many policies related to sex have already created a distinction between adults 
and children, such as restrictions in viewing or making pornography, entering adult 'toy' shops, and statutory rape laws. While some of these areas seem deeply ingrained in society's moral fabric, such as the illegality of child pornography, the universality of these practices as legal and moral taboos in the United States is a recent development (Linedecker 1981). These recent laws have provided many nationally consistent protections from sexual abuse specifically for children; however, prostitution law didn't experience the same schism. Juveniles were processed under the same laws as adults, and even when the case was passed onto the family court system the dispositions were not very different than those that were handed down through the adult system (Crile 2012). The creation of a legal distinction between juveniles and adults is a recent development in a long history of the highly politicized area of trafficking law.

Prior to the existence of the TVPA, the Mann Act of 1910 was the dominant piece of legislation that addressed commercial sexual exploitation, making transporting women or girls for prostitution or any "immoral practice" a federal crime. The Act came as the Progressive Movement started, where the response towards prostitution was increasingly being criminalized and driven underground. Just twelve years after its creation of the first juvenile court, Chicago was once again leading the nation in a sweeping criminal justice trend by commissioning a report on the state of prostitution. The Chicago Vice Commission recommended tactics such as: requiring women to have a male escort when entering a saloon and punishing prostitution with probation or jail time instead of a mere fine. Inspired by Chicago's salacious findings of its prostitution market, New York and other cities launched their own investigations and increased the enforcement of prostitution penalties. This increase in enforcement has been credited with driving the sex 
work industry to formalize as an institution, as well as increase the opportunity for coercion and violence by diminishing sex worker access to legal protections (Simowitz 2013).

It was in this climate that the Mann Act made its debut. While the act was ostensibly about trafficking, it was also used to enforce a resurgent sexual morality and punish miscegenation. Formally named the White Slave Traffic Act, it grew from a hysteria around the increased freedom of white women working outside of the home as well as the racist and xenophobic fears that these women would be tempted or forced into sex by black and immigrant men. The most well known use of the Mann Act was to convict black boxer Jack Johnson of 'transporting a prostitute' when he went with his white girlfriend across state lines. In 1978, the act was updated to protect male minors in addition to girls. The act was updated again in 1986 with adoption of gender-neutral language allowing for the protection of male victims of all ages (Klain 1999).

The Mann Act, which can be said to target the demand side of prostitution, was met with resistance. Several district court cases challenged the constitutionality of parts of the act relevant to this study's population of interest. In United States v. Brockdorff (1997) the court upheld that crossing state lines with the intent of engaging in commercial sex with a minor, whether or not the act takes place, was within Congress's power under the Commerce Clause. United States v. Campbell, in the fifth circuit, and United States v. Vang, in the seventh circuit, ruled that prostitution does not need to be the dominant reason of travel, only that it is a reason the act has occurred. Similarly, United States v. Snow ruled that the transportation of a person does not have to be for the sole purpose of prostitution in order to be considered a violation of Mann (Klain 1999). 
While circuit court cases are only binding to their circuit, they serve as precedent cases for other courts and sometimes have a direct impact on policy. The most salient example of the judicial system impacting trafficking policy is on the federal level with the 1988 Supreme Court case United States v. Kozminski. This case acknowledged the limitations of existing anti-trafficking legislation and set the stage for Congress to develop the 2000 Victims of Trafficking and Violence Protection Act (TVPA). In this case, two cognitively impaired defendants faced psychological as well as physical and legal manipulation to keep them involuntarily confined as farm workers. The legal issue addressed by this case was whether psychological factors could be considered coercion. Justice O'Connor, in writing for the majority, specifically speaks to the statutory confines in which the opinion defining involuntary servitude could be rendered. In a unanimous decision, the Court of Appeals ruling to throw out the psychological factors was affirmed and the case was sent back to the lower court to determine whether the defendants were guilty of involuntary servitude with only the physically and legally coercive measures being considered.

In explaining the Court's decision, Justice O'Connor looks at two pieces of legislation that defined the scope of the Thirteenth Amendment. The first was the original Slave Trade statute and its 1909 amendment, which the court writes was not intended to expand the scope of coercive tools beyond legal or physical means. The second piece of legislation interestingly considers the trafficking of children. The 1874 Padrone Statute was enacted to make illegal the act of men bringing Italian boys to the United States to work in the street as musicians, beggars, or newsboys. This legislation criminalized "whoever shall knowingly and willfully bring into the United States... any person 
inveigled or forcibly kidnapped in any other country, with the intent to hold such person... in confinement or to any involuntary service..." (US v. Kozminski 1988, emphasis added) While the use of the word inveigle appears to provide protection from psychological means of coercion, the Court drew a sharp distinction between being enticed to leave one's country of origin and the means in which a person is confined domestically. The Court recognized that the conditions under which youth or cognitively impaired persons could be coerced are likely different than an average adult, but the Court averred that it has no legal grounds to consider these factors.

Twelve years after the case was decided, the opinion of Justice O'Connor was used to set the stage for a new comprehensive and responsive federal law. The TVPA explicitly cites US v. Kozminski, stating that while the Court had narrowly defined involuntary servitude to include only physical or legal coercion, involuntary servitude statutes were intended to cover non-violent coercion.

\section{The TVPA and State Law}

This new federal legal framework shifts the standard of protection beyond the questions presented in the Kozminski case. It is important to remember that while trafficking carries a connotation that borders have been crossed, the federal legal definition of trafficking does not require any movement of persons. Although movement is not formally required, federal legislation only supersedes state legislation in areas of federal jurisdiction. In reality, this means that while a sweeping federal protection exists, it is rarely applicable in intrastate cases. In practice, where the incident occurs and whether movement is involved often impacts the outcome for those involved.

The adoption of the TVPA in 2000 brought public attention to labor and sex 
trafficking in the United States. Despite the broad language in the definitions presented earlier, the background information on trafficking provided in the act had a strong focus on transnational forms of trafficking, where victims are brought into the United States from abroad. Additionally, while all prostitution may be legally classified as trafficking under this federal definition, sanctions have only been applied to those who are classified under one of the two definitions for a Severe Form of Trafficking in Persons quoted earlier (Chuang 2010). Taken together, these factors have created a disconnect between the text of the law and its potency. Several changes to the 2000 law are discussed below, however, these changes have had a limited impact on the discrepancies discussed in this paragraph.

Since 2000, the TVPA has been revised and reauthorized four times, but the definitions and standards set in the original act have mostly remained intact. The first revision to the act was called the Trafficking Victims Protection Reauthorization Act of 2003 (TVPRA) and it added peonage, slavery, and trafficking to the federal definition of racketeering activity. This increased the federal government's ability to prosecute organized prostitution rings (Dysart 2013). Additionally, it allowed for state and local law enforcement statements to be used in obtaining federal protections, potentially saving the victim months of time and frustration in waiting to receive support (Kara 2007). It wasn't until the second reauthorization of the act in 2005 where domestic trafficking is mentioned directly. This version states: "Trafficking in persons also occurs within the borders of a country, including the United States." It also cites a prominent study of trafficked children by Estes and Weiner (2002) and provides statistics on the vulnerability of runaway youth. Unlike previous versions of the act, the 2005 reauthorization provided 
channels for funding to support services and efforts against domestic minor trafficking (Dysart 2013). A final and perhaps less forthright component of this reauthorization is its use to further so-called anti-terrorism intelligence by "explicitly [directing] government officials to uncover links between human trafficking and terrorism" (Farrell and Fahy 2009).

The 2008 reauthorization of the TVPRA is called the William Wilberforce Trafficking Victims Protection Reauthorization Act and it again focused primarily on foreign-born victims. It did, however, reauthorize funding for juvenile residential treatment, required some federal agents to receive training in identifying juvenile victims, and broadened the scope of who was considered culpable of trafficking to include those who acted "in reckless disregard" of the age of the person they consort with (Dysart 2013). Finally, it is important to note that the 2008 reauthorization contained a savings clause, formally acknowledging the limitation of its application, and this has been the subject of research for at least one legal scholar. The 2013 reauthorization extended funding and created additional protections for foreign-born unaccompanied minors and youth victims in the foster care system.

The TVPA may be the most comprehensive piece of legislation on the commercial sexual exploitation of children, but it is not alone. A second important act is called the Prosecutorial Remedies and Other Tools to End the Exploitation of Children Today, and it can fortunately be abbreviated with the acronym PROTECT. The PROTECT Act (S. 151 2003) increased penalties for many crimes against children, formalized penalties against U.S. citizens engaging in sex tourism abroad and facilitated a more coordinated national AMBER Alert communication strategy for missing children. 
A third federal act called The Adam Walsh Child Protection and Safety Act, which included the Sex Offender Registration and Notification Act (SORNA), was passed in 2006 and it too served to increase the penalties for those convicted of commercial sexual exploitation of minors and other sexual crimes, including reporting requirements as sex offenders for juveniles convicted of certain sex offenses. This legislation was controversial, unfunded but expensive for states to implement, and its constitutionality was questioned on numerous fronts (Vermont Act 58 2010). Additionally, this act ties state implementation of SORNA provisions directly to the controversial Federal Byrne Grants, reducing the amount the state receives if it is not in 'substantial compliance' (Dysart 2013). While Federal legislation like SORNA has found some ways, depending on perspective, to encourage or cajole state compliance to federal sex offender registration standards, the TVPA has firmly taken a stance to not interfere with state law. It is a common misconception that federal law automatically trumps law of lower jurisdictions. The Constitution outlines the ways by which the federal government is able to supersede state law, generally in areas that have national interest or involve conflict between states. Within the realm of human trafficking, there is often an unclear boundary between what is the rightful domain of the state and what is appropriate for the federal system. Past federal human trafficking and sex trafficking legislation has been justified based on a national interest in regulating commerce. Congress very explicitly uses this explanation to justify the existence of the 2000 TVPA in section 102b (12) of the legislation: "Trafficking in persons substantially affects interstate and foreign commerce. Trafficking for such purposes as involuntary servitude, peonage, and other forms of forced labor has an impact on the nationwide employment network and labor market." 
Similarly, the Mann Act is explicit in its language that the law applies, with little exception, to cases involving interstate or international travel only.

The use of this interstate and foreign commerce justification for the TVPA limits the jurisdiction of the law to include only those cases that involve some commercial transaction that crosses state lines or a few other special circumstances, such as in US territories and possessions or maritime jurisdiction (Klain 1999). In cases where a child or a john crosses state lines to engage in commercial sex, even with only a fifteen-minute drive from New Jersey to New York, the case can be tried in the Federal system. However, many domestic cases of commercial sexual exploitation involve youth selling sex (or being sold for sex) in their own neighborhoods. In the cases where the youth, john, and pimp (if the child is acting under a pimp) are all from New Jersey, and the act takes place in New Jersey, it is unlikely that the case will ever be subject to anything other than New Jersey's state laws. Largely disparate state laws can result in an entirely different outcome for a youth in New Jersey as opposed to a youth in California or Illinois.

Researchers considering this disparity have promoted at least three general legal frameworks. The first strives to retain the ability for children to be prosecuted for prostitution generally or under certain circumstances. The other two models agree with the standard created under the TVPA, which treats all youth as victims, but disagree on how this should be institutionalized. The first promotes states adopting comprehensive trafficking legislation individually, while at least one scholar promotes federal preemption of state laws that conflict with the TVPA.

It is clear that not all agree with the federal standard. New York State's difficulty in 
passing state anti-trafficking legislation is a good example of some of the common arguments against passing a blanket prohibition on juvenile arrests for prostitution. The 2008 New York Safe Harbor Act was originally proposed as a completely decriminalized model, but after a long period of disagreement it was passed as a much weaker conditionally decriminalized model. At the time, the New York Legislature and law enforcement did not agree that all youth were necessarily victims, with many believing instead that at least some youth should be considered culpable. Additionally, law enforcement saw the reduction in their discretion with prostitution offenses as countereffective in curbing prostitution. District Attorneys also held onto the popular sentiment that it is easier to prosecute adult pimps, and ultimately provide greater protection to children, when they are able to use the threat of prosecution to secure testimonies from youth. Concerns that the new legislation would be too costly were also raised, however, the Act's required social services were only applicable when funding is available and the Act itself did not provide any funds (Fichtelman 2014).

The compromised version of the law mandates that children under the age of sixteen be classified as 'PINS' cases: persons in need of supervision, instead of the more punitive label 'delinquent.' The age maximum of sixteen is lower than the originally proposed eighteen, however, adopting the federal standard for age would be particularly challenging since New York is one of two states that tries all individuals aged sixteen and older in the adult system (Raise the Age NY n.d.). The Act's original intention was further diminished by the addition of four general exceptions to the PINS mandate. Juveniles could have a delinquency case if: they do not meet the federal trafficking standard, they have previously committed a prostitution offense, the minor had a previous 
PINS designation, or the minor was unwilling to cooperate with services ordered by the court (Fichtelman 2014).

Much of the current research in this field advocates for strong state protections for minors. While many strong, conservative voices in this area may be politically inclined to support the retention of state authority in legislating commercial sex, many practical reasons have also been given for why states and localities need their own strong trafficking laws. Some of these reasons include the inadequacy of limited federal resources to address the pervasive issue of trafficking and that the daily police work of local agencies is more likely to come into contact with youth engaged in commercial sex (Dysart 2013, Smith and Vardaman 2011). Several different model laws have been proposed, while other research has argued that states should not use these prepackaged models and instead develop their own that fit into the state's general legislative framework. The Protected Innocence Initiative, a component of the organization Shared Hope International, decided to focus its work away from developing a model law for child trafficking and instead focus on developing a measure for rating and quantifying state policy effectiveness. This measure will be discussed later on in the methodology section.

At least one researcher argues that the TVPA should preempt, or overpower, those state laws that conflict with it. Crile (2012) cites other areas of law traditionally regulated by the state in which the Supreme Court upheld preemption, including domestic regulations relating to divorce in McCarty v McCarthy 453 U.S. 210 (1981) and cigarette advertising with Lorillard Tobacco Co. v Reillet (533 U.S. 525 (2001). Even more compelling, preemption has been applied even when a federal law contains a savings 
clause. A savings clause provides an exception to how the legislation should be applied. Some federal laws contain savings clauses that dictate that the law is not to preempt existing state legislation that may conflict. For example, the 2008 reauthorization of the TVPA has a broad savings clause stating that nothing in the current act, or any of the former iterations of TVPA, "shall preempt, supplant, or limit the effect of any State or Federal criminal law."

Notwithstanding, the Supreme Court has ruled that a federal law with a savings clause barring preemption does in fact supersede state law in at least one case. It has also considered whether another federal law impliedly preempted a state statute and narrowed the scope of other savings clauses (Crile 2012). The author recognizes that the Supreme Court has applied preemption inconsistently; however, the foundation of Crile's argument is that there are state laws that 'frustrate the TVPA's purpose' which makes it an appropriate candidate for consideration. On one hand, Crile's position may be seen as advocating for the encroachment of the federal government into prostitution law, which has almost exclusively been managed by states and local jurisdictions. With some of the most vocal and well-organized anti-trafficking advocates having a strong right lean in their political constitution, it is likely that Crile's position would face opposition of those in this field. Although, as Reid and Jones (2011) astutely discuss, there are many areas of law where juveniles and adults are held to different standards nationwide. Of particular interest is Supreme Court case New York v. Ferber (1982), which created a federally protected class of minors from pornography production. The opinion in the case spoke directly to the interest the federal government has in protecting the welfare of children from the physical and mental harm involved in creating pornography. Additionally, as 
previously mentioned, Congress has attached SORNA compliance as a prerequisite for receiving some federal funds. Even without the use of state law preemption, the federal government has elicited state compliance in similar areas of law.

Scholars in this area have created an impressive body of literature that discusses the relative merits of the content of individual laws and how these laws should be codified; however, noticeably absent from this work is a discussion of their merits based on how these laws have been implemented. Arguments for or against laws have centered on logical and legal inconsistencies, not on outcomes such as how an increase in prosecutorial power has been used to further anti-trafficking efforts or if law enforcement training provisions have led to an increase in victim identification. This study attempts to bridge this divide by studying youth outcomes before and after changes to state sex trafficking policy. The following chapter will review the literature that discusses these two spheres of interest: the criminal justice literature regarding youth involvement in commercial sex and the political science literature that discusses anti-trafficking law compliance. 


\section{CHAPTER III}

\section{LITERATURE REVIEW}

Despite the challenge in measuring juvenile participation in sex work, there are many articles that discuss this population and several studies have produced meaningful quantitative data about which youth engage in commercial sex and why they do so. Many of these articles rely on interviews, although surveys and secondary data analysis have been used as well. The first part of the chapter divides this research into two groups: those that study the population of youth who engage in commercialized sex, and those that focus on the subset of youth who get arrested for prostitution. The second part of this chapter will review literature pertaining to the second major theme of this study by considering the role of anti-trafficking legislation. This discussion will cover the existing ways that state anti-trafficking law has been systematically evaluated. It will also connect how the 3P index (Cho et al. 2011), currently used to score the trafficking policy of nations, can be used to frame domestic legislation.

\section{Characteristics of Commercially Sexually Exploited Children (CSEC)}

One of the most pervasive images regarding commercially sexually exploited children is the image of a sadistic trafficker who has total physical control over his captives. Many non-profit anti-trafficking organizations dutifully repeat stories of brutal pimp control, and research often holds this narrative central when justifying the study's importance. For example, a 2013 article gratuitously titled “Trick or Treat” implies pimp recruitment is a central part of the definition of trafficking and offers no space for other 
narratives beside the girl who is under near absolute control of a male pimp (Mir 2013). Other articles speak to a larger understanding of trafficking experiences, although this literature often falls back on the experiences that youth have with pimps as being central to defining victimhood. Reid and Jones (2011) use statistics cited by a few different studies to conclude that the majority of girls engaged in prostitution are under the control of a trafficker, which they use synonymously with the word pimp, and refer to the trauma bonding some youth experience to pimps as the "superglue of sexual exploitation." However, the studies they cite do not reflect the breadth of the estimates put forth in the field. Curtis et al. (2008) discussed their difficulty in locating pimp-controlled youth; even after targeting this demographic less than a fifth of their sample identified as having a 'market facilitator.' When only the female youth were considered, the percentage still hovered just over 26 percent. A more recent study including some of the same researchers arrived at stronger conclusions about the focus on pimps and warns that the emphasis on this narrative overestimates the role of the pimp, oversimplifies the complexities of the relationships that youth encounter, and results in misleading stereotypes about youth recruitment and retention in the sex economy. This study found that many youth relied on "spot pimps" - a hustler who receives a cut of the profit for helping drive business, but does not have an exclusive relationship with the sex worker (Marcus et al. 2014). Male youth have been identified as less likely to operate under a pimp (Curtis 2008), and studies that emphasize pimp-controlled girls also place genderbased limitations on the understanding of child trafficking victimization.

Part of the wide discrepancy in the reported proportion of youth being "pimped" or operating under a "market facilitator" may be definitional. About 13 percent of youth 
in the Curtis et al. study reported sharing money with one or more friends and almost half reported being recruited into sex work by a friend. Friends who are older than 18 may be legally classified as traffickers if they facilitate youth prostitution in any way. ${ }^{1}$ Those that are legally labeled as traffickers can have a wide range of relationships with the youth some in which youth are acting autonomously and some in which they may experience trauma bonding or other means of coercion. In addition, the level of mutuality and authenticity in friendships youth describe likely varies; there is evidence that traffickers sometimes use the guise of friendship to bring youth into the trade (Bigelsen et al. 2013; Clarke et al. 2012). What is most apparent is that the relationships youth engaged in sex work have with others are not easily classified and quantified. Individuals may play multiple roles with unclear boundaries, such as: friend, business partner, lover, trafficker, roommate, and abuser. If the role of the pimp is a potentially overstated factor in youth involvement in the sex industry, what other factors do youth, law enforcement, and other professionals attribute to initial recruitment? Some consistent themes emerge from the literature.

\section{Dysfunctional Home Life}

Studies consistently show evidence that youth involved in the sex industry are very likely to come from dysfunctional homes; however, studies operationalized this concept in a variety of ways. Three studies that interviewed youth in different large U.S.

\footnotetext{
${ }^{1}$ There are also some accounts of anti-trafficking laws being used by police to target sex workers, although little formal research has been conducted. An example of this would include an older sex worker providing housing or other support to a younger sex worker in a peer or mentor fashion, but they are arrested or threatened with arrest on the charge of facilitating the prostitution of a minor. The Atlantic has an article that discusses this in both Alaska and New York (Berlatsky 2014). More research is needed on who is arrested under these laws and the extent to which these laws further the criminalization of those who may be in need of services or who provide services to youth in need.
} 
cities found that this population frequently discussed leaving home and childhood abuse as major driving forces into sex work. Ashley (2008) found prior sexual abuse and running away to be common themes for entry during a focus group of cisgender women ${ }^{2}$ from Chicago who were in the industry as minors. The women were identified through their participation in a local non-profit organization that has a mission of supporting women and girls in the sex trade. New York City's Covenant House conducted a second study, in which it interviewed boys, cisgirls, and transgirls involved in Covenant House services (Bigelsen et al. 2013). In this study, seventy-eight percent of the respondents who reported childhood engagement in commercial sex had experienced sexual abuse prior to their entry. Finally, Cobbina and Oselin (2011) found that a high percentage of girls fit into a category they labeled fleeing abuse and reclaiming control. This category did not just focus on the act of running away, but also the psychological experience of the respondents who had to make the conscious, proactive decision to leave in order to remove themselves from an abusive situation. The authors argue that these young people trade one form of abuse for another; however, they also stress that the girls reported that sex work gave them a sense of control of their lives and their sexuality.

While all of these studies found abuse as a dominant reason for juvenile entrance into sex work, a second comparative study between girl and woman entrants reported finding lower rates of abuse than other studies, but concluded it may be due to sampling methods and differences in how abuse was operationalized (Clarke et al. 2012). Additionally, the sample was drawn from was just one diversion program in a single location. However, statistically significant results were found in this study for a couple of

\footnotetext{
${ }^{2}$ Cisgender women are women who are not transgender.
} 
other factors that related to the stability of the woman's home environment, including: whether a family member had a drug or alcohol problem, the age the respondent first used drugs, and the highest level of education she completed.

\section{Insufficient or Ineffective Services for Youth}

Youth who fled to the streets to leave dysfunctional and abusive homes were frequently confronted with the decision of whether they should sell sex to meet basic survival needs. While some describe being forced or tricked into the industry by another person, many described being compelled through the lack of viable alternatives to obtain basic necessities like food and shelter or the funds to obtain these things. In at least one study, all participants in a focus group had identified social services as an institution that, at best, did not help or at its worst, misunderstood, misdiagnosed or stigmatized the youth it was charged to support (Ashley 2008). Available services have also been described as insufficient to meet the need and are vulnerable to budget cuts and political agendas. One of the most prominent lacking services was housing, with nearly half of Covenant House youth who had engaged in commercial sex reporting they have done so in exchange for a place to stay. Youth openly discussed how pimps would advantageously cruise outside of youth shelters when they were full (Bigelsen et al. 2013), and Covenant House itself was identified by another study as a place where pimp recruitment and initial initiation into sex work was very high. Additionally, at least one youth reported being sexually assaulted multiple times and the workers did not intervene in the attacks (Curtis 2008). This underscores that the mere existence of services does not automatically equate to improved outcomes for youth. In addition to feeling misunderstood, misdiagnosed, or stigmatized, youth may experience revictimization, violence, or face pressure from 
pimps. For these youth, the Covenant House study identified the lack of a single, caring adult as a major risk factor for entrance into the industry (Bigelsen et al. 2013).

A lack of viable employment opportunities appeared to be particularly salient for transgender youth. In addition to interviewing cisgender girls, the Chicago and New York City studies discussed in the previous section also spoke with transgender girls in the industry. Both of these studies drew the conclusion that a lack of legitimate employment opportunities was a major barrier, which was compounded by discrimination and violence (Ashley 2008; Bigelsen et al. 2013). Studies discussed how transgirls and transwomen in the industry create surrogate familial relationships (Ashley 2008; Curtis 2008). Like Bigelsen et al. (2013), these two studies also demonstrate the need for protection and security that youth require from others.

\section{Entrance by Choice}

While many of the youth described dysfunctional homes and a lack of resources as factors that compelled them to consider sex work, it was common for some youth to discuss their entrance as voluntary. Two studies characterized youth entrance dichotomously, grouping factors for entrance based on survival or safety separate from those who stated that they entered by choice. The first attributed a child's decision to enter into the trade to how it had been normalized in the child's environment. The study, which compared adult women who had entered the trade as adults to those who had entered as juveniles, found that those who entered as girls were far less likely to see commercial sex as morally disagreeable. The women who related to this narrative saw prostitution as a viable way to make money and have access to the same types of material possessions that others in their community had achieved through selling sex (Cobbina 
and Oselin 2011). Similarly, Ashley (2008) identified the desire for non-essential material goods as a driving factor for some focus group participants but explained that this desire for material possessions may be rooted in a pressure that feels more compulsory than it does voluntary. The researcher found that this drive was sometimes fueled by underlying safety concerns (such as bullying) or rooted in psychological needs (such as insecurity or the desire to feel loved and cared for). Whether this seemingly voluntary entrance can be explained by a child's environment or underlying emotional needs, it important that this subset of youth is not cast aside because they do not fit a convenient narrative of the pimp-controlled girl.

Although the majority of youth appear to be pressured into the industry, pimps are only one of several factors that exert this pressure on youth. Childhood abuse, dysfunctional home lives, unmet survival needs, and lacking or ineffective support structures were commonly reported throughout these studies. It is important to note that not all youth reported being compelled by a person or circumstance; in more than one study, youth discussed their decision to enter based on a desire for expensive material goods. Some also expressed the position that to have sex without receiving money was to be taken advantage of, a perspective that is antithetical to the mainstream societal understanding of sex and sex work. These factors are important considerations in this study because changes may influence arrest rates. It is expected, for example, that states with a higher proportion of dysfunctional families will have more youth who face pressure to participate in the sex industry, and thereby increase the amount of contact law enforcement has with youth who engage in commercial sex. 


\section{Characteristics of CSEC Susceptible to Arrest}

Factors that influence the proportion of juveniles vulnerable to sex work are not the only important considerations in fluctuating arrest rates. Studies consistently find that arrests for prostitution do not appear to be evenly dispersed throughout the population of youth who are in the industry. The factors that studies have identified as relevant to arrest fall into two general categories: characteristics of the child, and characteristics of the situation. Although studies varied considerably in what they measured, generally the characteristics that made youth appear more vulnerable made them less susceptible to arrest. Youth characteristics found significant in lessening arrest in at least one study included: appearing frightened, being dirty or having noticeable body odor (Mitchell et al. 2010), cooperating with the police (Halter 2010), and having no prior arrest record (Halter 2010). Age and gender were also studied but yielded inconsistent results. Age was an important characteristic in two studies, such that the older the child was, the more likely they were to face arrest (Finkelhor and Ormrod 2004; Mitchell et al. 2010). However, age was not found significant in the Halter (2010) study. Finally, being female reduced the likelihood of arrest in two studies (Finkelhor and Ormrod 2004; Mitchell et al. 2010), although the studies did not specifically consider the presence of a third party facilitator or whether the police had been called to the scene, two of the factors that were consistently found statistically significant in the others. As boys have consistently been found to be less likely to operate under a pimp (Curtis 2008; Finkelhor and Ormrod 2004; Klain 2009), some of the gender variance in arrest may have been explained by the presence or absence of a third party facilitator. 
Additionally, the literature has been divided over the role that race plays in arrest. Halter (2010) and Finkelhor and Ormrod (2004) did not find race to be an important factor in arrest, while the data from the National Juvenile Prostitution Study was more nuanced. In this study, white youth were 3 times as likely to be classified as a victim than a delinquent while black youth were only 1.5 times as likely (Mitchell et al. 2010). However, when race is considered alongside other characteristics from the police report - such as whether the youth were described as frightened or dirty, how the officer came into contact with the youth, and whether the child had a history of running awayrace was not found to be statistically significant. It appears that the variance in outcome by race can explained through some of these other characteristics. Of the three studies that consider race in arrest, the Mitchell et al. study is the only one that is designed to be representative. The National Juvenile Prostitution Study (see Mitchell et al. 2010; Wells et al. 2012) was explicitly designed to provide a national estimate of juvenile arrests for prostitution and explore the demographic and situational characteristics that correlated with disparate law enforcement treatment for a sub-sample of those arrested. The other two studies looked at very limited non-representative data, such as large cities (Halter 2010) or specific FBI reporting from a small number of agencies in a handful of states (Finkelhor and Ormrod 2004). For this reason, the data from the National Juvenile Prostitution Study was given more weight when developing the model used in this study.

In addition to a youth's demographic factors and behavior, the situational characteristics that an officer encounters when they arrive to a scene also appear to matter. Consistent with the characteristics of arrested youth from the previous paragraph, the more autonomy youth appeared to have in their decision to solicit sex, the more likely 
they were to be arrested. Mitigating factors included: the presence of a third party facilitator or pimp (Halter 2010; Mitchell 2010), the youth not being a resident of the area in which they were intercepted (Halter 2010), and police responding to a call to the scene as opposed to arriving unsolicited (Halter 2010; Mitchell 2010).

Although differing methodologies make it difficult to closely compare the impact of specific variables, in general, studies seem to agree that the characteristics that make youth appear more vulnerable or less autonomous have consistently been significant in predicting their legal status as victim. While some of these factors are easier to objectively measure (such as a youth's age or gender presentation) factors such as looking frightened, unkempt, or even whether another person is acting as a trafficker may be interpreted differently depending on the officer. Law enforcement is expected to use proper discretion within the bounds of the law when deciding how to appropriately manage a situation. Anti-trafficking laws have not only attempted to shift the boundaries for who can be arrested, they have also created channels for training criminal justice professionals in how to identify victims and increased the tools officers and prosecutors have at their disposal for punishing these offenses. However, there is often disagreement among legislators, law enforcement, and advocates as to what a 'better' or 'stronger' trafficking statute entails.

\section{The 3P Index and Defining a 'Strong' Anti-Trafficking Law}

Although the focus of the research in this thesis is state-level legislation, the 3P Index, used to rate international compliance with the U.N.'s anti-trafficking protocol, is pertinent for two primary reasons. First, it validates the importance of this study's research question. Secondly, the model for nations can be applied domestically to frame 
state laws. This index will be useful in understanding how existing measures that rate state trafficking legislation differ and it will also be used to clarify what this study will and will not attempt to measure with respect to anti-trafficking laws. As discussed earlier, research has not tested whether theories in international trafficking compliance apply domestically. However, evidence suggests that some of the same patterns exist, such as an emphasis on prosecutorial remedies and a view by some charged with implementing new trafficking policy (e.g. police officers) that it is a political, rather than a practical, tool. With these thoughts in mind, this section will explain the 3P index and discuss some of the major themes that have come from this research, specifically pertaining to victim protection.

\section{The 3P Index: Protection, Prevention and Prosecution}

Studies that consider international compliance with the U.N. Protocol to Prevent, Suppress and Punish Trafficking in Persons, especially women and children often employ Cho et al.'s 3P index, which separates trafficking legislation into three subsections: protection, prevention, and prosecution. The index was developed by classifying the components of each of the articles of the U.N. Protocol, which allowed for the researchers to create a score for each nation's level of compliance in each category. Compliance was determined by using the U.S. State Department's Trafficking in Persons (TIP) report. The TIP report is a comprehensive document that describes each nation's anti-trafficking efforts and categorizes them into one of three tiers. This report compares each nation against the United States' own domestic trafficking standard, section 108 of the TVPA (“2015 Trafficking in Persons Report” n.d.).

It is important to note that while Section 108 was designed to be a general standard 
by which other countries can be compared, it is a standard that was developed with little transparency by the U.S. State Department (Cho et al. 2011), and it has been accused of being driven, at least in part, by U.S. political interests. Comparisons between the tiered ranking system used by the state department and an independent measure used to evaluate some European nations show a large amount of incongruence. Even more suspect is the placement of countries with the same score into different tiers. While the 3P index uses the TIP reports to create their scores, there is a surprising amount of variability in scores within each tier (Dijk and Mierlo 2014). Although there is not another source of information as detailed as the TIP reports (Amahazion 2014), the 3P index has attempted to check the validity of the State Department reports through using the more general reports submitted to the United Nations (Cho et al. 2011).

The partitioning of data from the TIP reports allowed for researchers to determine whether specific portions of the Protocol were more frequently enforced than others. Each of the three subcategories contains specific elements discussed in a chapter or chapters of the Protocol. The sub-categories under prevention focus on areas such as advertising campaigns to raise awareness or policy to encourage reporting of suspicious behavior. It also includes coordinating efforts and communication among various stakeholders and authorities. The prosecution component focuses on the tools available to law enforcement and prosecutors in punishing those that further trafficking, while protection focuses on the tools and services victims have at their disposal to successfully reintegrate into society, as well as the legal protections available to prevent the victim from facing punishment as a result of being trafficked. Table 1 shows the points that the index measures for each of the 3Ps. 


\section{Table 1}

Cho et al. (2011) 3P Index Sub-Categories

\begin{tabular}{cl}
\hline Categories & \multicolumn{1}{c}{ Criteria } \\
\hline Protection & No Punishment of Victims \\
& Imposing No Self-Identification in Order to Prove Victim Status \\
& Assistance for Legal Proceedings \\
& Provision of Residence Permits \\
& Basic Services for Housing \\
& Medical Training \\
& Job Training \\
& Assistance for Rehabilitation \\
& Assistance for Repatriation \\
Implementation of Campaigns for Anti-Trafficking Awareness \\
Training Officials (Government, Military, Peacekeepers) \\
Facilitating Information Exchange Among Authorities \\
Monitoring Borders, Train Stations, Airports, etc. \\
Adopting National Action Plans for Combatting Trafficking \\
Promoting Cooperation with NGOs and International Organizations \\
Facilitating Cooperation with Other Governments \\
\end{tabular}

Through their initial analysis, Cho et al. found that while all three of these measures saw an increase in the average degree of compliance over the eight-year period they studied, the score and rate of compliance varied considerably. Compliance with prosecution policy rated highest in both 2002 and 2009, and it also experienced the largest increase in average score (from 2.90 to 4.26 on a five-point scale). On the opposite end, protection policy had the lowest levels of compliance and the lowest growth rate. This is consistent with the findings of a second study, which suggests that nations are more motivated by the anti-crime components of the Protocol than the human 
rights aspects (Simmons and Lloyd 2010). Several theories have been put forth about the disparate levels of compliance between each of the 3Ps.

\section{Compliance Decision Making and International Trafficking Policy}

A major theme that has emerged from this body of literature is the role a nation's reputation or public image plays in its anti-trafficking laws. This idea was first put forth by Avdeyeva (2011), who found support for her theory that European Union members and aspirant members would improve compliance with the U.N. Protocol out of an interest in maintaining or strengthening their reputation. In a second study, Cho and Vadlamannati (2012) expanded the application of 3P Index and the themes from Avdeyeva's work. The researchers posited that nations do not indiscriminately increase their compliance with the Protocol, but do so in a strategic way.

Of the 3Ps, Cho and Vadlamannati identified prevention policy as the component likely to be the most eagerly adopted because it could be implemented through public awareness campaigns or institution-level policy adjustments, such as increasing border control. The policies connected to prevention were identified as having the largest payoff due to low political costs, low public resistance, and its ability to appease the interests of the most influential nations behind the Protocol. Conversely, protection and prosecution were identified as requiring a change to law, and requiring more effort, resources, or political support. An additional barrier to implementing protection policy was that immigration classifications to protect trafficking victims could be perceived as encouraging illegal forms of migration and be less politically viable for some nations. The low political costs associated with adopting prevention policies are what the authors label efficient compliance: nations balance the financial and political costs of compliance 
with their own interests to receive the biggest payoff possible for their investment. In support of the primary hypothesis regarding efficient compliance, the study found that ratification of the Protocol had a consistent positive and significant effect on prevention policy, but not prosecution policy. Protection policy was found significant in a limited number of circumstances, which are more thoroughly discussed below. The two articles discussed in this section suggest that nations vary in the extent to which they implement the Protocol, but they are overall likely to privilege policies with low barriers to implementation that will be perceived favorably in the international arena.

\section{Compliance Decisions for the Protection Component of Trafficking Law}

This study is primarily concerned with protectionism element of the 3Ps, the component that seems to have garnered the lowest levels of support. Three hypotheses from two studies emerge in the international trafficking compliance literature that focus specifically on a nation's protection score. These three hypotheses can be roughly classified as: the urgency a nation has for addressing trafficking, its human rights principles, and its governmental efficacy. Cho and Vadlamannati (2012) showed that ratification of the Protocol on protection policy compliance was found significant in only a few instances, most notably when only the subset of developing countries is included in the model. However, significance was lost in both the full sample and the developing country subset when the variable outflows of human trafficking was added. This was an ordinal variable considering the reported volume of trafficked persons leaving the country. Cho and Vadlamannati suggest that ratification and increased protection policy compliance may be occurring together in countries that have large reported numbers of 
trafficked persons migrating into or out of the country, as these countries are more likely to perceive trafficking as a serious national concern and be moved to action.

The other theories come from an author who only considered protection scores in their model to test whether those nations with stronger ties to 'world culture' and have capable governments adopt stronger laws for victims (Amahazion 2014). The first theory suggests the diffusion of international human rights and expanding rights of the individual underlie protectionist policy. Secondly, Amahazion considers the notions of government effectiveness and capacity. While nations may believe in an obligation to protect its citizens and those within its borders from harm, they vary in their abilities to execute these protections either due to inefficiencies, corruption, competency, or capacity. The author found support for the theory that protectionist policies are influenced by both a nation's ties to world culture (defined as global norms and policies) and the competency of its government (considering the efficiency, effectiveness, and legitimacy of its institutions). Overall, the international literature suggests that antitrafficking policy may be strategically adopted to maximize political relationships while minimizing the effort expended by participating nations. As discussed in the introduction, similar research on compliance with state-level laws has not been conducted; however, there is evidence to suggest that these theories should be considered in domestic models.

\section{Domestic Measures of 'Strong' Anti-Trafficking Laws}

The research discussed in Chapter 2 looked at three different frameworks that legal scholars have considered in order to develop a consistent set of anti-trafficking laws across the United States. In addition to these studies, there is a large body of work that discusses the comparative merits and weaknesses of individual laws. While this research 
tends to focus on qualitative comparisons with a small number of states, public education and advocacy groups have also developed metrics against which all states are measured and ranked. This approach to critiquing anti-trafficking law is more relevant to this study, as a uniform and objective measure is needed to assess a state's level of protection for juveniles.

Finding ways to succinctly and systematically discuss the differences in policy in all 50 states is a formidable task. This task was undertaken by at least three different groups that attempted to create metrics for measuring the strength of trafficking legislation against the model set forward under the TVPA, two of which are detailed enough to warrant discussion here. ${ }^{3}$ The organizations that have developed annual trafficking legislation metrics, Shared Hope International and Polaris Project, play lead roles in anti-trafficking advocacy and policy research. The work from these two groups is pervasive in the academic literature on trafficking and both are cited in this study. However, the scope and underlying philosophies of their work vary in several important ways.

Former congresswoman Linda Smith started Shared Hope International in 1998 with a mission of preventing sex slavery and restoring victims. The state policy ratings are carried out through a partnership between Shared Hope International and the American Center for Law \& Justice (ACLJ) — an outwardly conservative legal organization. Both Shared Hope and ACLJ identify a strong Christian and politically right foundation to their work. Recently, Shared Hope has added a direct service component to its work by operating an independent living home for young female

\footnotetext{
${ }^{3}$ See citation for Wagner (2012) for the third comparative metric.
} 
trafficking victims ("Shared Hope" n.d.). Conversely, there is no professed ideological or religious foundation to the Polaris Project. The Polaris Project was founded by two Brown University students, Katherine Chon and Derek Ellerman ("Polaris Project" n.d.), with a general mission of eradicating all forms of human trafficking. In addition to their policy research, training, and technical assistance, the Polaris Project operates The National Human Trafficking Resource Center hotline for victims and survivors of trafficking.

Both of these organizations have annually generated trafficking law scores and report cards for each state since 2011. The Polaris Project score ranges from -2 to 12 and awards points based on the presence or absence of certain points of law, such as the existence of a labor trafficking or victim assistance statute. There are a total of ten criteria considered by this metric: two require statutes prohibiting certain types of trafficking, two involve training and prevention, two involve increasing the tools available to law enforcement, and four involve supporting victims. It does not rate how 'strong' each of these components are, except to award half points in the case that a state has a law that only partially addresses a criterion. Unlike Shared Hope, the score generated by Polaris Project considers all types of trafficking.

Shared Hope International has a more detailed framework, but only scores components related to domestic minor sex trafficking, a much narrower scope than Polaris Project. States are awarded between 0 to 2.5 points for each component measured, for a total score of up to 102.5 points. The components are divided into six subcategories, which encompass the following six themes: the existence of a distinct anti-trafficking statute, criminalizing john activity, criminalizing trafficker activity, criminalizing 
behavior of other actors who facilitate child prostitution, expanded power of law enforcement in investigating child trafficking, and protective provisions for child victims. In addition to the scope of the metric, the focus differs as well. The majority of the subcategories for Shared Hope's metric measure the harshness of punishments and breadth of tools available to arrest and prosecute adults, which would all fall under the prosecution sub-component using the 3P index (see Table 2). Polaris Project contains these elements as well, but a larger share of their score is devoted to other elements of anti-trafficking law, such as protecting victims and prevention tools. Affixing a numerical score to each state can appear deceptively impartial and objective. In reality, states like California can be ranked highly under one measure and poorly in another due to differing methodologies. Table 2 shows the differences in the trafficking metrics for these two organizations by considering how each sub-component would be categorized under the 3P framework.

While informative, these existent metrics were not appropriate for this study for several reasons. First, data has only been collected in its current form since 2011, eleven years after the TVPA was adopted. Secondly, this study is attempting to measure the direct impact protectionist policy has had on youth. To achieve this goal, a systematic method for identifying state laws that provide protections for juveniles was needed. The way that these objectives were met will be discussed in the following chapter on the study's methodology. 
Table 2

Classification of Trafficking Metric Sub-Components Using the 3Ps

\begin{tabular}{lll}
\hline & \multicolumn{1}{c}{ Polaris Project } & Shared Hope International \\
\hline Protection & Safe Harbor & Protective Provisions for the \\
& Victim Assistance & Child Victim \\
& Access to Civil Damages & \\
& Vacating Convictions & \\
Prevention & Training/ Anti- & \\
& Trafficking Task Force & \\
& Posting of National & \\
& Hotline & \\
Prosecution & Asset Forfeiture/ & Criminal Provisions Addressing \\
& Investigative Tools & Demand \\
& Lower Burden of Proof & Criminal Provisions for \\
& for Trafficking Minors & Traffickers \\
& & Criminal Provisions for \\
& & Facilitators \\
Statue that & Sex Trafficking Statute & Criminalization of Domestic \\
Criminalizes & Labor Trafficking & Minor Sex Trafficking \\
Trafficking & Statute &
\end{tabular}




\section{CHAPTER IV}

\section{METHODOLOGY}

The intention of this study is to propose a model of testing the efficacy of state anti-trafficking legislation in providing protections from criminalization of juveniles engaging in sex work. This study uses a cross-sectional time series model to test the effects that legislative changes, policing strategies, and socio-economic factors have on youth prostitution arrest rates. The unit of analysis is states over a period of 14 years, from 2001 to 2014.

While state human trafficking laws ostensibly added protections from prosecution for juveniles in sex work at the same time that the juvenile prostitution arrest rate plummeted, no existing research has tested whether these trends are empirically related. Simply stated, this thesis asks: Can the decline in state arrests for juvenile prostitution be explained, in part, by changes in state sex trafficking law? It is hypothesized that states will see a steeper decline in the rate of juvenile prostitution arrests following the passage of anti-trafficking legislation that explicitly addresses the "protection" element of the 3Ps in its treatment of youth. The year 2001 was selected as the first year for data collection because it is the first time nearly complete FBI arrest data is available. It is also prior to the adoption of any state laws based on the TVPA, and Figure 1 indicates that arrest rates under this crime category were stable at this time. The last year for which arrest data is currently available is 2014. 


\section{Dependent Variable: Juvenile Prostitution Arrest Data}

The dependent variable, Juvenile Prostitution Arrest Rate, considers youth criminalization for prostitution by using FBI Crime in the U.S. data (CIUS) for the offense category Prostitution and Commercialized Vice. The rate is calculated using the number of juvenile arrests for this category as a proportion of the state's juvenile population that is covered by FBI crime reporting. It is reported as the number of arrests for every hundred thousand youth, which is consistent with the standard in presenting criminal justice data.

Data from Figure 1 clearly demonstrated a falling national arrest rate for juvenile prostitution, but it was unclear what occurred in each state individually. The CIUS data allows for this information to be disaggregated by state over time. Visual representations of this data show that states have disparate and variable levels of arrest, but nearly the entire nation seems to have renegotiated an acceptable maximum rate at which youth are arrested. When Nevada's very high values are excluded, the range tightens over time, with a minimum fixed at zero but a lower maximum rate.

\section{Figure 3}

\section{Selected Maps of Juvenile Prostitution Arrest Rate by State}

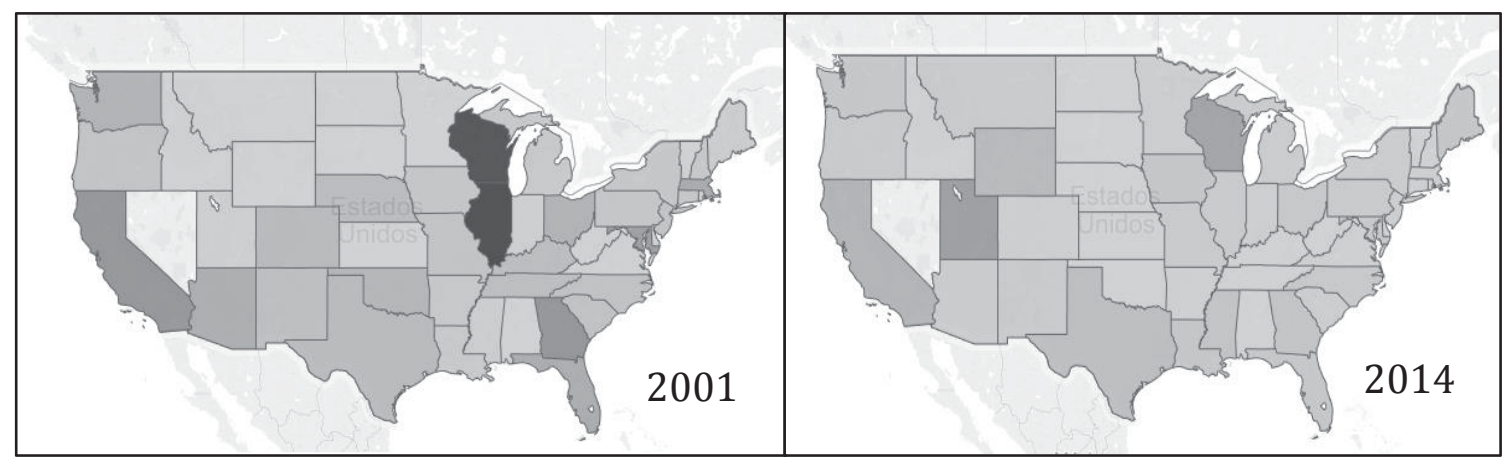


The maps presented in Figure 3 show the juvenile prostitution arrest rate of the first and last year of the study for the continental United States, excluding Nevada. ${ }^{4}$ Earlier years frequently show a couple of states with arrest rates that are close to the rates of Wisconsin and Illinois in 2001 (around one arrest for every ten thousand youth), whereas later years have maximum values around two or three for every hundred thousand youth. A visual guide for all years is available in the appendix.

When studying populations involved with the criminal justice system, the definition of a successful outcome can sometimes appear arbitrary. For example, recidivism rate is a popular proxy for success in rehabilitating offenders, but recidivism can be operationalized in very different ways, making comparisons between different interventions nearly impossible (Gehring 2000). Recidivism refers to a relapse into criminal behavior. However, is the study checking for recidivism 6 months after a treatment or 3 years? Does the prior offender need to be re-prosecuted or merely rearrested to be classified? For the purposes of this study, a variety of outcome measures could theoretically be employed, such as measuring the intervention services states have available, changes in law enforcement response, or a shift in the legal classification of youth that come into contact with the system. This study needed a proxy outcome measure that is both reflective of a general shift in the implementing population's strategy in responding to these youth and can be feasibly measured in a quantifiable way. Arrest rate seems to be the best suited measure to meet both of these objectives. The FBI consistently collects data about the population of juveniles criminalized for engaging in

\footnotetext{
${ }^{4}$ Nevada's values were removed from the map because when they are included the variation in arrest rates between the other states cannot be distinguished. Figures 4 and 5 provide a graphical representation of Nevada's values compared to the other states.
} 
sex work, and the data is easily accessible for the duration proposed for this study. In addition, it is an unambiguous, straightforward indicator of a juvenile's status as a crime perpetrator in the eyes of the law.

While using arrest rate may be an obvious choice, determining which dataset is the most appropriate to employ is more nuanced. The FBI contains the most detailed data; however, there are two separate datasets that contain arrest statistics for juvenile prostitution over time: Crime in the United States, and the National Incident Based Reporting System (NIBRS). ${ }^{5}$ For the purpose of this study, the CIUS dataset was selected for several reasons. The level of detail recorded for each incident results in large and unwieldy data files, despite having less complete reporting. In the beginning, only 10 states submitted data in NIBRS format ("NIBRS User Manual” 2013). That number had only increased to 37 by 2013 (“NIBRS Participation” 2013). Furthermore, states were counted as reporting to the NIBRS even if only a small number of jurisdictions in the state reported under the new system ("NIBRS Codebook" 2001). This results in large numbers of missing values for many of the years that this study considers. In addition, while new prostitution categories mandated under William Wilberforce may have been helpful, the first year that data was submitted under these new definitions was not until 2013. Although the methodology NIBRS employs has some benefits, the low numbers of states and agencies that report data make CIUS the only dataset comprehensive enough for this type of analysis.

\footnotetext{
5 There are two other datasets not used that should be mentioned. The National Juvenile Prostitution Study collected information about juvenile arrests for this offense category, but it does not align with the goals of this project because it did not have data for each state or data over time. Data through the Bureau of Justice Statistics (BJS) was not considered because BJS arrest statistics are national estimates calculated from raw data originally collected by the FBI.
} 
CIUS is an acronym for Crime in the United States, and it is the metric that is most similar to traditional UCR reporting. The bulk of the data focuses on counts of criminal offenses and arrests that can be broken down along a number of demographic and geographic characteristics. Counts are aggregated to the state level from law enforcement agencies throughout the country. While the majority of agencies report, it is important to note that not all jurisdictions are covered by this dataset. Although the CIUS dataset is the best suited for this analysis, it is subject to some limitations. The two most pertinent are the broad nature of the Prostitution and Commercialized Vice offense category and the inconsistency in agency reporting. A thorough explanation of potential limitations and how they were accounted for, alongside more information about the NIBRS and CIUS, can be found in the data limitations section and the appendix.

\section{Explanatory Variables}

\section{Measuring Juvenile Protections in State Trafficking Legislation}

The explanatory variable of interest in this study is the year a state first adopted an anti-trafficking law with some form of juvenile protection (State Trafficking Legislation). This enters the model as a dummy variable, where the year a state adopts relevant legislation and all subsequent years are coded as a one. All years prior to the adoption of legislation with protection elements are coded as a zero. States were identified as having passed a protection law when they provided a legal distinction between minors and adults in their trafficking statutes. This included immunity or partial immunity, adoption of separate services or pretrial diversions, or the removal of the force, fraud, or coercion requirement from the definition of what constitutes a trafficking offense with a juvenile. 
Understanding what is meant by protectionism domestically was critical in developing a clear boundary for what constituted the adoption of a juvenile protection policy in the model. Protection policy is often broken down into two components: decriminalization of minors, and the availability of services for them. However, most state legislation did not begin to address these two areas directly until recently, and few states have put forth the same level of protection as the TVPA. The majority of states were credited with having added protection provisions following the removal of force, fraud, or coercion from the definition of child sex trafficking (or a similar form of legal protection), but a few were first given credit for providing protections through institutionalizing services, such as through Safe Harbor legislation. ${ }^{6}$ Identifying the appropriate piece of legislation for this study was a multi-step process. The year, statute, and sources for each state, as well as the methodology for determining the legislation variable, are listed in Appendix B.

Because this study makes the case that protection elements of anti-trafficking law are specifically driving the reduction in juvenile prostitution arrests, a second legislation variable was coded to test whether more broad anti-trafficking legislation would have a similar effect. Previous literature found evidence that protection elements of antitrafficking legislation had the lowest levels of compliance and the test summarized in Appendix A suggests that domestic levels of protection compliance may be lower than the prosecution and prevention components as well. This additional legislation variable tests whether it is necessary to have protection-specific legislation to reduce the juvenile

\footnotetext{
${ }^{6}$ Safe Harbor laws in this field are designed with the stated intention of protecting commercially sexually exploited youth. They usually contain provisions for both legal protections and services ("Safe Harbor" 2015; "Human Trafficking Overview" 2014).
} 
prostitution arrest rate. The comparison variable, Initial Legislation, considers the year the first piece of anti-trafficking legislation was passed, using the list compiled by Center for Women Policy Studies ("CWPS" 2012). While it does not have theoretical significance to the question posed by this study, it varies over the same time period that the legislation variable of interest also varies.

\section{Police Response to Victimless Crimes}

To account for a change in law enforcement strategy towards similar juvenile crime, the model will include a measure for the rate of juvenile arrests for other 'victimless' crimes in the state, excluding drug violations. The measure is called Police Response to Victimless Crimes and includes CIUS data for: loitering, gambling, disorderly conduct, vagrancy, drunkenness and liquor law violations. The sum of the arrests for these six crime categories was divided by the estimated total youth population in the state. The rate of these arrests will be standardized by the proportion of the state's juvenile population that is covered by FBI crime reporting. Like the juvenile arrest rate, a complete description of how this rate was calculated to account for CIUS reporting idiosyncrasies is discussed in the data limitations section.

Figure 1 provided strong evidence that law enforcement has been arresting fewer juveniles for prostitution consistently since the mid-2000s. However, the number of juveniles arrested for prostitution may vary for reasons other than a deliberate change in law enforcement strategy towards this population. For example, a department historically responsible for a large proportion of the state's juvenile prostitution arrests may have recently adopted a community policing model which reduced its vice crime arrests. Alternatively, states may be incentivized to shift arrests from one crime category to 
another, such as through the influx of federal drug enforcement dollars for securing drug arrests. This variable considers the extent to which the arrest pattern for juvenile prostitution varies in a way that is distinct from similar offense categories that lack a clear victim.

Arrests for offenses without a clear victim are often justified on the basis that they protect the person being arrested from causing harm to themselves or that the arrest preserves public order. However, the definition of what constitutes a victimless crime varies, and the Crime Victims' Rights Act does not consider any group offenses inherently 'victimless' (NCVLI 2011). The six offense categories that are used for this index were chosen because the offense category itself does not suggest a clear victim and they are the type of quality of life offenses that occur in the public sphere in a similar way that prostitution does. There are other offense categories that are viewed as victimless with some frequency, namely: drug violations, DUIs, and weapons possession. Drug offenses were not included because of the very specific and targeted policing of this act and the federal law enforcement dollars that could influence state and local policing trends. The other two offense categories do not have an identifiable victim, but can have a direct safety risk for others. This index is particularly targeting those offense categories in which police choose to make arrests absent a clear risk to person or property. For this reason, a fourth offense category — suspicion, which is only used in some states and generally infrequently — was also not included. The offense category 'vandalism' was considered because it is often a quality of life offense, where officers come into contact with arrestees in public space in similar settings to prostitution arrests. It was ultimately 
excluded because it often has a direct victim, even if that victim is somewhat abstractly identified as 'the state' when public property is defaced.

\section{Socio-Economic Factors Contributing to Sex Industry Participation}

Fluctuations in the number of arrests in a given state may also be impacted by changes in the number of youth in the state or their demographic composition. In the previously discussed literature, juveniles frequently cited economic hardship after leaving a dysfunctional or abusive home as a major driving force into the industry. It is therefore expected that an increased number of juveniles experiencing these hardships could result in an increased number of youth selling or being sold for sex. Ideally, this study would include the number of runaway youth for each state; however, state-level annual data does not appear to exist. Instead, other conditions identified by the literature that make youth more vulnerable to running away, as well as the characteristics that make youth more likely to face arrest, are included here. All of the socio-economic variables included in this study have been lagged by one year because it is expected that the changing demographic makeup of the state would not have an immediate impact on prostitution arrest patterns.

The data for each of these variables were extracted from the Annie E. Casey Foundation's compilation of youth statistics in their Kids Count Data Center. All were included as rates in order to account for fluctuations in the number of a youth in the states. The original source of data for each of the variables is included in Table 3 below. Children in Poverty is the first of these variables, and it considers the percent of children that are living below 100 percent of the poverty line from the total number of children in the state. This variable was included to account for the literature citing 
family instability and lack of access to basic needs as being two of the major driving forces for entrance into the industry. It is expected that an increase in child poverty in one state would increase child vulnerability and, by extension, drive up the number of youth engaged in sex work, the number of these youth that come into contact with law enforcement, and the number of arrests made.

The second variable, Children Abused, considers the rate of reported child maltreatment. The rate will include the number of reported, substantiated child abuse victims out of every thousand children in the state. As discussed in the literature, abuse was consistently found to be an important factor driving youth to runaway where they face heightened risk for entrance into the sex industry. Data for this variable was originally drawn from the National Child Abuse and Neglect Data System (NCANDS); however, not all years were available publicly through the Kids Count Data Center. The large number of missing values for this variable is further discussed in the modeling section of Chapter 5.

Divorce was not explicitly discussed in the literature, but research suggests that even amicable divorces can create long lasting negative impacts on the social development of children and the stability of their home life (Marquardt 2006). To test whether divorce may foster youth instability and a greater propensity to engage in sex work, the variable Children in Single-Parent Families was added. This variable would include those children from divorced families, children living with cohabiting but nonmarried couples where only one adult is the biological parent of the child, and single parents. It does not include institutionalized youth and it is likely to over-estimate the number of children who meet these criteria but lived with committed same sex parents 
prior to the legalization of same sex marriage. The variable is included as a rate of children from single parent families out of every hundred children.

Finally, the variable Disengaged Youth was included. This variable was calculated as the percent of youth in the state not engaged in school that have also not graduated. While only one study identified the highest level of education completed as a significant indicator of entrance into the industry, other studies identified a lack of support structures or lack of caring adults as risk factors. This variable was chosen over the Youth Disengaged from School and the Work Force survey question due to a methodological change in how employment data in the American Community Survey (ACS) was calculated. This change made a comparison across the time range of this study inappropriate.

\section{Race as a Factor Contributing to Arrest}

The final explanatory variable included in this model is Black Youth, the portion of the state's juvenile population that is black. The proportion of children in poverty, abused, growing up in single parent households, and disengaged from school were variables included to account for dysfunctional or unstable home environments that pushed youth towards the vulnerabilities of the streets. In addition to these factors, it is also necessary to consider the characteristics of those youth that are more vulnerable to arrest. The literature has identified several factors that increase the likelihood that a child will be considered a victim and not face arrest for prostitution. Most of these factors are difficult to model, such as shifts in gender or age makeup of the population of youth selling sex. Some publications make the unsubstantiated claim that youth are being drawn into the sex industry at earlier ages today than they were in the past. It is difficult to 
imagine how this conclusion could be confidently reached with existing data; however if it were true, research regarding law enforcement arrest patterns suggests that these children would be more likely treated as victims. Additionally, no appropriate way to account for changes in situational factors that make children appear more vulnerablesuch as the proportion of youth who law enforcement perceive as cooperative or afraidhave been identified. For these reasons, the only variable included to account for disproportionate arrest is the changing racial composition of the state.

Although the literature is divided around the significance of race, there is some indication that a measure for the proportion of the youth population that is black is important to include. Data from the National Juvenile Prostitution Study, which attempted to create a nationally representative sample of juvenile prostitution cases known to law enforcement, shows a discrepancy in the outcomes for youth when they are classified as either white or black. White youth were 3 times as likely to be classified as a victim than a delinquent, black youth were only 1.5 times as likely (Mitchell et al. 2010). However, when race is considered alongside other characteristics from the police report— such as whether the youth were described as frightened or dirty, how the officer came into contact with the youth, and whether the child had a history of running awayrace was not found to be statistically significant. It is therefore likely that the variance in outcome by race can explained through some of these other characteristics.

While the other characteristics cannot be measured directly with the data available for the current study, it is expected that if the racial composition of a state changes, the characteristics that appear to be linked to race will also change. It should be noted that Latino youth had similar arrest patterns to white youth, so ethnicity was not considered 
separately. Black youth regardless of ethnicity will be included in the measure, but nonblack Latino youth or non-black youth of any other minoritized racial identity will not. Table 3 below provides a summary of these variables and their data sources. Further information about the state trafficking legislation variable can be found in Appendix B.

\section{Table 3}

\section{Explanation of Variables, Data Sources}

Dependent Variable

Rate

Explanatory Variables

State Trafficking Legislation Data compiled from a variety of sources

Dummy variable will be coded as ' 1 ' for the year protection law adopted and all subsequent years

Police Response to

Victimless Crime
FBI CIUS Data, Arrest Table 69

Number of juvenile arrests for Prostitution and Commercialized Vice as a proportion of the state covered by FBI reporting
FBI CIUS Data, Arrest Table 69

\footnotetext{
Children in Poverty

Children Abused

Number of juvenile 'victimless' crime arrests as a proportion of the state's population covered by FBI reporting

U.S. Census Bureau Supplemental Survey, American Community Survey from Kids Count

Rate measured as the proportion of youth in the state living below the poverty line

National Child Abuse and Neglect Data System (NCANDS) from Kids Count

Number of substantiated child maltreatment cases as a proportion of youth in the state
} 
Explanatory Variables

Children in Single Parent

Families

Disengaged Youth

Black Youth
U.S. Census Bureau, American Community Survey (ACS) from Kids Count

Number of non-institutionalized youth living with only one biological parent (unless non-biological and biological parent are married), as a proportion of the number of youth in the state

\section{U.S. Census Bureau, American Community Survey (ACS) from Kids Count}

Number of youth disengaged from school that have not graduated as a proportion of the number of youth in the state

Number of youth identifying as black as a proportion of the number of youth in the state

\section{Model}

The full model had 513 observations, from the potential 700. The low number of observations was due to missing data in the Children Abused variable. For this reason, the model was also run without this regressor. There were also a small number of observations that had missing arrest values due to incomplete CIUS data. Values for these data points were imputed manually by averaging the year prior and following the missing value. This method was chosen over the more complex algorithms provided by statistical software in order to retain full access to a range of commands. ${ }^{7}$ A statistical test was run in order to determine whether the random or fixed effects model is more appropriate.

\footnotetext{
${ }^{7}$ Of the 700 observations, seven values of the dependent variable were imputed this way. Four of these values were zeros because the neighboring values or all values for that state were zeros. Six data points were imputed for the other variable that uses CIUS data (Police Response to Victimless Crime) and all six were non-zero values.
} 
Two final considerations merit discussion. When the dependent variable was graphed in scatterplots with the other regressors, the majority of Nevada's values were higher than the maximum arrest rate for any other state. This may, at first, seem counterintuitive; prostitution is legal in half of Nevada's counties. However, prostitution is also highly regulated and heavily policed for both juveniles and adults who operate outside of the law. Figure 4 shows a scatterplot of just the juvenile prostitution arrest rate for all states and years. The black dots represent the values for Nevada, while all other states are represented in grey. For this reason, the effect of possible outlying values was tested.

\section{Figure 4}

Juvenile Prostitution Arrest Rate by State and Year, Nevada Highlighted

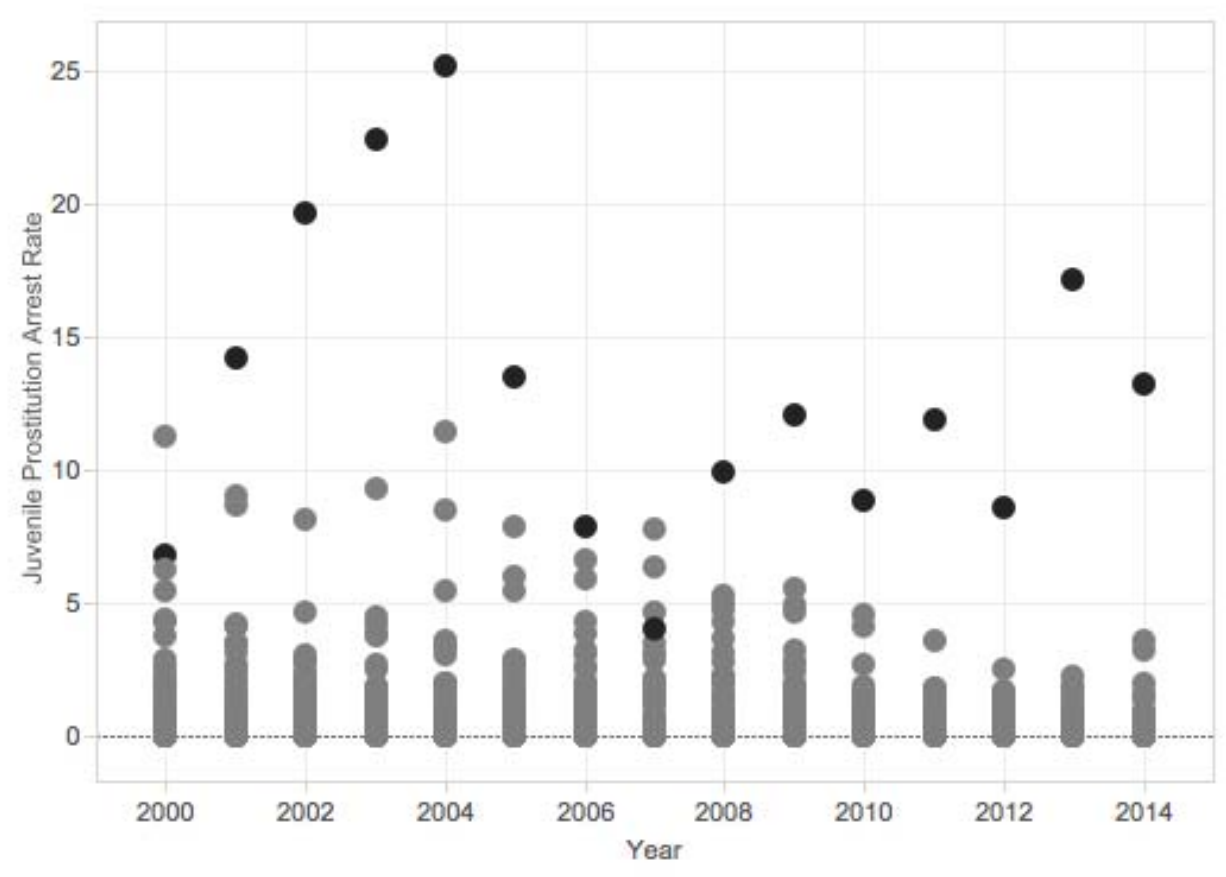

Secondly, it was also a concern that if the State Legislation variable were significant in the model, it would still be unclear if it were due to the protection elements 
of the law. For example, it may be that any changes to sex trafficking legislation would have driven down juvenile prostitution arrests. To test the effect of trafficking legislation in general, the Initial Legislation variable (discussed earlier) was run in a separate model. If this variable were not significant and State Legislation was, the results would support the hypothesis that the protection content of the law matters. However, if both or neither of the legislation variables were significant in their respective models, the hypothesis put forward in this paper would have to be revisited.

\section{Data Limitations of the CIUS}

Much to the chagrin of criminologists, even the most comprehensive crime data available through the FBI faces some limitations, and the CIUS data employed here is not exempt. As Loftin and McDowall (2010) emphasize, it is neither appropriate to entirely discount the utility of this data, nor employ it without understanding and attempting to account for its shortcomings. The authors stress the importance of understanding the UCR dataset being used, the context in which it is being used, and its relevance to the research question being studied. Although the limitations imposed by the data for this study have the potential to be problematic, fully considering and accounting for data weaknesses is far more likely to yield insightful results than ignoring these constraints. Full consideration of these factors and how they were addressed in the model can be found in Appendix C.

To summarize, there were two primary concerns about the data: incomplete reporting by states and the broad nature of the offense categories. Both were considered in the development of the model. First, incomplete reporting was accounted for by considering the proportion of the state's juvenile population covered by the FBI data for 
that state and year. This was calculated by using the number of the state's total population covered by the reporting as provided by the FBI and the proportion of the state's population that is comprised of juveniles from U.S. Census estimates. In this way, the rates are reflective of the number of arrests for the area covered by the statistics, not the state as a whole. This allows us to be more confident that fluctuations in the number of juvenile arrests in the state are not explained by a different number of agencies reporting data. Secondly, while the offense category Prostitution and Commercialized Vice is broadly defined, at most it would be expected to dampen the effects, not artificially inflate the results of this study. However, as mentioned in the appendix, a low frequency of demand-side and trafficker arrests makes it unlikely that these other offenses would generally influence the results in a meaningful way. Further details about these two concerns, as well as other commonly discussed limitations and why they are not applicable to this study can be found in Appendix C. 


\section{CHAPTER V}

\section{ANALYSIS OF THE DATA}

This chapter will discuss the four models on the hypothesis presented in Chapter 4. To reiterate, this study hypothesizes that states will see a steeper decline in their juvenile prostitution arrest rate following the passage of anti-trafficking legislation that adds protections for youth. In addition to presenting these models, this chapter will also discuss the way potential data concerns were addressed and how checks were conducted on the results obtained.

To begin, a summary of descriptive statistics for the variables is presented in Table 4. States were coded from 1 to 50 and years were coded from 1 to 14 before being entered into the model. As discussed in Chapter 4, both legislative variables, State Legislation and Initial Legislation, were coded as dummies. The socio-economic variables were included as decimals, with the exception of Children Abused, which was entered as the rate per 1000 youth. More than a quarter of the values are missing for this variable, so the model was tested both with and without the Children Abused variable. Additionally, all socio-economic variables were lagged by one year (noted by T-1 in the table below). Both of the arrest variables represent the number of youth arrested for every hundred thousand youth living in the state. Overall, there were approximately 1.21 prostitution arrests and approximately 596 arrests under Victimless Crimes for every hundred thousand youth across all states and years of the study. Although both arrest categories have a wide range, the highest values were carried by a small number of states. 
Only Pennsylvania and Wisconsin had some values greater than 2,000 for victimless crime arrest rates, and Nevada was almost single-handedly responsible for any prostitution arrest rates larger than 10 (Illinois had one year with a rate of 11.4).

Table 4

Variable Descriptives

\begin{tabular}{|c|c|c|c|c|c|c|}
\hline Variable & Unit & $\mathrm{N}$ & Mean & S.D. & Min & Max \\
\hline State ID & $1-50$ & 700 & & & & \\
\hline Year ID & $1-14$ & 700 & & & & \\
\hline State Legislation & Dummy & 700 & & & & \\
\hline $\begin{array}{l}\text { Initial Legislation } \\
\text { J. Prostitution Arrest }\end{array}$ & Dummy & 700 & & & & \\
\hline Rate & Per 100,000 & 700 & 1.21 & 2.23 & 0 & 25.18 \\
\hline Victimless Crimes & Per 100,000 & 700 & 596.20 & 489.31 & 20.80 & 4378.80 \\
\hline $\begin{array}{l}\text { Children in Poverty } \\
\text { (T-1) }\end{array}$ & $\begin{array}{l}\text { Percent as } \\
\text { decimal }\end{array}$ & 700 & 0.18 & 0.05 & 0.06 & 0.35 \\
\hline Children Abused (T-1) & Per 1000 & 513 & 9.64 & 5.10 & 1 & 32 \\
\hline $\begin{array}{l}\text { Children in Single- } \\
\text { Parent Families (T-1) }\end{array}$ & $\begin{array}{l}\text { Percent as } \\
\text { decimal }\end{array}$ & 700 & 0.32 & 0.05 & 0.17 & 0.49 \\
\hline $\begin{array}{l}\text { Disengaged Youth } \\
(\mathrm{T}-1)\end{array}$ & $\begin{array}{l}\text { Percent as } \\
\text { decimal } \\
\text { Percent as }\end{array}$ & 700 & 0.07 & 0.03 & 0.01 & 0.18 \\
\hline Black Youth (T-1) & decimal & 700 & 0.12 & 0.11 & 0.01 & 0.45 \\
\hline
\end{tabular}

Because the data structure consists of space and time, a cross-sectional and timeseries research design is employed to analyze data collected for all 50 states over the period 2001-2014. To begin the analysis, a random and a fixed effects version of Model 1 (the full model) were run in order to conduct the Hausman test. The chi squared value for this test was $5.91(\mathrm{p}=.43)$, suggesting that the between-entity error $\left(\mathrm{u}_{\mathrm{it}}\right)$ is not correlated 
with the regressors, and that a random effects model should be employed. ${ }^{8}$ The functional form of the random effects model is as followed:

$$
\boldsymbol{Y}_{i t}=\boldsymbol{\beta} \boldsymbol{X}_{i t}+\alpha+\boldsymbol{u}_{i t}+\varepsilon_{i t}
$$

This random effects model differs from the most basic regression model in that the superscripted terms represent matrices, accounting for each entity at each time period.

Additionally, there are two error terms, the $\boldsymbol{u}_{i t}$ term representing the between-entity error and the $\boldsymbol{\varepsilon}_{i t}$ term representing the within entity error (Torres-Reyna 2007).

In Model 1 none of the regressors were statistically significant, but the State Legislation variable approached significance $(\mathrm{p}$-value $=.056)$. This model also did not address any of the analytical concerns discussed earlier. The first concern was Nevada's high arrest rates relative to other states. Using the statistical software Stata, the individual juvenile prostitution arrest rates were charted for each state during the time period studied. These graphs are displayed in Figure 5 below. Most states have graphs that look nearly horizontal compared to Nevada's steep peaks, but a handful of other states have smaller peaks or humps either toward the beginning or middle of the time span studied. As shown in the maps from Chapter 4, all states except Nevada have rates at or around zero by 2014.

Using a statistical test, it was determined that nearly all values for Nevada were outliers. ${ }^{9}$ In addition to being anomalous statistically, Nevada also differed from its peers in

\footnotetext{
${ }^{8}$ The potential for multicollinearity was considered, but does not appear problematic. A correlation matrix reveals that most of the regressors are not highly correlated (the highest is Single Parent Families and Children in Poverty at .77; Williams (2015) suggests .8 as a rough "cut-off" point for potentially problematic bivariate correlations in large samples), nor are the regressor coefficients highly correlated (the same 2 variables have the highest coefficient correlation, at -.54). Further, the mean VIF score for socioeconomic and Victimless Crime regressors was 2.03 (conducted with the "collin" test). Additionally, the model does not exhibit signs of high multicollinearity, such as drastic changes in coefficients when small changes are made to the variables entered into the model.

9 To test if Nevada's extreme values were outliers, the hadimvo test was employed. The test identified 27 observations, with one in North Dakota, seven in each Illinois and Wisconsin, and the remaining 12 in
} 
its approach to prostitution due to its partial legality. For these statistical and legal reasons, it was dropped from the model entirely.

\section{Figure 5}

Juvenile Prostitution Arrest Rates by State, 2001-2014

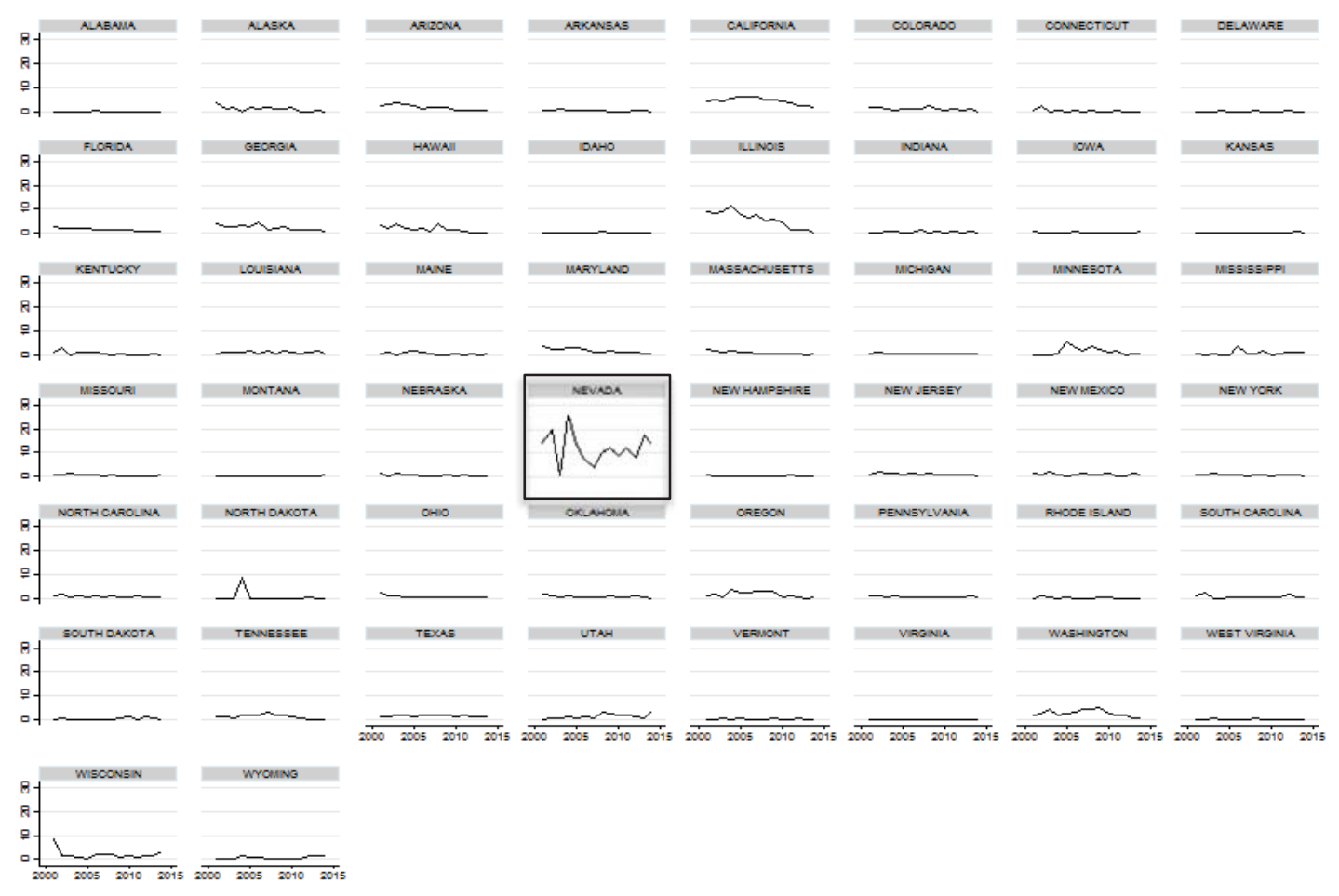

When Nevada was dropped in Model 2, both State Legislation and Child Poverty

became statistically significant and remained significant throughout the remaining models.

Nevada. Since all but two observations from Nevada were outliers, Nevada was dropped from Model 2. This approach was favored in order to keep the panel data balanced.

Because a high number of values were also outliers in Illinois and Wisconsin, an additional test was conducted to see the influence of these 2 states. A model identical to Model 2, except with all 3 states with multiple outliers removed, was also run. There were no important differences between Model 2 without NV and Model 2 without NV, IL, and WI. Maps presented in Figure 3 show that WI and IL had high juvenile prostitution arrest rates early on, but WI also had extremely high juvenile arrest rates for the Victimless Crime measure. See Constantini (2015) and "WCC" (2015) for more on arrest rates in WI. 
In this model, the State Legislation variable suggests that adding protections for youth in anti-trafficking legislation lowers the youth prostitution arrest rate by .25 arrests. The coefficient fell to .37 when Children Abused was removed due to its large number of missing values in Model 3. In the fourth model, the State Legislation coefficient fell again for a .47 arrest reduction in the juvenile prostitution arrest rate. This model accounted for a potential delay in the enactment of trafficking legislation by lagging the State Legislation variable by one year. Table 5 summarizes the differences between all five models and Table 6 summarizes the output for each of these models.

Table 5

\section{Model Descriptions}

\begin{tabular}{|c|c|c|c|c|c|}
\hline & $\begin{array}{l}\text { Model } 1 \\
\text { (Full) }\end{array}$ & $\begin{array}{l}\text { Model } 2 \\
(\text { No NV) }\end{array}$ & $\begin{array}{c}\text { Model } 3 \\
\text { (No } \\
\text { Abuse) }\end{array}$ & $\begin{array}{c}\text { Model } 4 \\
\text { (Leg. } \\
\text { Lag) }\end{array}$ & $\begin{array}{c}\text { Model } 5 \\
\text { (Alt. } \\
\text { Leg.) }\end{array}$ \\
\hline Nevada (Outlier) & Retained & Dropped & Dropped & Dropped & Dropped \\
\hline $\begin{array}{l}\text { Data) } \\
\text { Lagged Legislation }\end{array}$ & Retained & Retained & Dropped & Dropped & Dropped \\
\hline Variable & No lag & No lag & No lag & Lagged & No lag \\
\hline Type of Legislation & State & State & State & State & Initial \\
\hline Variable & Leg. & Leg. & Leg. & Leg. & Leg. \\
\hline & $\mathrm{N}=513$ & $\mathrm{~N}=504$ & $\mathrm{~N}=686$ & $\mathrm{~N}=686$ & $\mathrm{~N}=686$ \\
\hline
\end{tabular}

In Model 2 through Model 4, the results support the hypothesis that adopting state legislation with a protection component will reduce the juvenile prostitution arrest rate and while the size of the effect appears to be very small, the mean arrest rate for all states and all years was 1.26 , for which a .47 arrest reduction would be a sizable portion. To further test this hypothesis, a fifth model was tested, which considered the second legislation variable, Initial Legislation, in place of State Legislation. This model took into 
account the potential impact that general (not protection-specific) trafficking may have had on juvenile prostitution arrest rates. When this model was run, the legislation variable did not have, nor did it approach, statistical significance. This further supports the hypothesis that the protection component of trafficking legislation may be an important factor for driving down the arrest rate.

In contrast, the other statistically significant variable, Children in Poverty, had a large, negative coefficient. While theory suggests that an increase in poverty would exacerbate the factors that lead young people to sex work, the results of this study suggest that observations with higher state poverty rates have lower arrests for prostitution. For example, Model 2 suggests that a one percentage point increase in the child poverty rate would result in a 7.1 arrest decline in the juvenile prostitution arrest rate. This number rose slightly in Models 3 and 4 to a 6.5 and 6.3 arrest rate decline, respectively.

Like the measure for child poverty, the Single-Parent Families variable started with a negative coefficient when it was expected to be positive. However, once Nevada was removed, the coefficient stayed positive in the remaining models. This variable, along with Disengaged Youth and Black Youth, remained insignificant throughout all of the models studied. Each of these three variables did approach significance in at least one model; however, the 95 percent confidence interval consistently encompassed zero for all variables in all four models. The Children Abused variable was not significant in either of the models in which it was included, nor did it greatly impact the model when it was excluded. It was not included in Models 4 and 5 so that all 686 observations (excluding Nevada) could be retained. Finally, Victimless Crimes was not significant in any of the 
four State Legislation models tested, but it was significant when the atheoretical

legislation variable was used. The effect size consistently remained very close to zero.

Table 6

Model Parameter Coefficients and (Standard Errors)

\begin{tabular}{clllll}
\hline & $\begin{array}{l}\text { Model 1 } \\
\text { (Full) }\end{array}$ & $\begin{array}{l}\text { Model 2 } \\
\text { (No NV) }\end{array}$ & $\begin{array}{l}\text { Model 3 } \\
\text { (No } \\
\text { Abuse) }\end{array}$ & $\begin{array}{l}\text { Model 4 } \\
\text { Leg. } \\
\text { Lag) }\end{array}$ & $\begin{array}{l}\text { Model 5 } \\
\text { (Alt. Lag) }\end{array}$ \\
\hline State Legislation & -.243 & $-.245^{*}$ & $-.374^{* *}$ & $-.465^{* * *}$ & \\
& $(.127)$ & $(.103)$ & $(.111)$ & $(.114)$ & \\
Initial Legislation & & & & & .016 \\
& & & & & $(.106)$ \\
Victimless & -.000 & .000 & .000 & .000 & $.000^{*}$ \\
Crimes & $(.000)$ & $(.000)$ & $(.000)$ & $(.000)$ & $(.000)$ \\
Children in & -3.393 & $-7.090^{* *}$ & $-6.450^{* *}$ & $-6.255^{* *}$ & $-6.912 * *$ \\
Poverty & $(2.645)$ & $(2.100)$ & $(2.196)$ & $(2.190)$ & $(2.188)$ \\
Children Abused & .014 & .013 & & & \\
& $(.018)$ & $(.014)$ & & & \\
Children in & -1.134 & .630 & 1.564 & 1.762 & -.555 \\
Single- & $(3.027)$ & $(2.421)$ & $(2.460)$ & $(2.438)$ & $(2.472)$ \\
Parent Families & & & & & \\
Disengaged & 1.876 & .715 & 1.326 & 1.047 & 4.338 \\
Youth & $(3.052)$ & $(2.420)$ & $(2.257)$ & $(2.224)$ & $(2.328)$ \\
Black Youth & 1.616 & 2.400 & 2.109 & 2.033 & 2.524 \\
& $(.943)$ & $(1.459)$ & $(1.554)$ & $(1.553)$ & $(1.493)$ \\
N & 513 & 504 & 686 & 686 & 686 \\
& & & & & \\
\hline & & & $* \mathrm{p}<.05$, & $* * \mathrm{p}<.01$ & $* * * \mathrm{p}<.001$
\end{tabular}




\section{CHAPTER VI}

\section{CONCLUSIONS}

The results of this study provide an initial and insightful look at the potential impact anti-trafficking laws have on providing protections to youth in sex work. This final chapter will look critically at the implications of these results as well as the model itself. It will conclude with three overarching themes that are not often discussed in the literature: the role the criminal justice system plays in furthering harm to youth, the uneven application of criminal justice outcomes for youth, and the disproportionate legal responsibility that youth face in this area of law.

\section{Study Implications}

The analysis suggests that when states pass laws that explicitly address youth protection, there is a reduction in the juvenile prostitution arrest rate. It also indicates that the content of the law matters; merely passing an anti-trafficking law in the state does not, in and of itself, result in a reduction in the arrest rate. This is evident in the disparate outcomes of the two legislation variables. The results of this study are promising, given the amount of advocacy that has gone into the passage of these laws. However, the other factors that were expected to influence the prostitution arrest rate did not have a significant impact. The only exception to this was the measure of child poverty in the state, which influenced the arrest rate in the opposite direction than what was anticipated. It is not certain why this occurred, although while the literature discussed the role that 
poverty can play on an individual's decision to enter into the sex industry, the effect that poverty has on data aggregated at the state level has not been studied and may be different. Since the unit of analysis for this study is the state, institution-level factors that are not present at the individual level may need further consideration. For example, increased poverty may increase other types of crime, and law enforcement may make fewer prostitution arrests when there are higher rates of more serious crime. The crime variable included in this study only attempted to capture the enforcement of other similar quality of life offenses, not other types of crime rates. Although states had an overall reduction in arrests over time in both measures studied, the rate of 'victimless' crime arrests did not have a significant impact on prostitution arrests.

Overall, the socio-economic variables had small fluctuations over the short time period studied. Youth that reported turning to sex work often talked about long-term, persistent factors in the home environment. It is unclear how a youth's risk for entrance to sex work based on an individual history of childhood trauma translates to a state level analysis of risk based on these varying characteristics. For example, what occurs in states that see a small increase in their rate of poverty? Are those who are recently or temporarily facing poverty at the same risk as the chronically poor? Small, short-term fluctuations in state level measures may not be adequate in capturing the same risk factors as individuals who report chronic poverty and childhood abuse. Secondly, institution-level changes are also not captured in the remaining socio-economic variables. This is particularly apparent in the Children Abused variable, where other unrelated factors that could be driving fluctuations should be considered, such as changes in reporting methods or the willingness of residents to report abuse, as well as jurisdiction- 
level policy changes that influence what criteria are used to return a substantiated finding. A more comprehensive analysis of the impact that state-level socio-economic factors have on crime and arrest rates would improve the model.

While the outcomes of this study seem promising for reducing the criminalization of youth in the sex industry, this study does not imply that youth have had improved outcomes. First, a reduction in arrest means that there are still youth under the age of 18 facing arrest for commercial sex with adults. In a nearly identical situation where an adult had filmed the encounter, the adult would be automatically labeled as a crime perpetrator. Additionally, this study can only quantify youth who are explicitly being arrested under the offense category Prostitution and Commercialized Vice. If law enforcement in a state is prohibited from making an arrest explicitly for prostitution, it is unknown how an arresting officer will adjust his or her behavior. Officers who suspect that a youth is engaging in sex work may instead make an arrest based on other circumstances, such as trespassing or loitering, resisting arrest, or, if applicable, drug or alcohol violations. This study is unable to account for what officers choose to do in place of making an arrest.

Even with a reduction in arrest, there is no certainty that these youth will have an improved outcome - it merely means that they will not have the experiences attached to criminalization. Ceasing to arrest youth for sex work is not a long-term solution to addressing the forces that compel many youth into the trade. If the desire to protect youth from dangerous situations is genuine, providing access to the necessary job, education, health, and housing services must be approached with the same vigor as criminalization has been. 


\section{Broader Implications}

The question studied in this thesis raises larger societal issues such as the level at which the state should intervene in potentially coercive or abusive circumstances for youth and whether corrections systems are appropriate responses for them. The use of the juvenile justice system as a response to youth participation in the sex industry has been hotly contested; however, the data shown in Figure 1 indicates that the past decade has seen a decline in the use of prostitution as the arresting offense for youth.

As discussed in Chapter 2, treating youth separately from adults under the law is a recent distinction, as is seeing child protection as a governmental responsibility. In the past hundred years, there has been a divided approach to regulating commercial sex. The first is through legislation like the White Slave Traffic Act, or Mann Act, which was enforced by punishing those who transport others for "immoral purposes", a precursor to modern anti-trafficking laws. The second is through the arrest, of both adults and children, for prostitution.

This chapter will argue that arrest and detention is not only an inappropriate response, but also furthers the harm created by the 'paradox' of juvenile prostitution arrest where age of consent laws are in place. Secondly, this study contends that the demographic of youth most likely to be considered culpable for selling sex is not ahistorical, nor does selective arrest separate "guilty" youth from the "true victims." Instead, the criteria some states use to determine who is culpable likely criminalizes the most vulnerable and victimized youth. With this in mind, the third point argued here is that researchers and advocates should reframe their language about child victims of 
trafficking and refrain from tokenizing the most brutal incidents of forced prostitution when pushing for a legislative change. These points are discussed individually below.

\section{Arresting Youth Furthers the Paradox between Prostitution and Consent Law}

Many organizations and articles make the case against criminalizing youth for

prostitution. The often-cited Estes and Weiner study (2002) warns that even if the intention is to use the juvenile justice system as a conduit to provide services, it is likely to produce more harm than it is capable of repairing. Beck et al. (2013) agree services that are introduced through juvenile justice channels may cause additional harm to youth, while Smith et al. (2009) add that arrest may disqualify youth from accessing other victim funds and services in some states. Additionally, there is a body of research to suggest that using arrest or detention as a "last resort" for some youth is an ineffective compromise.

While some states require participation in services to avoid detention, research on the dismal state of services indicates that they are likely ill equipped to keep youth from the juvenile justice system. In general, services may not be able to provide the breadth of support needed to keep youth from returning to sex work (Williams 2009). Such services may also be perceived by youth as demeaning, dangerous or inaccessible (Ashley 2008; Bigelsen et al. 2013; Curtis 2008). Where services do exist, such as shelter beds, demand for even subpar assistance can outstrip the resources available (Bigelsen et al. 2013; Annitto 2011). Another area that has been addressed little in the literature is that the female-focused nature of many services is likely to alienate the large numbers of males needing services. Transgender and gay youth may also find that services are not equipped to treat them in a way that is respectful of their identities. The inadequate and often non- 
existent service landscape increases the role that the juvenile justice system plays, whether through law enforcement feeling compelled to make an arrest when there is no alternative placement (Farrell et al. 2013), or through mandated participation in services that are not able to meet youths' needs.

The paradox of arresting a child for engaging in commercial sex when they are unable to provide consent for having sex is frequently denounced for being an inconsistent and unjust practice. However, many jurisdictions end up in an even more vicious quagmire: a youth who is unable to legally consent to sex is arrested for sex with an adult, and then sent to a place where he or she is at increased risk for sexual assault. At the most fundamental level, the connection between juvenile prostitution, childhood sexual abuse, and the high incidence of sexual assault in juvenile detention facilities is missing from the conversation.

The high incidence of sexual victimization inside youth facilities is well documented, especially following new PREA reporting requirements. ${ }^{10}$ Sexual violence in facilities occurs with and without physical force, and can be perpetrated by other youth as well as staff (Beck 2013). In addition to sexual abuse within facilities, there are also well-documented experiences of criminal justice actors at all stages using a youth's record or perceived engagement in prostitution as an invitation to bribe or cajole the youth into having sex with them in return for favorable treatment (Dank 2015; Beck 2013; Curtis 2008). Youth who have experienced this or other forms of misconduct such as violence that is not of a sexual nature - commonly express not having any avenue to escape from the situation or for redress after the incident occurred. Simowitz

\footnotetext{
${ }^{10}$ PREA is an acronym for the Prison Rape Elimination Act (2003). In part, it created reporting mandates around the incidence of sexual assault inside juvenile and adult facilities.
} 
(2013) discussed how the criminalization of sex workers has broadly decreased access to legal channels for redress for sexual abuse or violence; this adds to the increased burden of risk they grapple with, particularly for those involved in street prostitution. Youth face additional systemic and developmental limitations that increase their vulnerability — for example, the often have limited employment opportunities or little access to legitimate financial services, like making payments on credit or starting a savings account. These age-related disadvantages decrease the options youth have when they leave home due to trauma or abuse. For many child survivors of sexual violence, the juvenile justice system becomes another place where they do not have autonomy over their body. They have to be constantly vigilant to avoid a physical or sexual attack, and the idea that they are bad, shameful, or criminal because of their placement in the system reinforces what many youth have internalized over years of maltreatment.

With this being said, diverting young people from the juvenile justice system means that an alternative must exist. Law enforcement officers are forced to choose between not intervening and making an arrest in absence of an alternative placement. Developing successful programs requires a sustained, proactive commitment beyond green-lighting small scale pilot programs. States who wish to increase the services they provide not only need to develop effective policy, but also need to identify the stakeholders who can implement programs successfully. Active investment in these programs includes appropriate oversight and standards, consistent and adequate funding, as well as an in depth understanding of the needs of this population. 


\section{Perceptions of Culpability Are Non-Random, Historically Consistent, and Suggest Bias}

A second characteristic of the juvenile prostitution paradox that is not often addressed in the literature is that its effects are felt inconsistently. Existent research suggests that the public generally perceives female child sex workers as culpable, although this effect is lessened when their history of victimization or coercion into the industry is known (Menaker and Miller 2012; Menaker and Franklin 2013). This sense that only certain youth are "deserving" of victim status has been seen with law enforcement professionals as well. Officers are more likely to perceive youth with certain characteristics as victims, particularly those who had visible signs of coercion into the industry (Halter 2010; Mitchell et al. 2010).

The research in this area, while sparse, is consistent with the burgeoning understanding that not only do youth have different needs and capacities as adults, they also have disparate access to existing resources and support, some of which is based on a generally agreed upon perception of which youth are 'worthy' or 'capable.' The three factors related to juvenile prostitution identified by Halter: cooperation with law enforcement, no prior record, and visible signs of coercion, are not neutral factors. For example, poor, urban youth of color live in areas where they are more likely to come into frequent contact with officers. Historically, relationships with the police in many communities of color have been contentious. Youth who come from broken homes in 'tough' communities may not appear to officers like persons in need, particularly if they are engaging in commercial sex without a pimp and have been caught in other illicit activity such as drug use or survival crimes like petty theft. Fichtelman (2014) refers to 
the "[i]llusion of choice" that authority figures project onto children in the sex industry, especially those that resist intervention by law enforcement. While youth may not show vulnerability to law enforcement, research discussed in Chapter 3 shows that youth involved in commercial sex are often seeking housing, economic opportunities, and security.

\section{Child Prostitution as Child Victimization}

In addition to criminalization and institutional disadvantages, researchers make the case that youth in the sex industry are disadvantaged by their invisibility in the mainstream. One sociological explanation for why stories of youth in sex work are not more visible is the threat they pose to "society's image of itself as nurturing of, and considerate to, its children" (Melrose 2002). This theory suggests that information which conflicts with a society's own cultural mythology around the innocence or asexuality of children is met with resistance. Discussing issues that are deeply rooted in cultural and moral sentiments of a society can rouse strong emotions. One team of researchers described the language in the media used to identify this group of youth as textual abuse, language that both objectifies children and minimizes the seriousness of the harm done to them, often to shield the consumer from the discomfort associated with learning about uncomfortable forms of abuse (Goddard et al. 2005; also see Reid and Jones 2011).

Classifying youth into 'victims' and 'perpetrators' allows for society to feel good about successful cases that fit the victim-rescue archetypes while allowing other youth to be disregarded as an anomalous or problematic 'other'. This dismissal fails to recognize the harm that adults inflict onto this invisible population. Society expects adults to obey laws that prohibit the distribution of alcohol or cigarettes to a minor, viewing or making 
pornography with a minor, and upholding statutory rape laws. An exchange of money in the first two scenarios does not create a sound legal defense for adults to avoid legal consequences for illicit behavior, though a financial transaction is frequently enough to cast aside society's general agreement about statutory rape laws. However, children who cannot legally consent to sex under statutory rape laws do not develop a special autonomy or maturity when they are offered money for sex. Laws need to be consistent about the level of autonomy youth have in their sexuality without exception. Creating exceptions to allow for some children to be prosecuted inappropriately redirects the legal responsibility away from the adult and onto the youth.

Providing protection from criminalization is an appropriate first step in addressing the disconnect between prostitution law and trafficking law, but it is not a sufficient end goal. The results of this study suggest that trafficking legislation with a protection component may be an effective tool in reducing arrests; however, a larger investment in the outcomes of youth engaged in sex work is needed to achieve the spirit with which these laws are championed by legislators and advocates. 


\section{REFERENCES}

Amahazion, FikreJesus. 2014. "Global Anti-Sex Trafficking: State Variance in Implementation of Protectionist Policies." Human Rights Quarterly 36(1): 176209. DOI: $10.1353 /$ hrq.2014.001

Annitto, M. 2011. Consent, Coercion, and Compassion: Emerging Legal Responses to the Commercial Exploitation of Minors. Yale Law \& Policy Review. 30(1) Retrieved from: http://papers.ssrn.com/sol3/papers.cfm?abstract_id=176289

Ashley, Jessica. 2008. "The Commercial Sexual Exploitation of Children and Youth in Illinois.” Prepared by Illinois Criminal Justice Information Authority. Retrieved from http://www.icjia.state.il.us/publications/the-commercial-sexual-exploitationof-children-and-youth-in-illinois

Avdeyeva, Olga A. 2011. “Does Reputation Matter for States' Compliance with International Treaties? States Enforcement of Anti-Trafficking Norms." The International Journal of Human Rights 16(2): 298-320. DOI: 10. 1080/13642987 .2010 .540240

Beck, Allen J, David Cantor, John Hartge, and Tim Smith. 2013. Sexual Victimization in Juvenile Facilities Reported by Youth, 2012. Bureau of Justice Statistics. NCJ 241708

Benekos, Peter J., Alida V. Merlo and Charles M. Puzzanchera. 2013. "In Defence of Children and Youth: Reforming Juvenile Justice Policies.” International Journal of Police Science \& Management 15(2): 125-143. doi: 10.1350/ijps.2013.15.2.307 
Berlatsky, Noah. 2014. “Alaska's Prostitution Law Isn’t Working.” The Atlantic. Retrieved from: http://www.theatlantic.com/health/archive/2014/12/alaskasprostitution-law-isnt-working/383818/

Bigelsen, Jayne, Stefanie Vuotto, et al. 2013. "Homelessness, Survival Sex and Human Trafficking: As Experienced by the Youth of Covenant House New York.” Prepared by and for Covenant House New York. Retrieved from: https://www.covenanthouse.org/homeless-teen-issues/human-trafficking Boutros, Victor. 2014. Presentation at Illinois State Bar Association conference. Cho, Seo-Young and Krishna C. Vadlamannati. 2012. "Compliance with the AntiTrafficking Protocol.” European Journal of Political Economy 28: 249-65.

Cho, Seo-Young, Axel Dreher and Eric Neumayer. 2011. "The Spread of AntiTrafficking Policies - Evidence from a New Index.” Discussion Paper, Center for European Governance and Economic Development Research, No. 199. Retrieved from: http://www.econstor.eu/bitstream/10419/70211/1/65377124X.pdf

Chuang, Janie A. 2010. "Rescuing Trafficking from Ideological Capture: Prostitution Reform and Anti-Trafficking Law and Policy.” University of Pennsylvania Law Review 158:1655-1728. Retrieved from http://scholarship.law.upenn.edu/cgi/viewcontent.cgi?article=1161\&context=penn _law_review.

Clarke, Ross J., Elizabeth A. Clarke, Dominique Roe-Sepowitz, and Richard Fey. 2012. "Age at Entry into Prostitution: Relationship to Drug Use, Race, Suicide, Education Level, Childhood Abuse, and Family Expectations.” Journal of Human 
Behavior in the Social Environment 22: 270-289. doi:

$10.1080 / 10911359.2012 .655583$

Cobbina, Jennifer E. and Sharon S. Oselin. 2011. "It's Not Only for the Money: An Analysis of Adolescent versus Adult Entry into Street Prostitution.” Social Inquiry 81(3): 310-332. doi: 10.1111/j.1475-682X.2011.00375.x

Costantini, Cristina. 2015. "It Isn't Easy Being Black in the Badger State." Fusion. Retrieved from: http://fusion.net/story/203830/wisconsin-african-americansjuvenile-arrests/

Crile, Susan. 2012. "A Minor Conflict: Why the Objectives of Federal Sex Trafficking Legislation Preempt the Enforcement of State Prostitution Laws Against Minors." American University Law Review 61: 1783-1824. Retrieved from: http://digitalcommons.wcl.american.edu/aulr/vol61/iss6/4/

Curtis, Ric, Karen Terry, Meredith Dank, Kirk Dombrowski and Bilal Khan. 2008. "The Commercial Sexual Exploitation of Children in New York City.” Report submitted to: United States Department of Justice, National Institute of Justice. Retrieved from Center for Court Innovation website: www.ncjrs.gov/pdffiles1/nij/grants/225083.pdf

"CWPS". 2012. "Fact Sheet on State Anti-Trafficking Laws from US PACT [Policy Advocacy to Combat Trafficking] A Program of the Center for Women Policy Studies. Center for Women Policy Studies. Retrieved from: http://www.centerwomenpolicy.org/documents/11.CWPS_FactSheetonStateAntiT raffickingLawsMarch2012_000.pdf 
Dank, M. et al. 2015. "Interactions with the Criminal Justice and Child Welfare Systems for LGBTQ Youth, YMSM, and YWSW Who Engage in Survival Sex.” Urban Institute. Retrieved from http://www.urban.org/

Dess, Melissa. 2013. "Walking the Freedom Trail: An Analysis of the Massachusetts Human Trafficking Statute and Its Potential to Combat Child Sex Trafficking." Boston College Journal of Law \& Social Justice 33(1): 147-182. Retrieved from: http://lawdigitalcommons.bc.edu/jlsj/vol33/iss 1/5

Dijk, Jan V. and Fanny K. Mierlo. 2014. “Quantitative Indices for Anti-Trafficking Policies: Based on Reports of the U.S. State Department and the Council of Europe.” Crime Law and Social Change 61: 229-250. doi: 10.1007/s10611-013$9510-6$

Dysart, Tessa L. 2014. “Child, Victim or Prostitute? Justice Through Immunity for Prostituted Children.” Duke Journal of Gender, Law \& Policy 21. Retrieved from: http://papers.ssrn.com/sol3/papers.cfm?abstract_id=2451238

Dysart, Tessa L. 2013. “The Protected Innocence Initiative: Building Protective State Law Regimes for America's Sex-Trafficked Children.” Columbia Human Rights Law Review 44(3): 619-97. Retrieved from http://ssrn.com/abstract=2264439

Estes, Richard. J., and Neil A. Weiner. 2002. "The Commercial Sexual Exploitation of Children in the U.S., Canada and Mexico: Full Report of the U.S. National Study." Retrieved from: http://www.hawaii.edu/hivandaids/Commercial Sexual Exploitation of Children in the US, Canada and Mexico.pdf 
"FBI CIUS". n.d. "Arrest Table 69" Crime in the United States from the Federal Bureau of Investigations. Retrieved from: https://www.fbi.gov/about-us/cjis/ucr/crime-inthe-u.s

Farrell, Amy, Colleen Owens and Jack McDevitt. 2013. "New Laws but Few Cases: Understanding the Challenges to the Investigation and Prosecution of Human Trafficking Cases." Crime, Law and Social Change 61(2): 139-68. doi: $10.1007 / \mathrm{s} 10611-013-9442-1$

Farrell, Amy and Stephanie Fahy. 2009. "The Problem of Human Trafficking in the U.S.: Public Frames and Policy Responses.” Journal of Criminal Justice 37: 617-26. doi: 10.1016/j.jcrimjus.2009.09.010

Federal Advisory Committee on Juvenile Justice. 2007. "Federal Advisory Committee on Juvenile Justice Annual Recommendations Report to the President and Congress of the United States. Retrieved from: http://www.facjj.org/annualreports/2007FACJJReport508.pdf

Fichtelman, Ellen. 2014. "The Double Entendre of Juvenile Prostitution: Victim versus Delinquent and the Necessity of State Uniformity." Juvenile and Family Court Journal 65(3): 27-46.

Finkelhor, David and Richard Ormrod. 2004. "Prostitution of Juveniles: Patterns from NIBRS.” OJJDP Juvenile Justice Bulletin. Retrieved from: http://permanent.access.gpo.gov/lps50568/lps50568.pdf

Gehring, Thom. 2000. "Recidivism as a Measure of Correctional Education Program Success." Journal of Correctional Education 51(2): 197-205. ERIC EJ607580 
Goddard, Chris, Lillian De Bortoli, Bernadette J. Saunders, and Joe Tucci. 2005. "The Rapist's Camouflage: 'Child Prostitution'..' Child Abuse Review 14(4): 275-91. doi: $10.1002 /$ car.894

Halter, Stephanie. 2010. "Factors That Influence Police Conceptualizations of Girls Involved in Prostitution in Six U.S. Cities: Child Sexual Exploitation Victims or Delinquents?" Child Maltreatment 15(2): 152-60. doi:

$10.1177 / 1077559509355315$

Heiges, Moira. 2010. "From the Inside Out: Reforming State and Local Prostitution Enforcement to Combat Sex Trafficking in the United States and Abroad." Minnesota Law Review 94: 428-466. Retrieved from: http://heinonline.org "Human Trafficking Overview." 2014. National Conference of State Legislatures. Retrieved from: http://www.ncsl.org/research/civil-and-criminal-justice/humantrafficking-overview.aspx

In re B.W. 2008. Court of Appeals of Texas, Houston (1st Dist.). No. 01-07-00274-CV. Retrieved from: http://caselaw.findlaw.com/tx-court-of-appeals/1117461.html

Kara, Shashi I. 2007. "Decentralizing the Fight Against Human Trafficking in the United States: The Need for Greater Involvement in Fighting Human Trafficking by State Agencies and Local Non-Governmental Organizations." Cardozo Journal of Law \& Gender 13(3): 657-83. Retrieved from: http://cardozolawandgender.com/uploads/2/7/7/6/2776881/13-3_kara.pdf

"Kids Count”. n.d. "KIDS COUNT Data Center". Annie E. Casey Foundation. Retrieved from: http://datacenter.kidscount.org 
Klain, Eva J. 1999. "Prostitution of Children and Child-Sex Tourism: An Analysis of Domestic and International Responses.” For the National Center for Missing and Exploited Children. Retrieved from:

http://www.hawaii.edu/hivandaids/Prostitution of Children and Child Sex Tourism.pdf

Linedecker, Clifford L. 1981. Children in Chains. New York: Everest House.

Loftin, Colin and David McDowall. 2010. "The Use of Official Records to Measure Crime and Delinquency.” Journal of Quantitative Criminology 26: 527-32 DOI $10.1007 / \mathrm{s} 10940-010-9120-8$

Lynch, James P. and John P. Jarvis. 2008. "Missing Data and Imputation in the Uniform Crime Reports and the Effects on National Estimates." Journal of Contemporary Criminal Justice 24(1): 69-85 doi: 10.1177/1043986207313028

Marcus, Anthony, Amber Horning, Ric Curtis, Jo Sanson and Efram Thompson. 2014.

"Conflict and Agency among Sex Workers and Pimps: A Closer Look at Domestic Minor Sex Trafficking." The Annals of The American Academy of Political and Social Science. 653: 225-246. doi: 10.1177/0002716214521993 Marquardt, Elizabeth. 2006. Between Two Worlds: The Inner Lives of Children and Divorce. New York: Three Rivers Press.

Melrose, Margaret. 2002. "Labor Pains: Some Considerations on the Difficulties of Researching Juvenile Prostitution.” Social Research Methodology 5(4): 333-51. Retrieved from:

http://www.hawaii.edu/hivandaids/Labour_Pains__Some_Considerations_on_the _Difficulties_of_Researching_Juvenile_Prostitution.pdf 
Menaker, Tasha A. and Cortney A. Franklin. 2013. "Commercially Sexually Exploited Girls and Participant Perceptions of Blameworthiness: Examining the Effects of Victimization History and Race Disclosure.” Journal of Interpersonal Violence 28(10): 2024-51. doi: 10.1177/0886260512471078

Menaker, Tasha A. and Audrey K. Miller. 2013. "Culpability Attributions Towards Juvenile Female Prostitutes." Child Abuse Review, 22(3): 169-81. doi: 10.1002/car.2204

Mir, Tanya. 2013. "Trick or Treat: Why Minors Engaged in Prostitution Should be Treated as Victims, Not Criminals.” Family Court Review. 51(1) doi: $10.1111 /$ fcre. 12016

Mitchell, Kimberly J., David Finkelhor and Janis Wolak. 2010. “Conceptualizing Juvenile Prostitution as Child Maltreatment: Findings from the National Juvenile Prostitution Study." Child Maltreatment 15(1): 18-36. doi:

$10.1177 / 1077559509349443$

Muhammad, Khalil G. 2011. The Condemnation of Blackness: Race, Crime, and the Making of Modern Urban America. Harvard University Press.

Myers, John E.B. 2008. “A Short History of Child Protection in America.” Family Law Quarterly, 42(3): 449-463. Retrieved from Hein Online.

"NCVLI". 2011. "Protecting the Victims of "Victimless" Crimes." Newsletter of Crime Victim Law, 14 ed. from the National Crime Victim Law Institute at Lewis \& Clark Law School. Retrieved from: https:/law.lclark.edu/live/files/15461protecting-the-victims-of-victimless-crime-sep 
"NIBRS Codebook”. 2001. “National Incident-Based Reporting System, 2001” United States Department of Justice, Federal Bureau of Investigation. Retrieved from the Inter-University Consortium for Political and Social Research.

"NIBRS Participation". 2013. "NIBRS Participation by State". Federal Bureau of Investigation. Retrieved from: https://www.fbi.gov/aboutus/cjis/ucr/nibrs/2013/resources/nibrs-participation-by-state

"NIBRS User Manual”. 2013. "National Incident-Based Reporting System (NIBRS) User Manual”. Federal Bureau of Investigation. Retrieved from fbi.gov

“Offense Definitions”. 2011. “Crime in the United States 2011”. Federal Bureau of Investigation. Retrieved from fbi.gov

"Polaris Project". No date. "Founding Story". Polaris Project. Retrieved from: http://www.polarisproject.org/about-us/overview/founding-story

Prosecutorial Remedies and Other Tools to End the Exploitation of if Children Today Act. U.S. law S. 151. (2003) Retrieved from: http://www.state.gov/j/tip/laws/ "Raise the Age NY." No date. "About Us". Raise the Age NY. Retrieved from: http://raisetheageny.com/about-us

Reid, Joan A. and Shayne Jones. 2011. "Exploited Vulnerability: Legal and Psychological Perspectives on Child Sex Trafficking Victims." Victims \& Offenders: An International Journal of Evidence-based Research, Policy, and Practice 6(2): 207-31. doi: 10.1080/15564886.2011.557327

"Safe Harbor". 2015. "Human Trafficking Issue Brief: Safe Harbor.” Polaris Project. Retrieved from: https://polarisproject.org/sites/default/files/2015\%20Safe $\% 20$ Harbor\%20Issue\%20Brief.pdf 
Sager, Rebecca C. 2012. "An Anomaly of the Law: Insufficient State Laws Fail to Protect Minor Victims of Sex Trafficking." New England Journal on Criminal \& Civil Confinement. 38(2): 359-378. Retrieved from Offerofproof.net

"Shared Hope". No date. "Our Story". Shared Hope International. Retrieved from: http://sharedhope.org/about-us/our-story/

Simmons, Beth and Zachary Elkins. 2004. "The Globalization of Liberalization: Policy Diffusion in the International Political Economy.” American Political Science Review. 98(1): 171-89. doi:10.1017/S0003055404001078

Simmons, Beth and Paulette Lloyd. 2010. "Subjective Frames and Rational Choice: Transnational Crime and the Case of Human Trafficking." Prepared for Cornell University. Retrieved from: http://government.arts.cornell.edu/department/related/psac/calendar/2010-2011/ Simowitz, Aaron D. 2013. "How Criminal Law Shapes Institutional Structures: A Case Study of American Prostitution.” American Criminal Law Review. 50: 417-53. Retrieved from: http://heinonline.org

Smith, Linda and Samantha H. Vardaman. 2011. "A Legislative Framework for Combating Domestic Minor Sex Trafficking." Regent University Law Review 23(2): 265-96. Retrieved from:

https://www.regent.edu/acad/schlaw/student_life/studentorgs/lawreview/docs/issu es/v23n2/01Smith-Vardamanvol.23.2.pdf

Smith, Linda A., Samantha H. Vardaman, and Melissa A. Snow. 2009. “The National Report on Domestic Minor Sex Trafficking: America's Prostituted Children.” 
Retrieved from Shared Hope International website: http://sharedhope.org/wpcontent/uploads/2012/09/SHI_National_Report_on_DMST_2009.pdf

Snyder, Howard N. and Mulako-Wangota, Joseph. “Arrest Data Analysis Tool.” Bureau of Justice Statistics. www.bjs.gov

Spohn, Cassia. 2014. "The Non-Prosecution of Human Trafficking Cases: An Illustration of the Challenges of Implementing Legal Reforms." Crime, Law and Social Change 61: 169-78. DOI 10.1007/s10611-013-9508-0

“2014 State Ratings on Human Trafficking”. 2014. Polaris Project. Retrieved from: http://polarisproject.org/resources/2014-state-ratings-human-trafficking-laws

"2013 State Ratings on Human Trafficking". 2013. Polaris Project. Retrieved from: https://polarisproject.org/sites/default/files/2013-State-Ratings-Analysis.pdf

“2012 State Ratings on Human Trafficking”. 2012. "How Does Your State Rate on Human Trafficking Laws in 2012?” Polaris Project. Retrieved from: https://polarisproject.org/sites/default/files/2012-State-Ratings.pdf

“2011 State Ratings on Human Trafficking”. 2011. "How Does Your State Rate on Human Trafficking Laws?” Polaris Project. Retrieved from: https://polarisproject.org/sites/default/files/2011-State-Ratings.pdf “2010 State Ratings on Human Trafficking”. 2011. "State Ratings Chart: Key Human Trafficking Provisions". Polaris Project. Website link inactive, email: policy@polarisproject.org

Steffensmeier, Darrell, Casey T. Harris and Noah Painter-Davis. 2015. "Gender and Arrests for Larceny, Fraud, Forgery, and Embezzlement: Conventional or 
Occupational Property Crime Offenders?" Journal of Criminal Justice. 43(3): 20517. doi:10.1016/j.jcrimjus.2015.03.004

Torres-Reyna, Oscar. 2007. "Panel Data Analysis Fixed and Random Effects using Stata." Data and Statistical Services, Princeton University. Retrieved from dss.princeton.edu/training/

“2015 Trafficking in Persons Report”. U.S. Department of State. Webpage: http://www.state.gov/j/tip/rls/tiprpt/

United States v Brockdorff. 1997. 992 F. Supp. 22 (D.D.C.)

United States v Kozminski. 1988. 487 U.S. 931

Vermont Act 58 (2010). "An Act Relating to Expanding the Sex Offender Registry."

Retrieved from:

http://legislature.vermont.gov/assets/Documents/2010/Docs/ACTS/ACT058/ACT 058\%20As\%20Enacted.pdf

Victims of Trafficking and Violence Protection Act. U.S. law H.R.3244. (2000)

Retrieved from: http://www.state.gov/j/tip/laws/

Wagner, S. (2012). "An Examination of State laws on Human Trafficking.” The Renewal Forum, Inc. Retrieved from http://renewalforum.org/wpcontent/uploads/2012/01/State-Law-Analysis.pdf

"WCC". 2015. "Continuing Trends in Juvenile Justice in Wisconsin.” Wisconsin Council on Children and The Annie E. Casey Foundation KIDS COUNT Project. Retrieved from: http://www.wccf.org/assets/juvenile-justice-report_10-15-15.pdf Wells, Melissa, Kimberly J. Mitchell, and Kai Ji. 2012. "Exploring the Role of the Internet in Juvenile Prostitution Cases Coming to the Attention of Law 
Enforcement.” Journal of Child Sexual Abuse 21:327-342. doi:

$10.1080 / 10538712.2012 .669823$

WestLaw. Thomson Reuters. www.westlaw.com

Williams, L.M. 2009. "Pathways Into and Out of Commercial Sexual Victimization of Children: Recommendations for Policy and Practice.” Retrieved from http://faculty.uml.edu/lwilliams/WilliamsPathwaysRecommendationsandPolicy20 06-MU-FX-0060FINAL.pdf

Williams, Richard. 2015. "Multicollinearity.” Retrieved from: www3.nd.edu/ rwilliam/stats2/111.pdf 


\section{APPENDIX A \\ LEVEL OF COMPLIANCE WITH PROTECTION AND PROSECUTION ELEMENTS OF DOMESTIC ANTI-TRAFFICKING LAW}

International trafficking studies suggest that nations are less likely to enact laws that address the protection element of the 3Ps. A cursory analysis of domestic law was conducted on the trafficking legislation scores assigned to states by Shared Hope International.

To test this hypothesis, the average protection and prosecution points earned by states were considered (none of the Shared Hope categories focused specifically on the prevention category). The 2014 Scores from Shared Hope International's Protective Provisions for Child Victims were compared to the other 5 categories in their metric, which focus on criminalization statutes, penalties, and tools. The average score states received in their protection category was 17.31 out of 27.5 . When considering only the 5 remaining categories, states averaged 57.61 points out of a total possible score of 75 , resulting in a percentage of 76.8 . This approximately 14 percentage points higher than the 62.9 percent average for only the protection category. 


\section{APPENDIX B}

\section{STATE LEGISLATION}

\section{Methodology for Compiling Legislation Data}

Identifying the year in which each state had enacted its 'turning point' legislation was also a complex task. In general, individual states adopted a series of laws that address trafficking instead of one comprehensive law. Although there are a lot of similarities in the themes of these laws, their order, timing, and details have varied a great deal. For many states, initial laws did not provide any additional protections for juveniles, while some did very explicitly. In order to distinguish which law provided initial protections, archived charts from the Polaris Project were used to narrow the range of

years considered for each state. When the Polaris Project gave the state credit for juvenile protections in the same year that the initial legislation was passed, the initial legislation was reviewed to ensure that it met the criteria for this study before the year was recorded. The dates that initial trafficking laws were passed are listed by The Center for Women and Policy, or CWP. For states in which the initial legislation and Polaris Project's assessment did not align, the initial law description provided by CWP was first reviewed and then additional analysis was conducted to identify a later piece of legislation. The CWP list of initial legislation passage dates was also coded to create a second legislative variable used to test the model. It was easier to isolate a year or a short range of years for those states that did not implement a law with juvenile protections until after 2010. This was the case because many pertinent data tools began collecting data in 2011 , several of 
which were used heavily for compiling this variable, including: the Open States

database, Polaris Project state ratings with state reports, and Shared Hope International's report cards. States that had unclear legislative histories prior to 2010 were more difficult to complete. In some instances, scholarly articles had been written about their trafficking law history. Over 20 articles and reports were drawn upon, which included detailed legislative histories of one or more states. A few states had very little data available and required more extensive research. States that had spotty or unclear legislative history are noted in the figure below.

Notes on each state's trafficking protection law begins on the following page. 


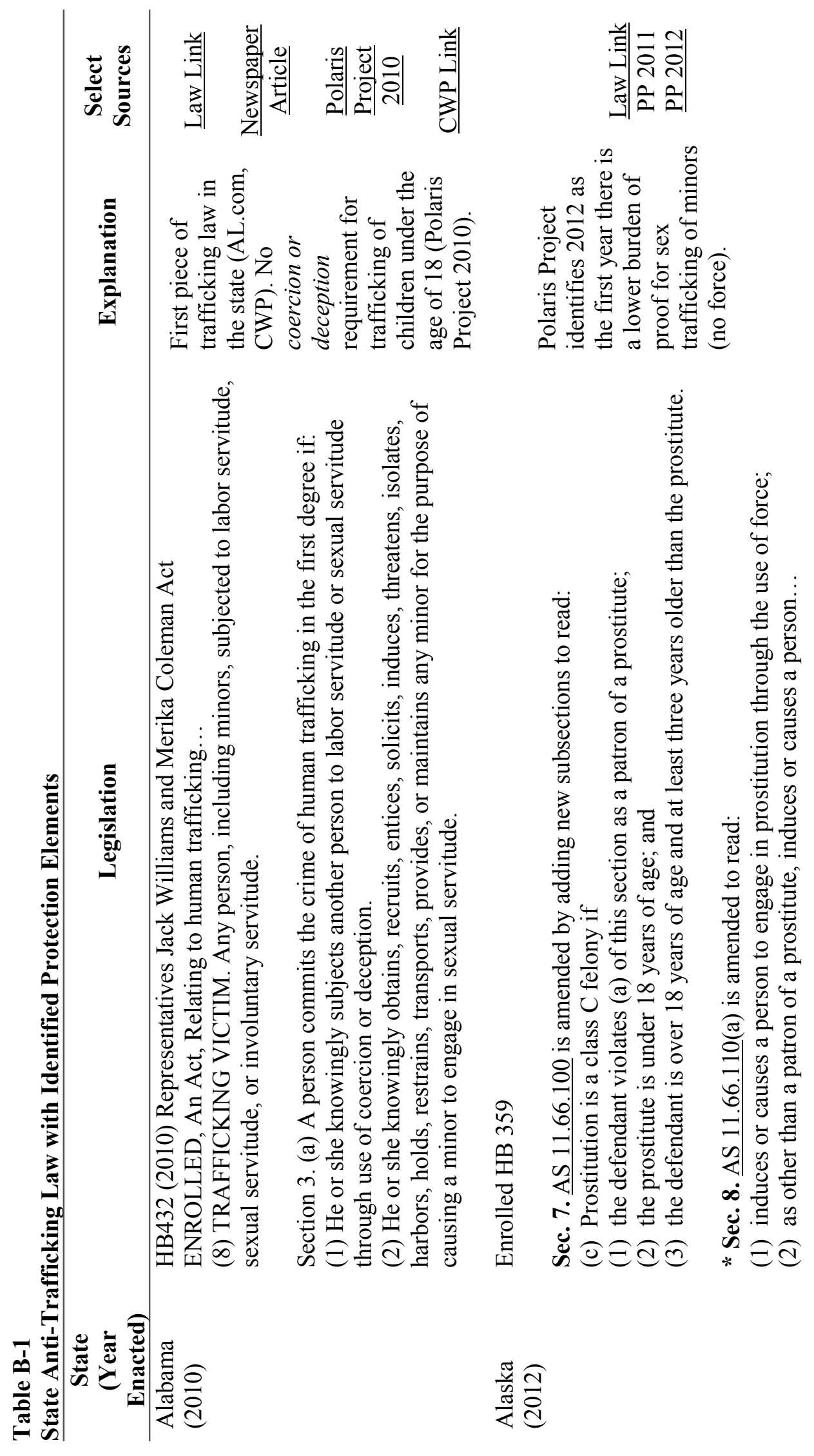

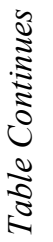




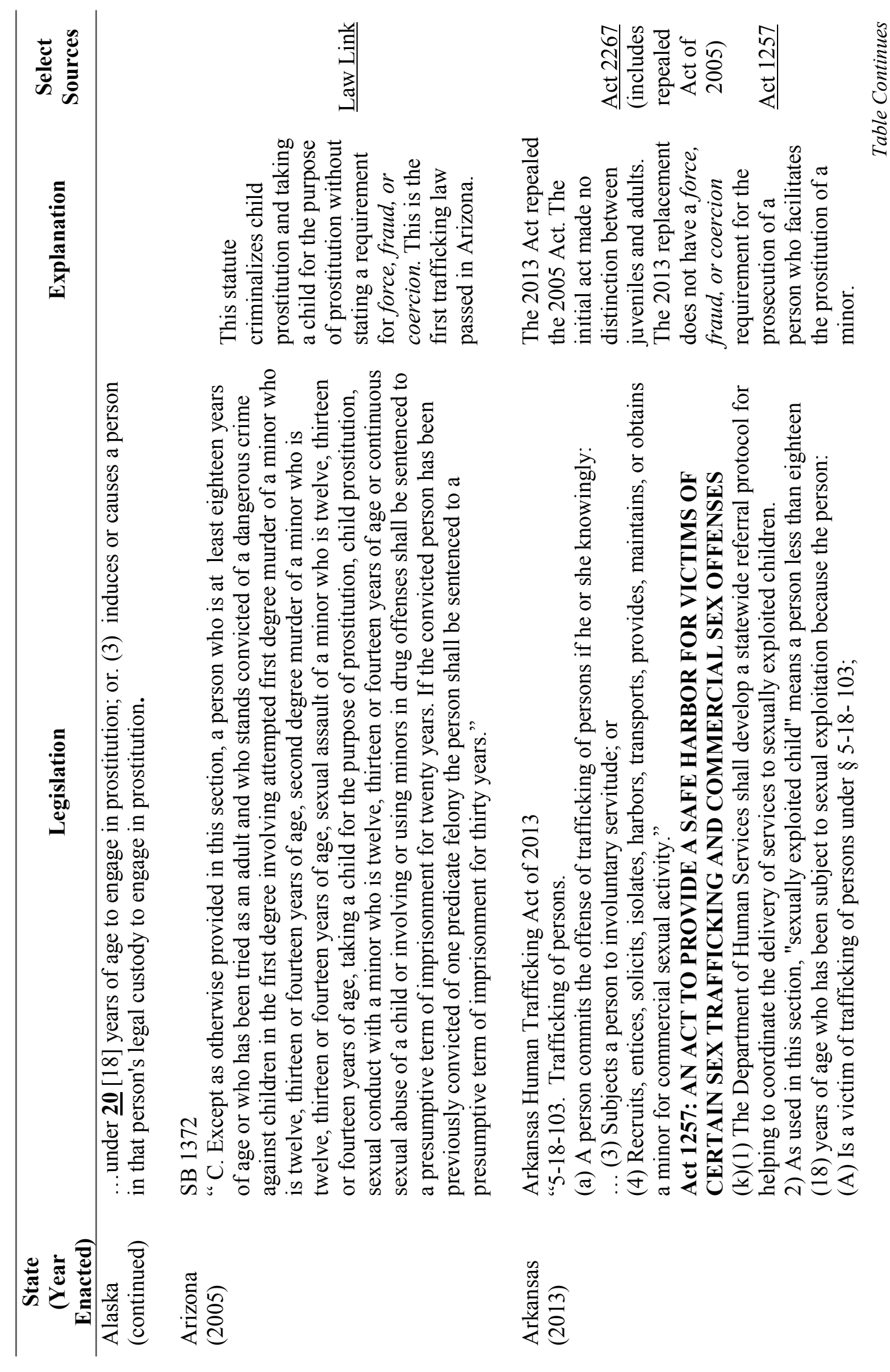




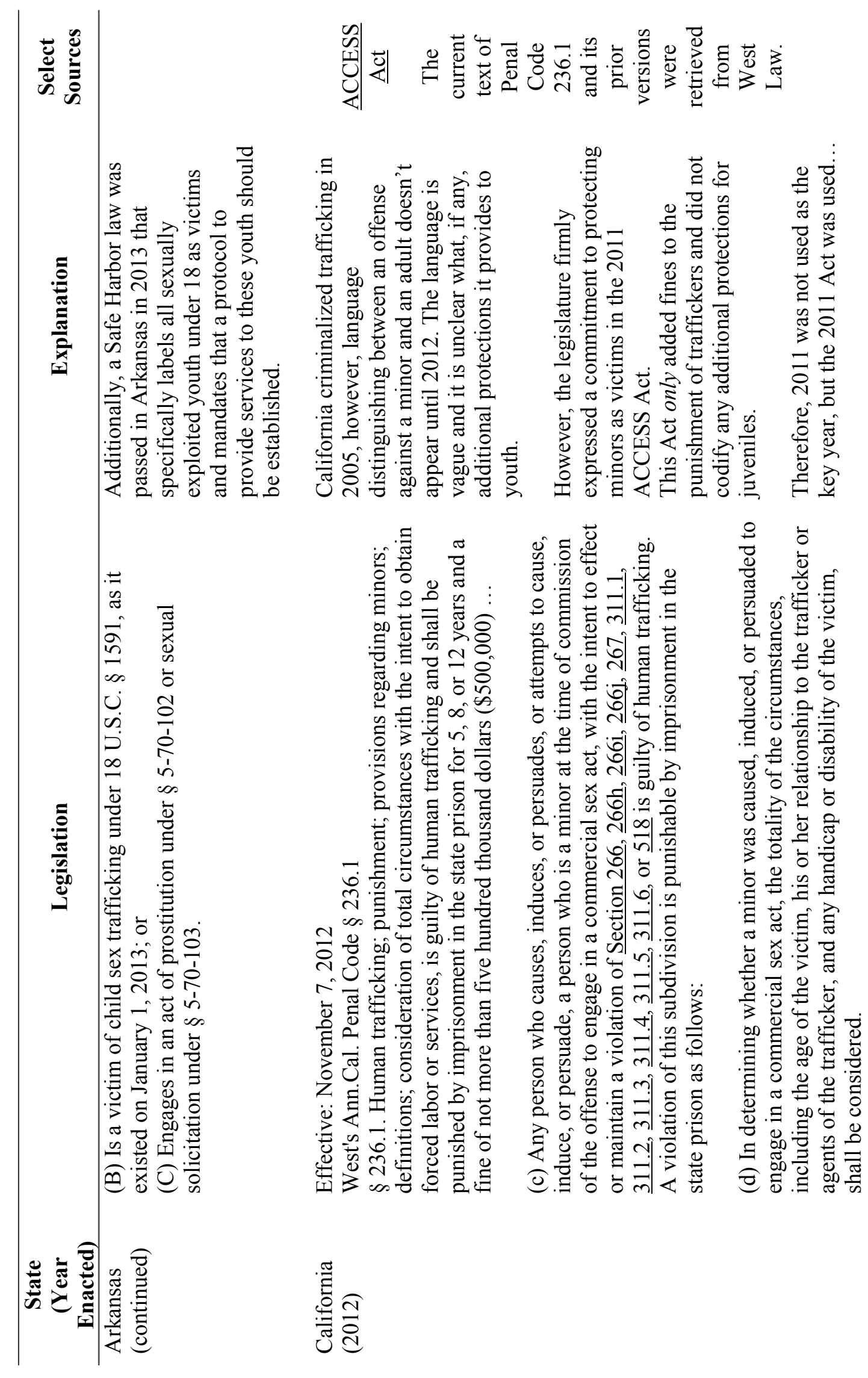

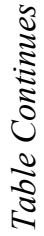




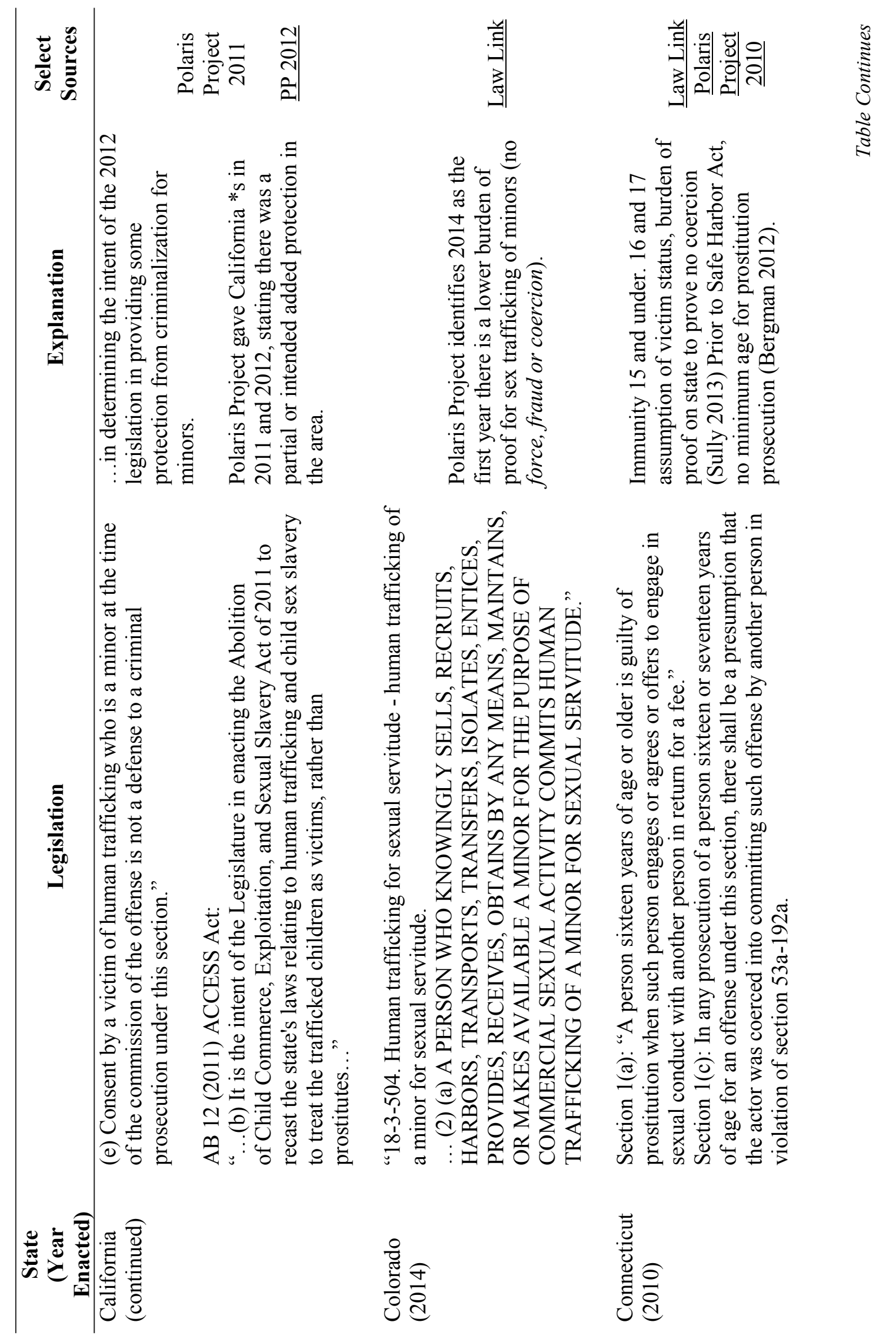




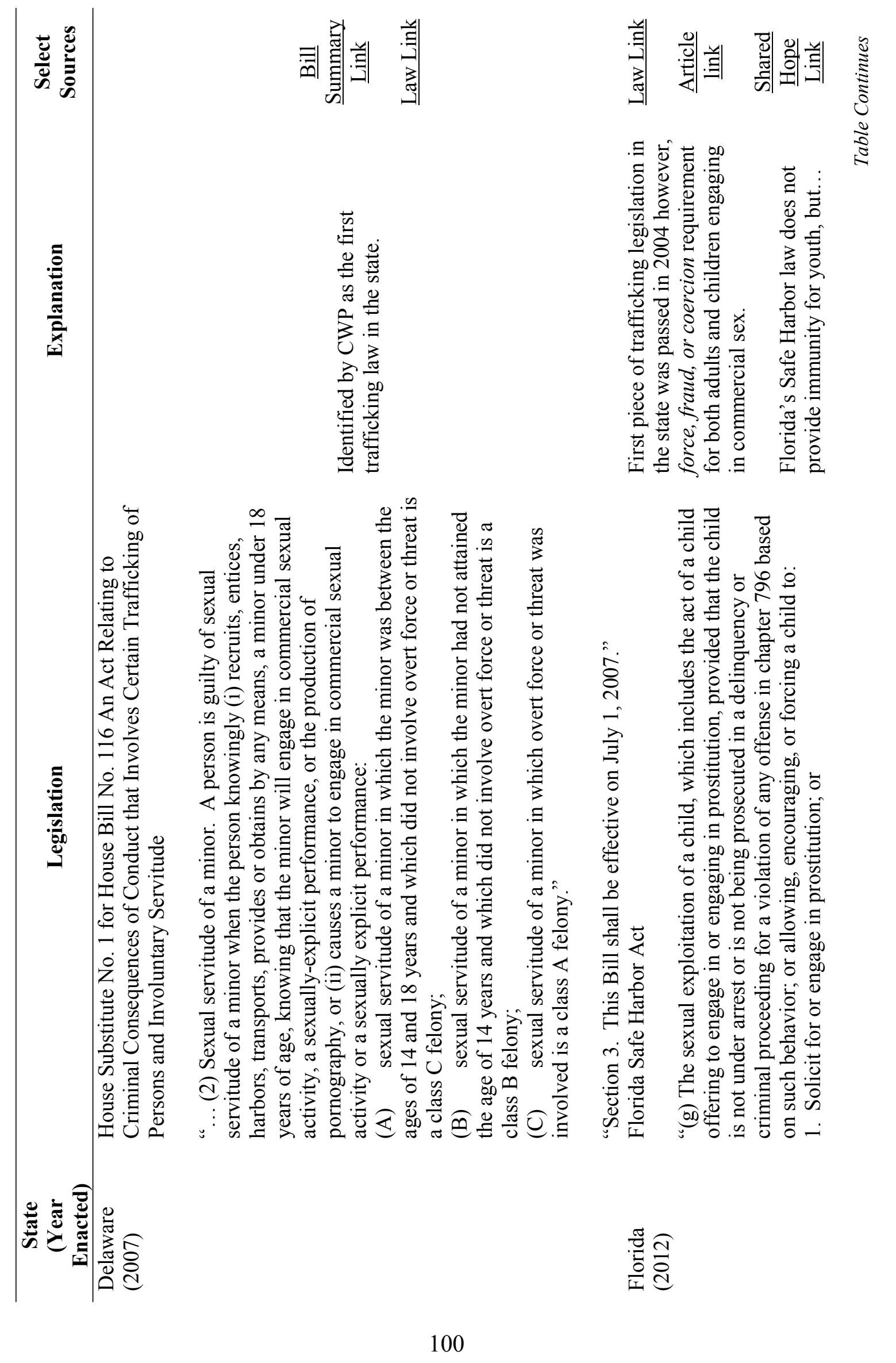




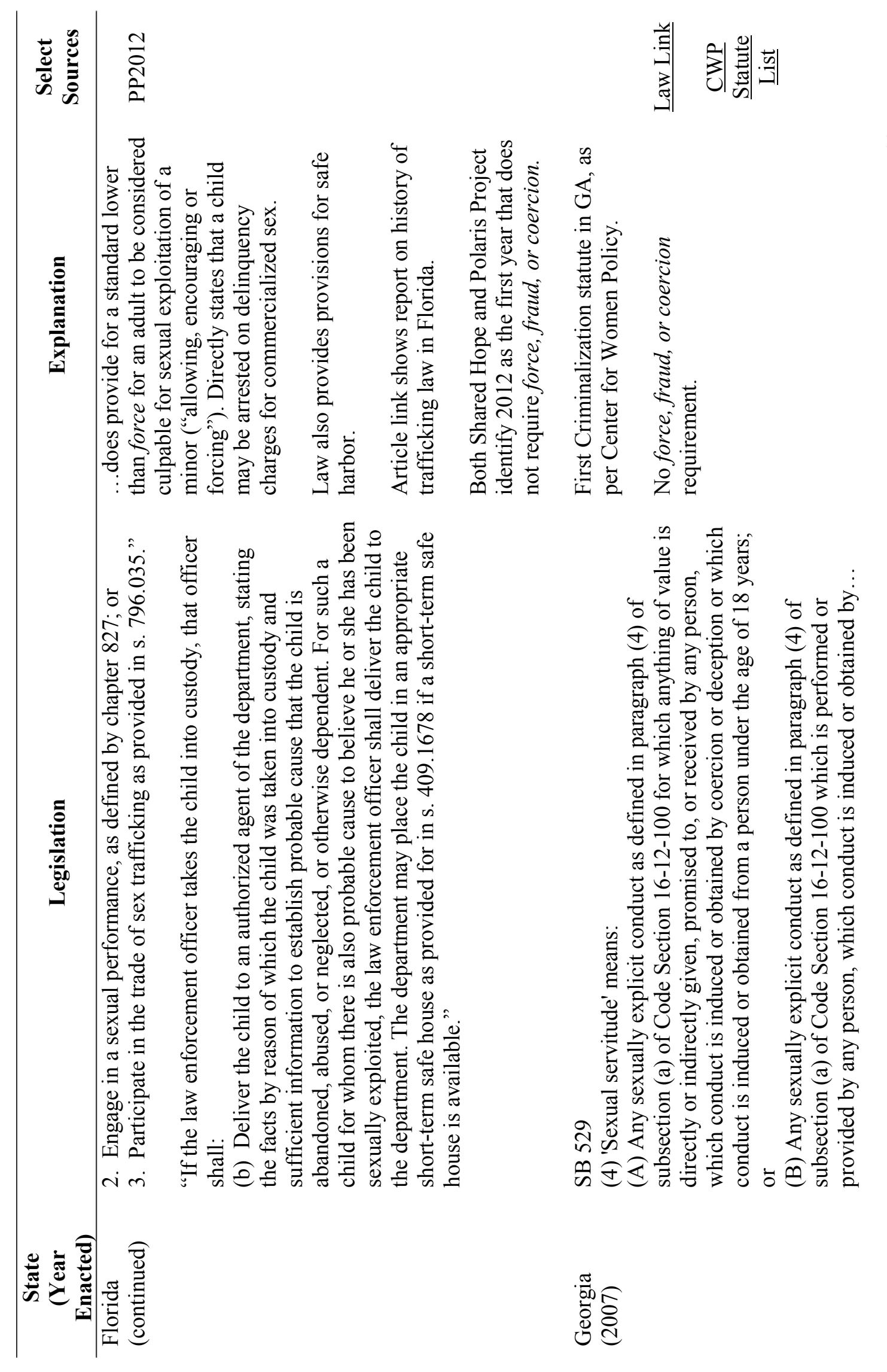




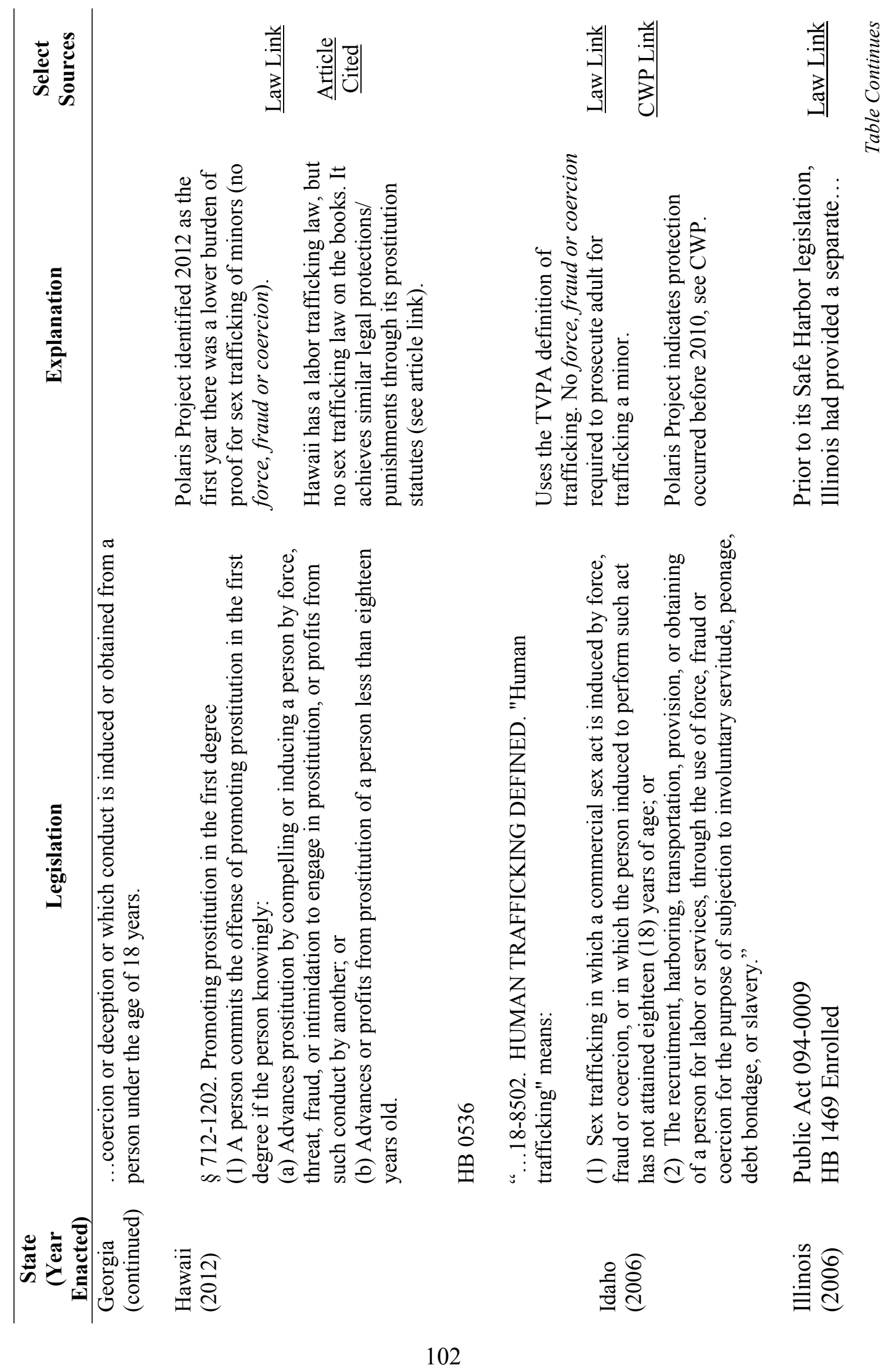




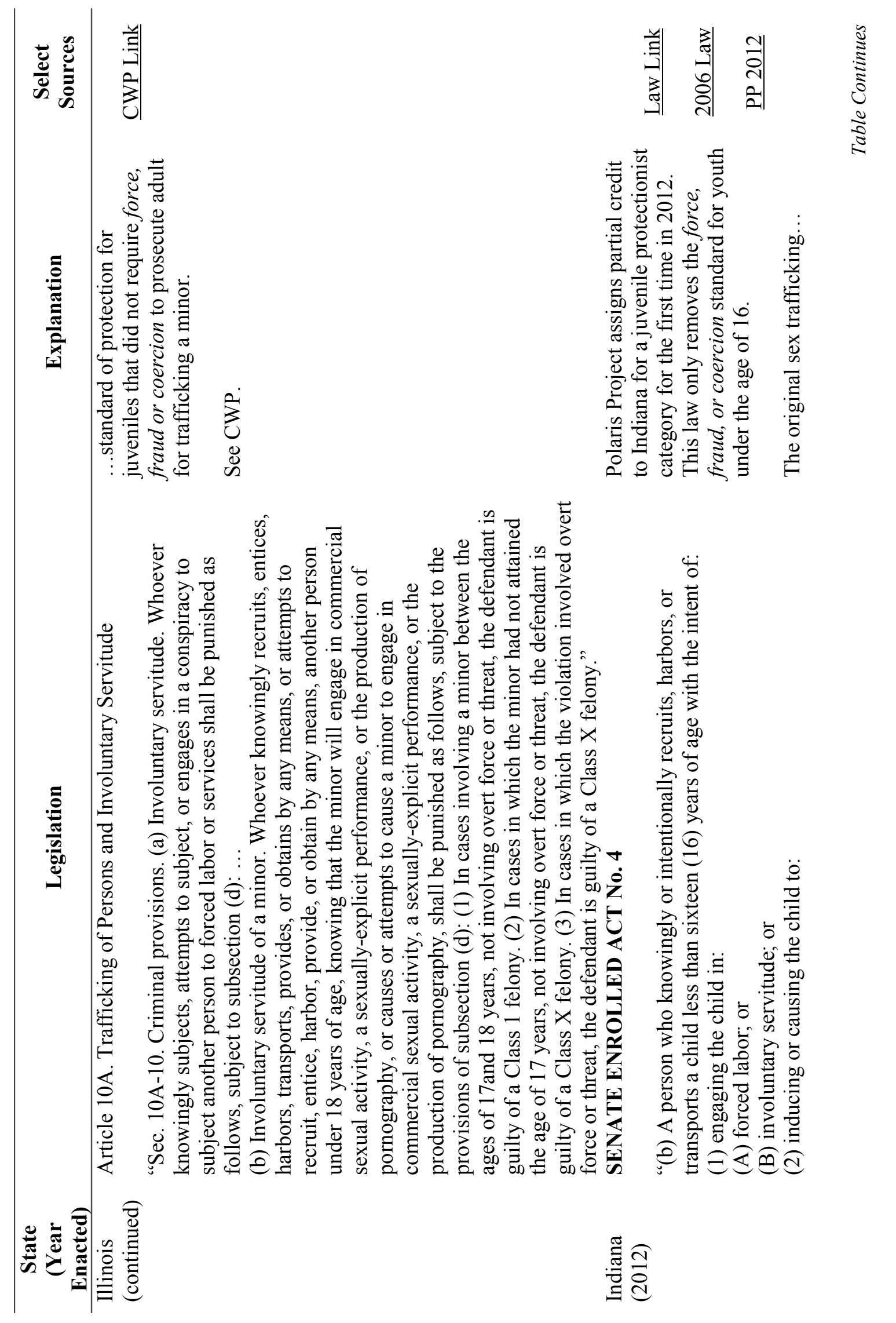




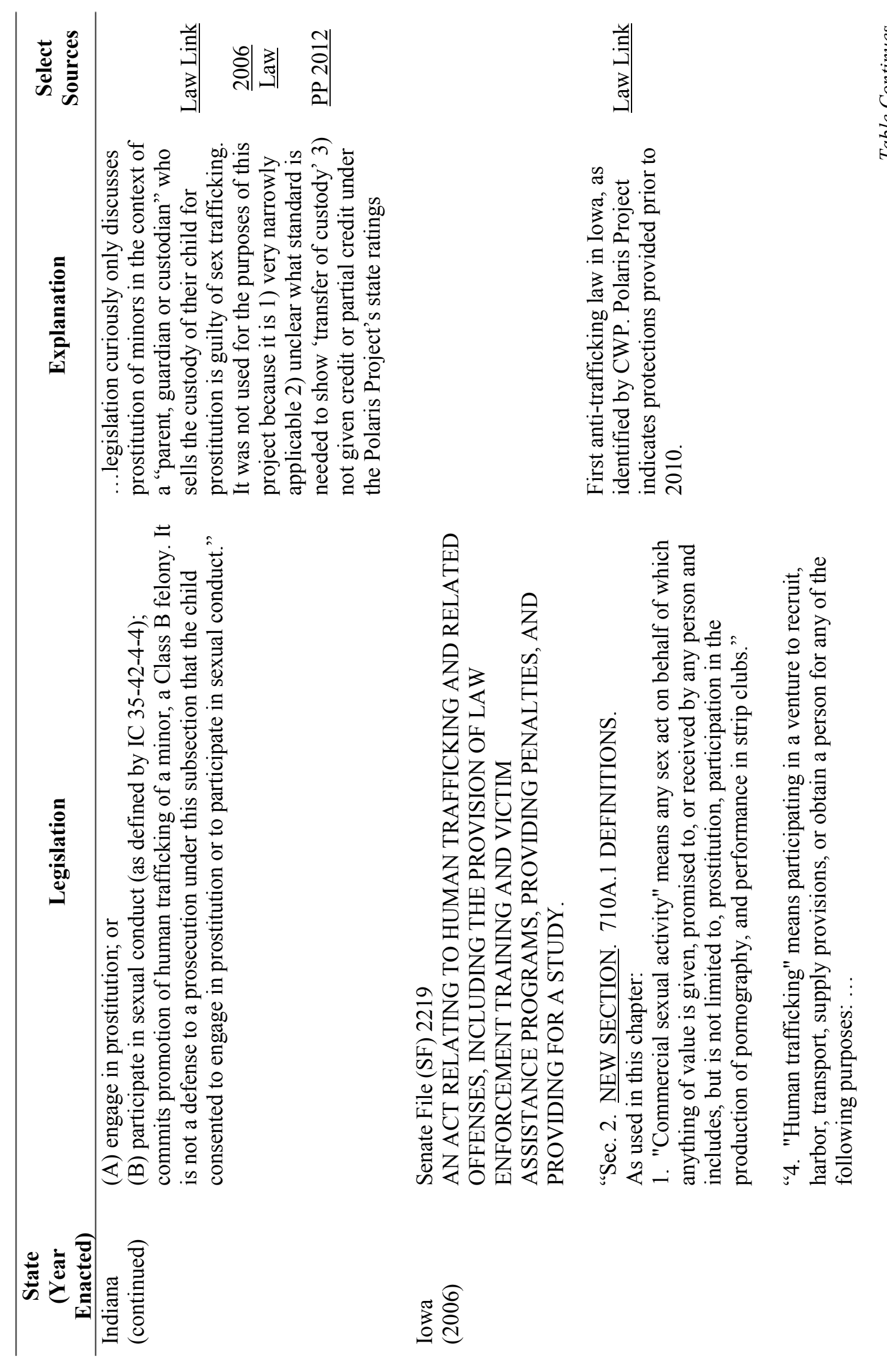




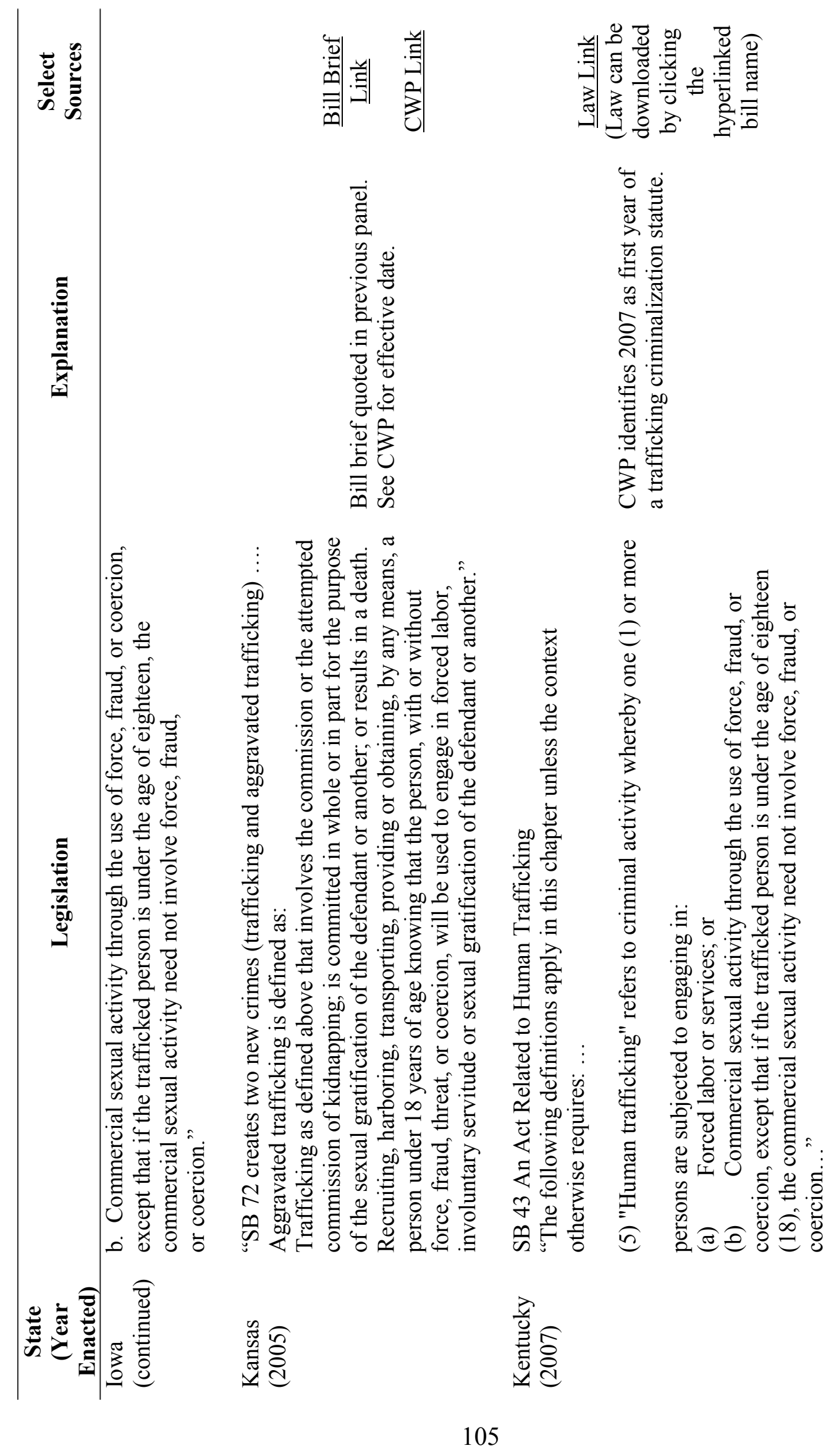




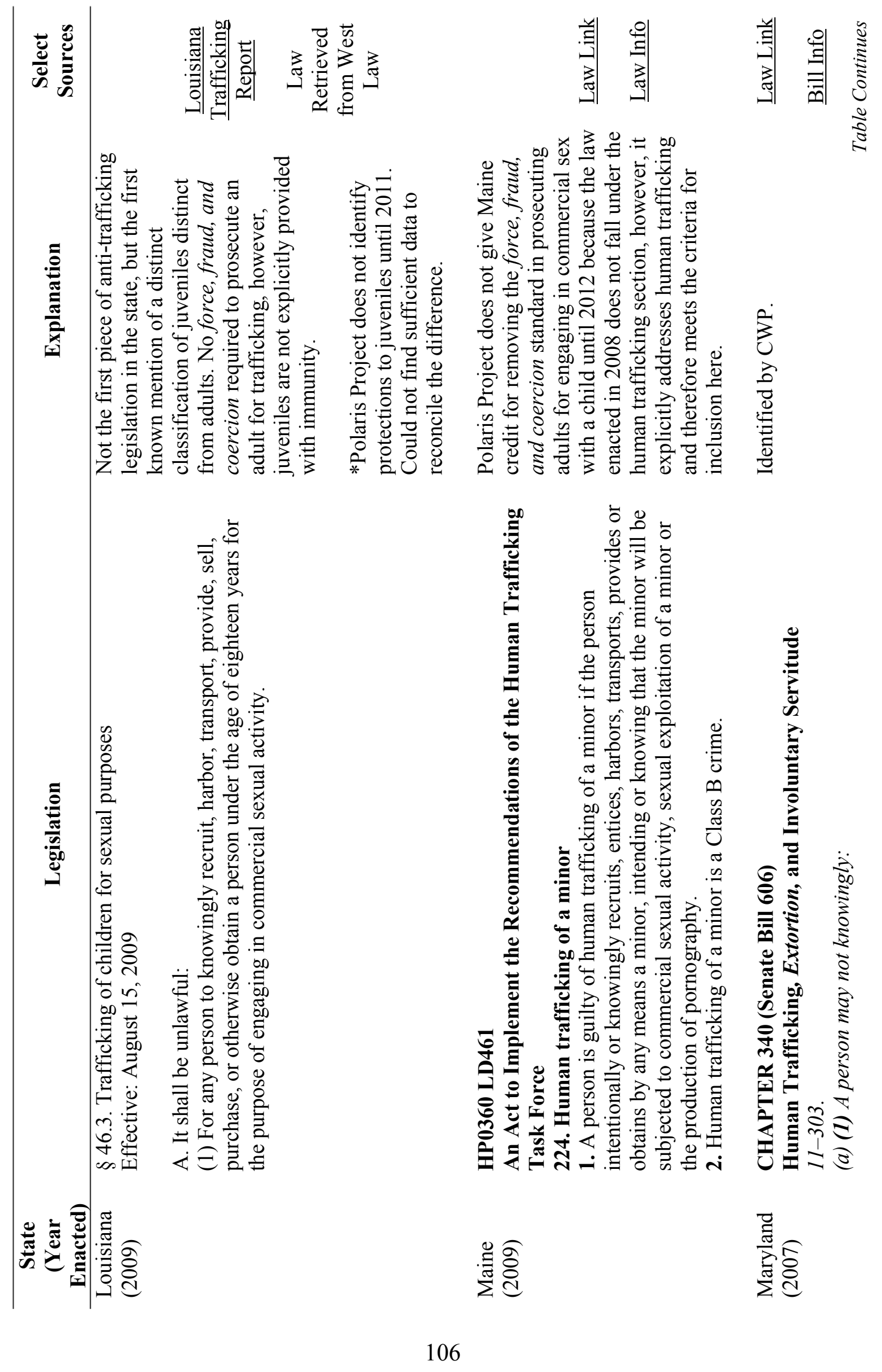




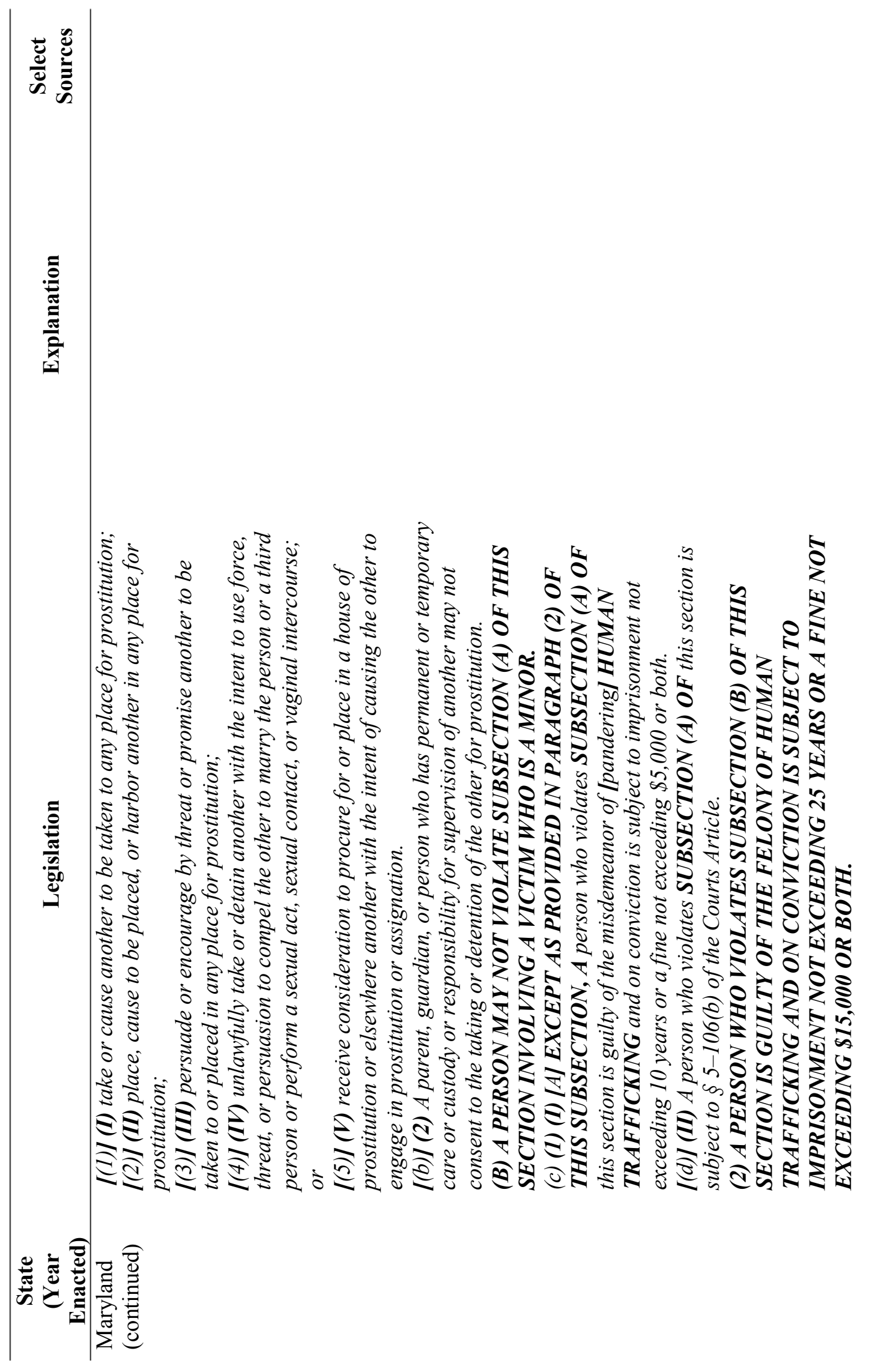




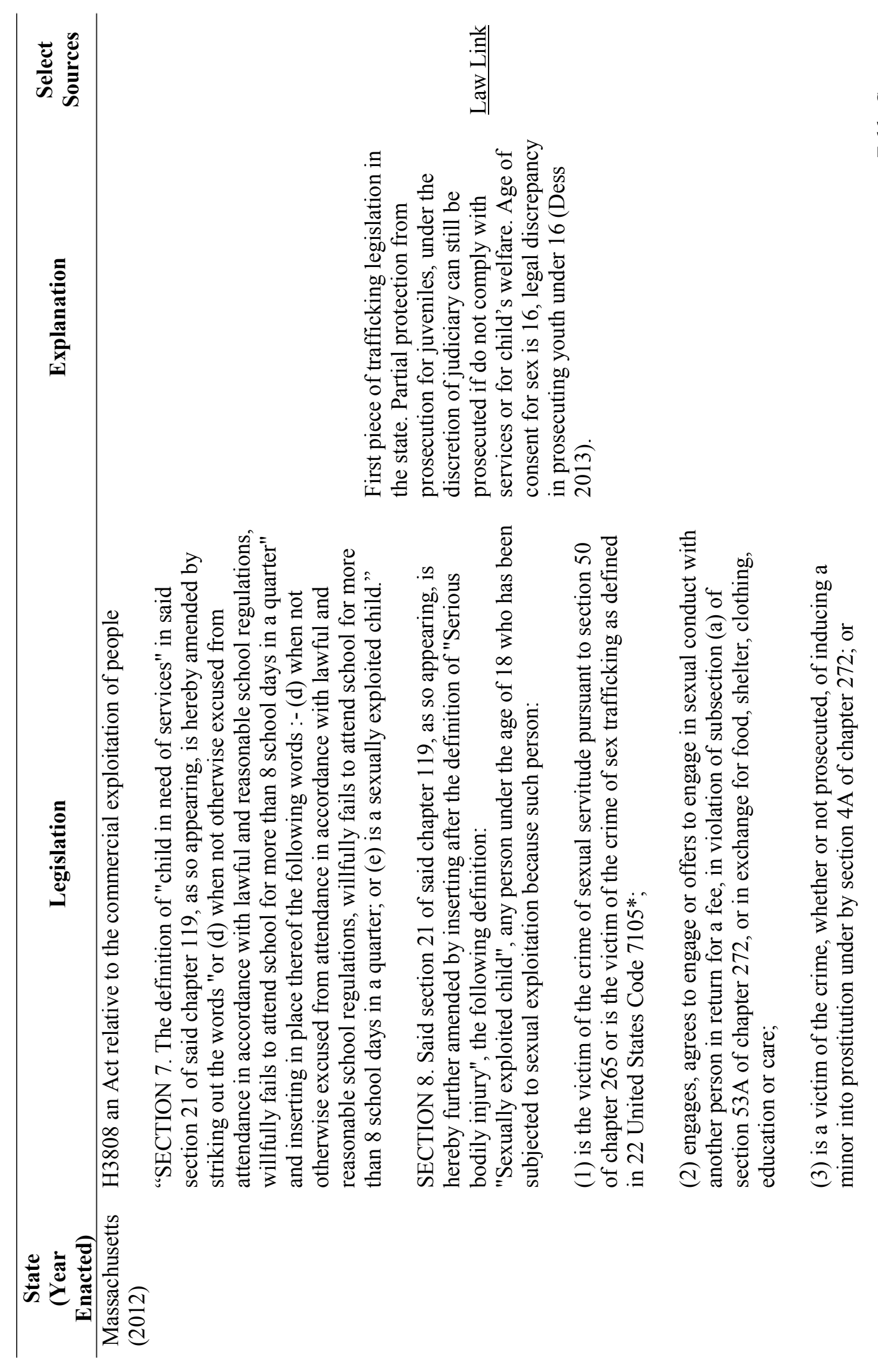




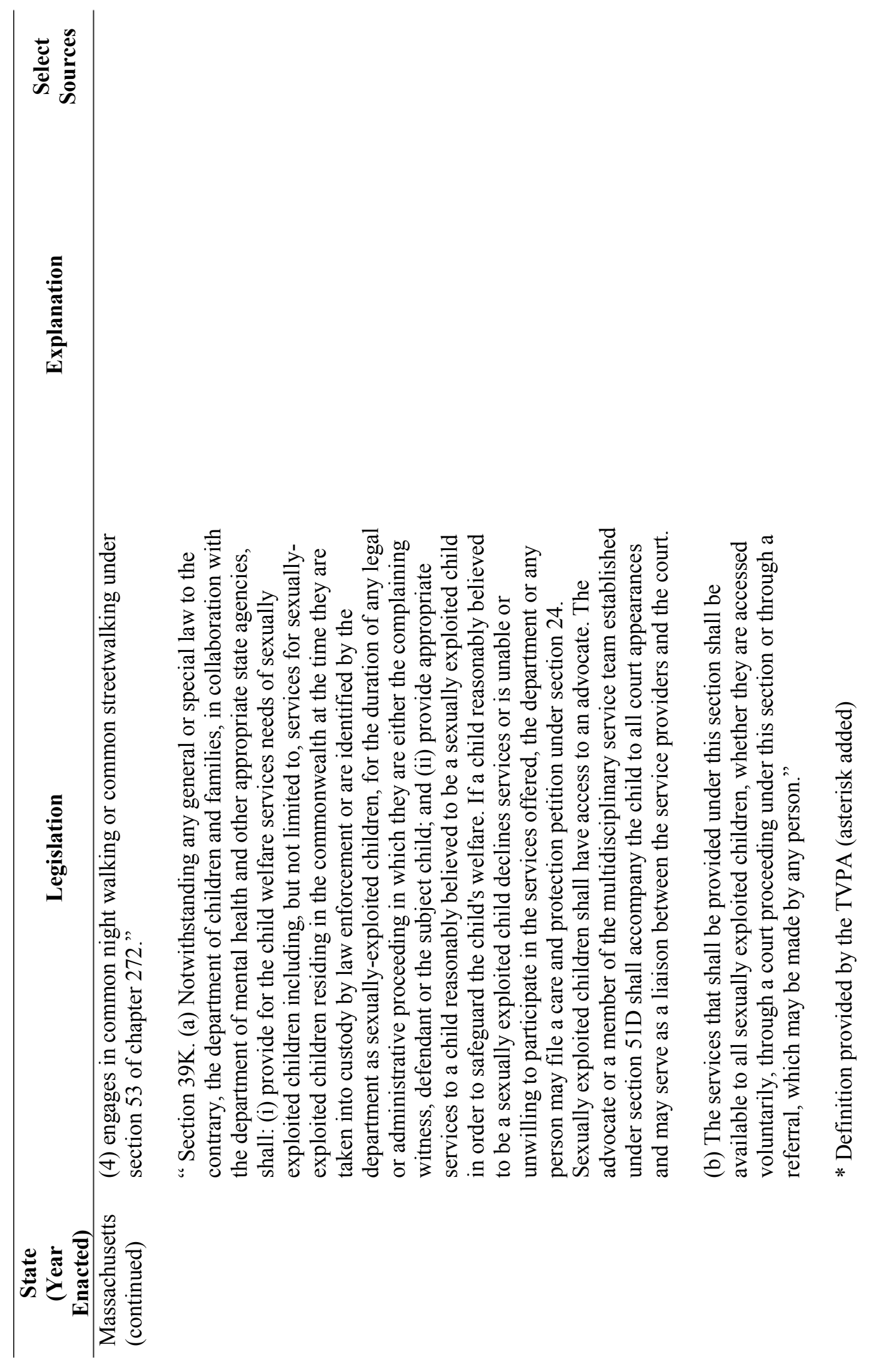




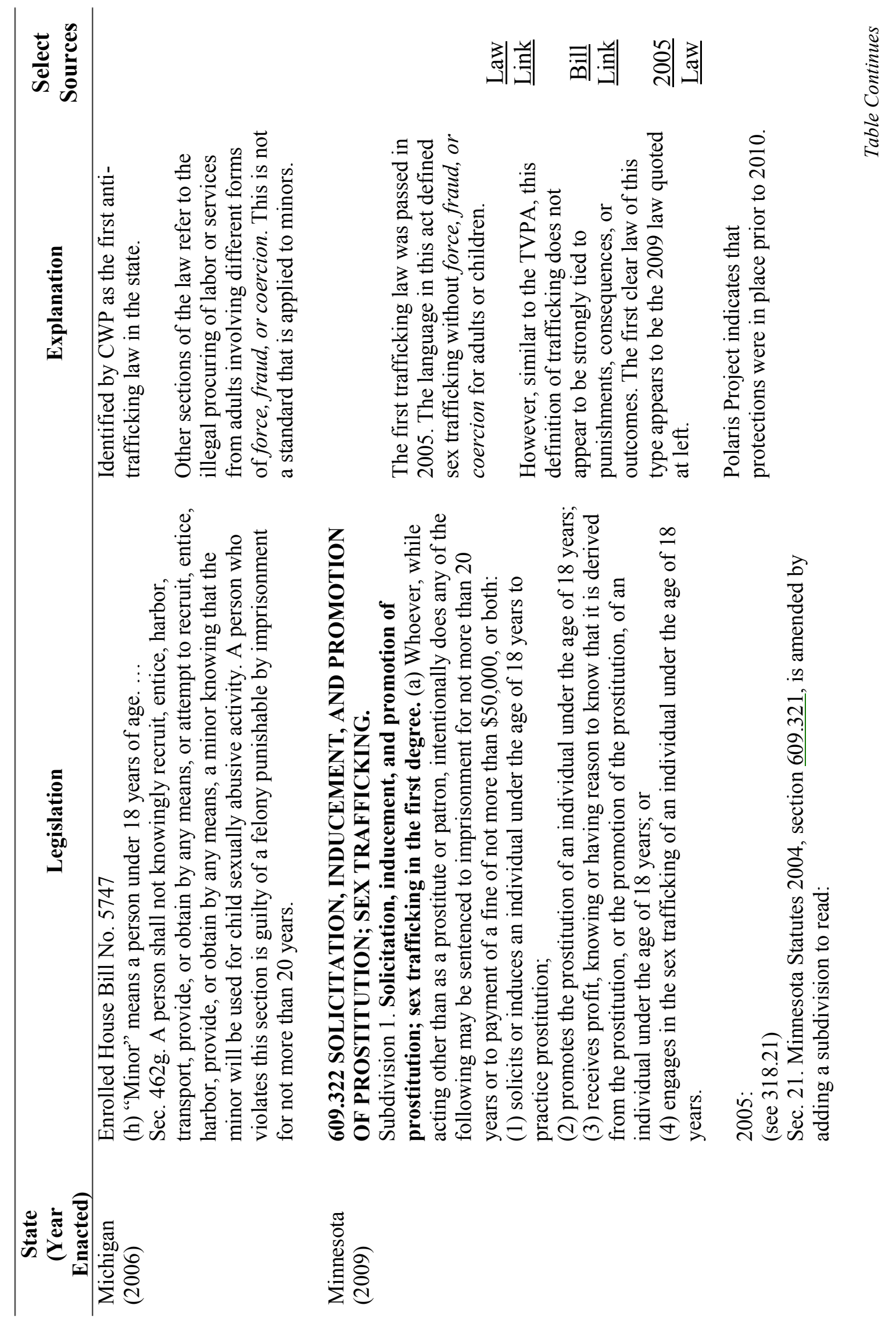




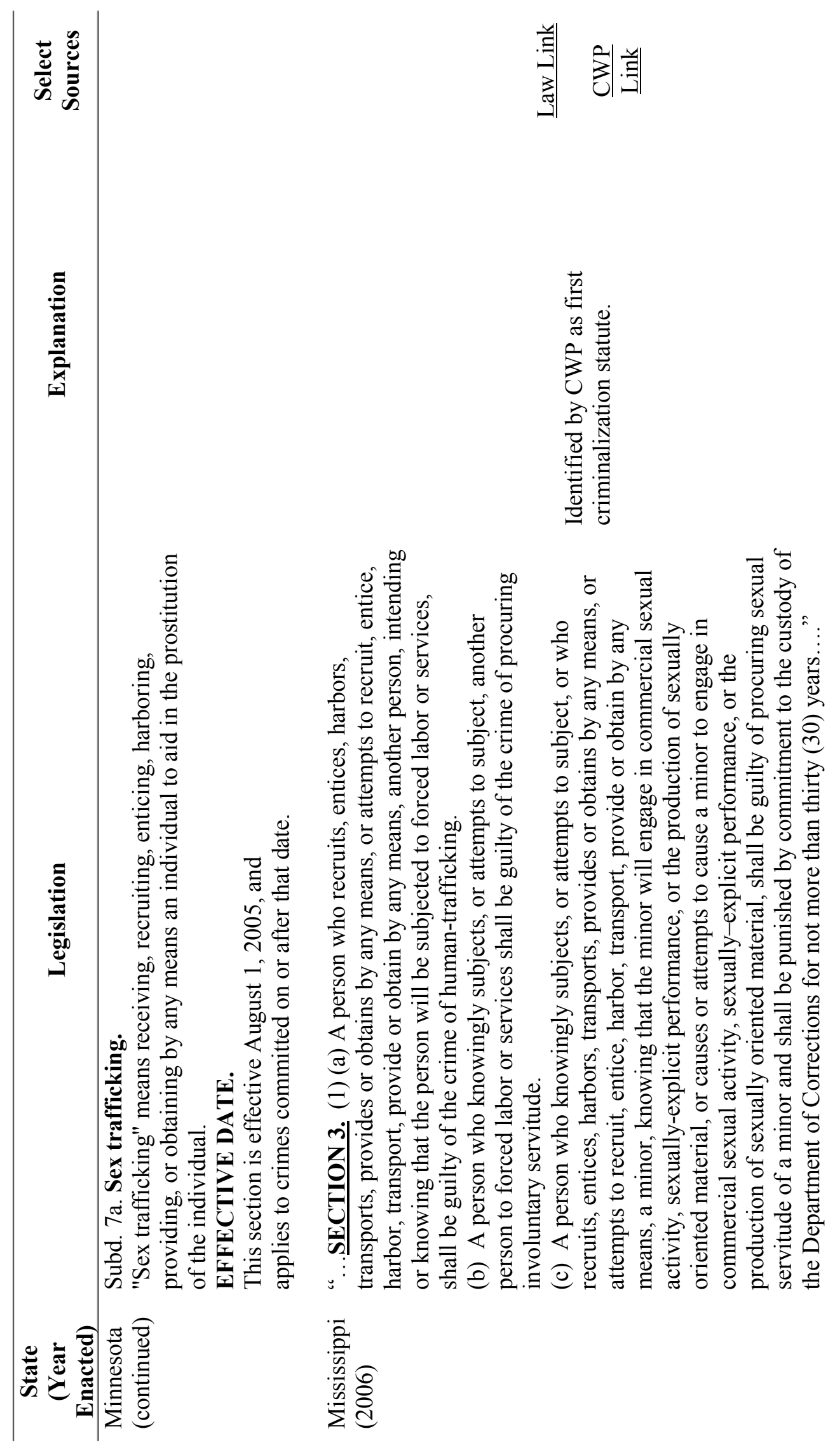




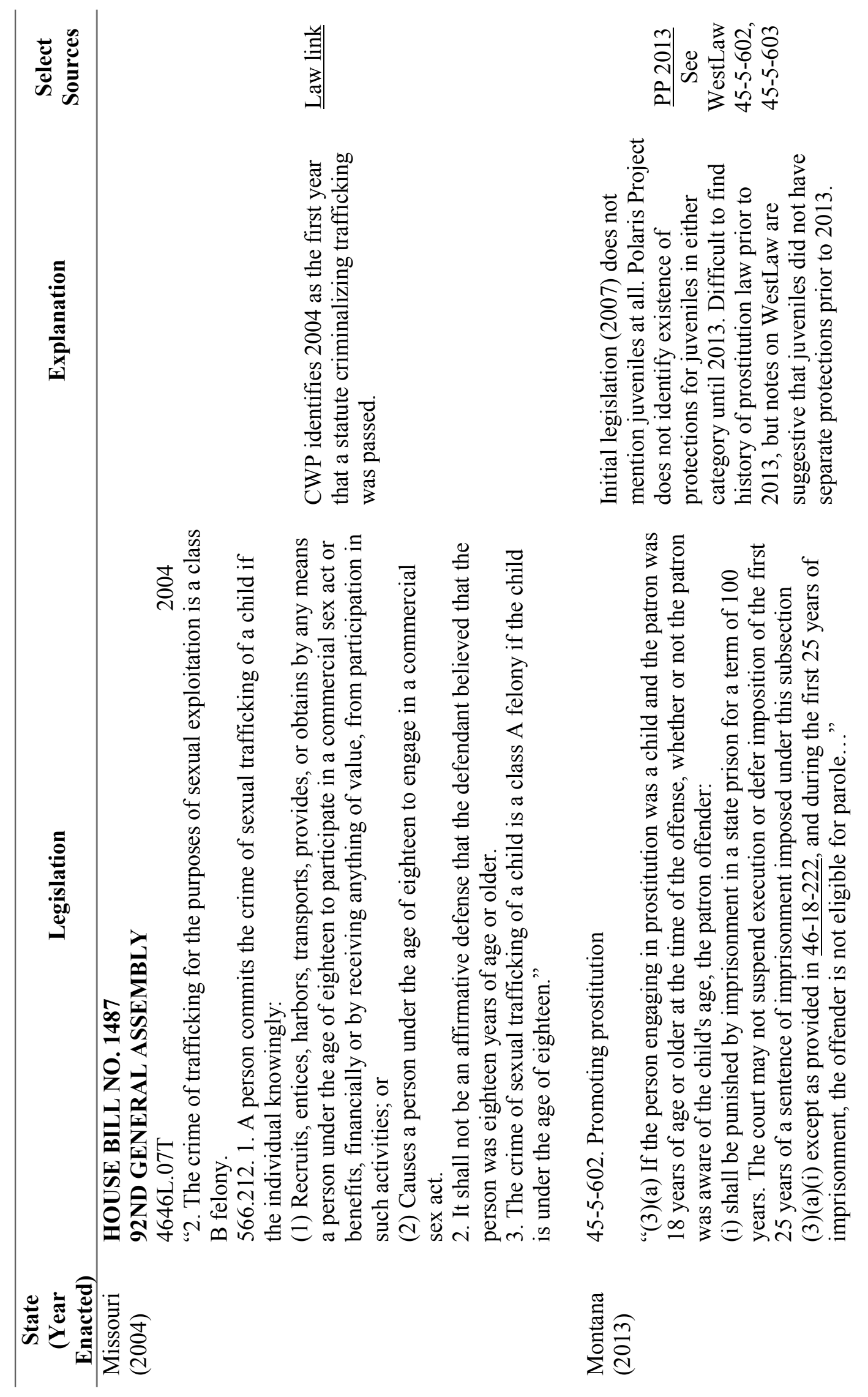




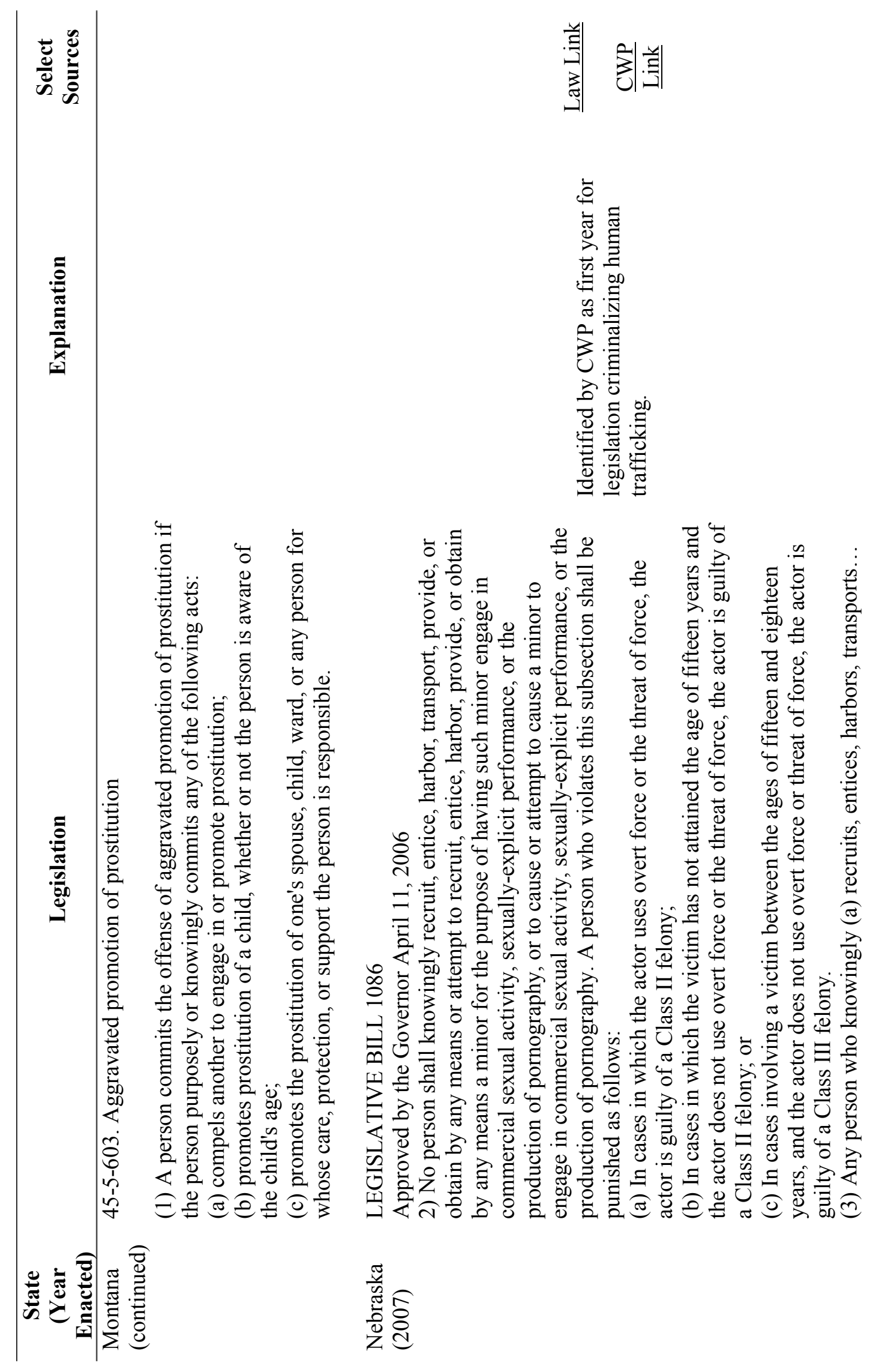




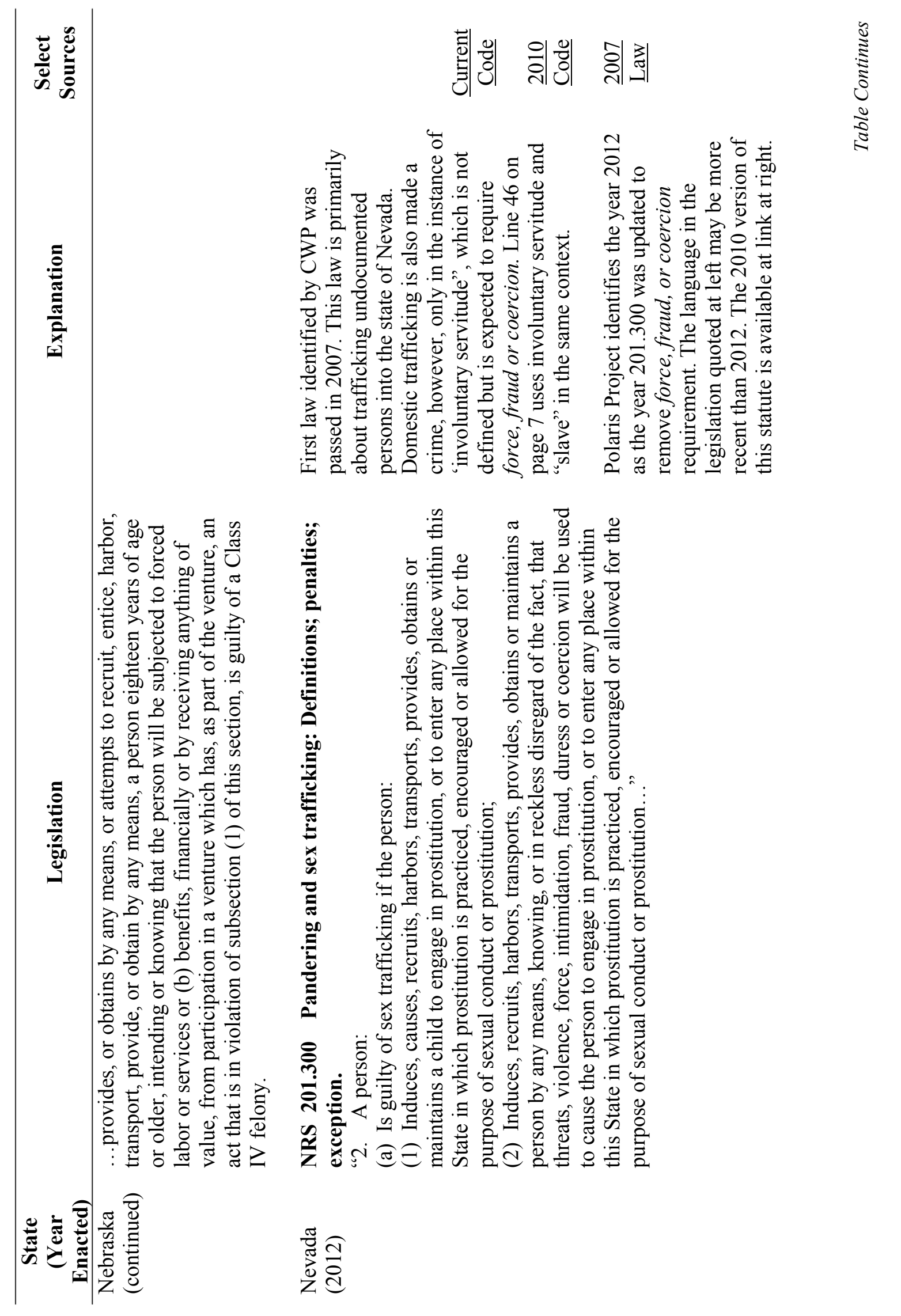




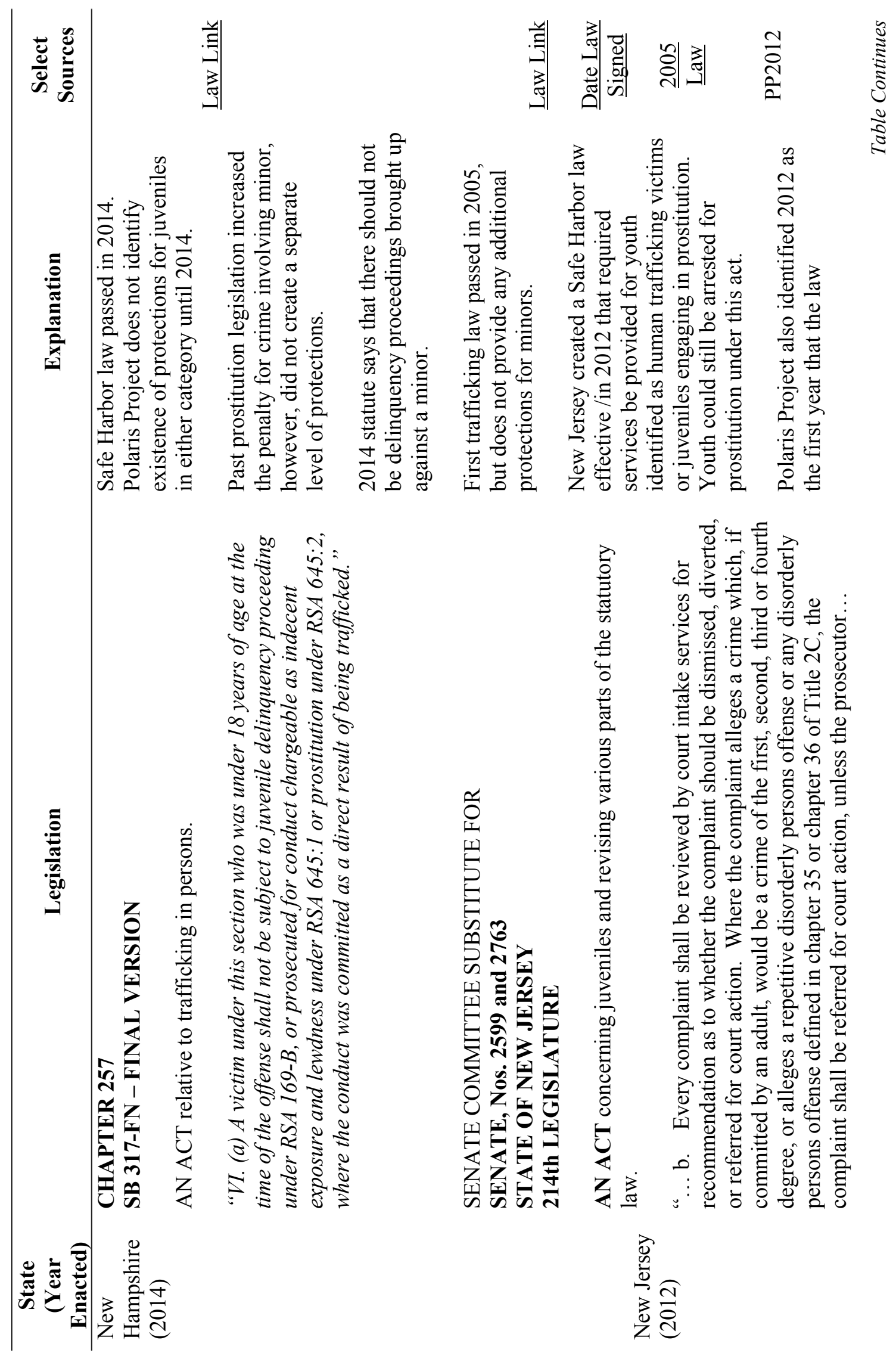



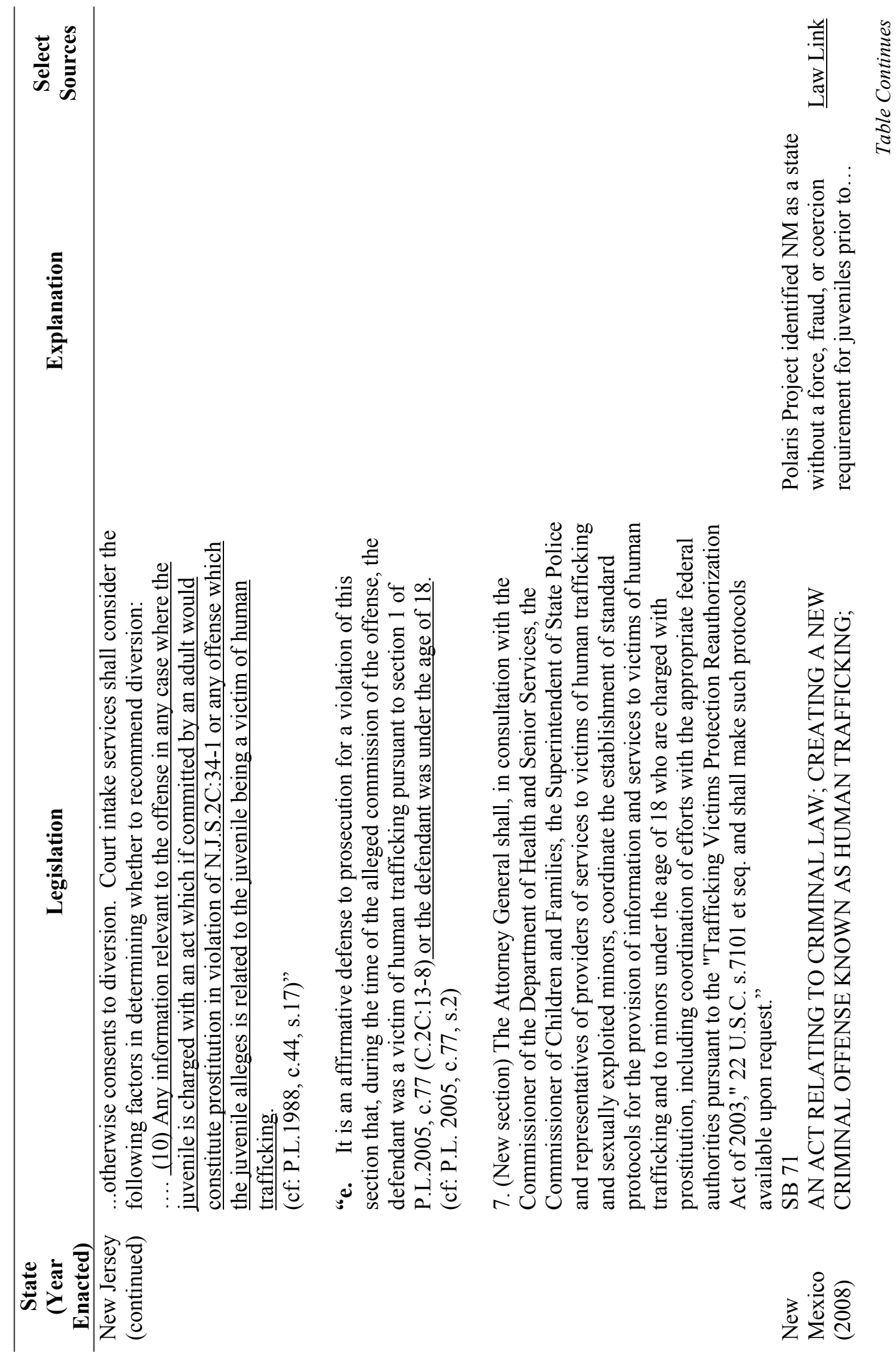

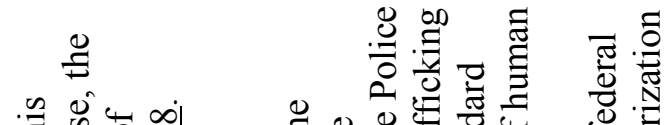

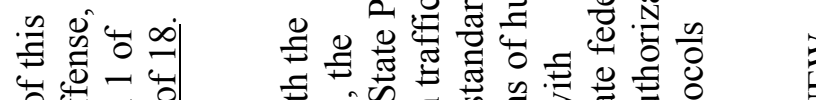

藏

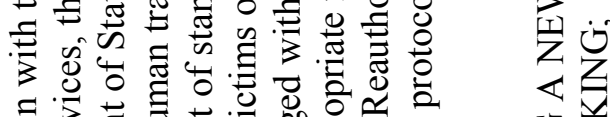

全

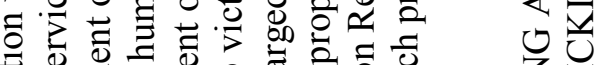

ช.

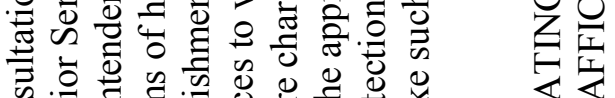

远.

ฮี పี

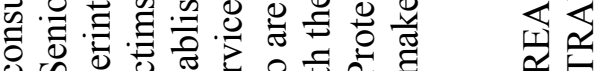

ठํ

웅

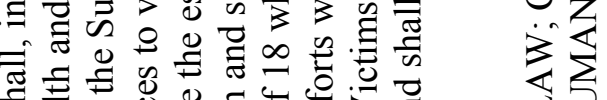

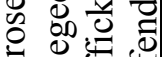

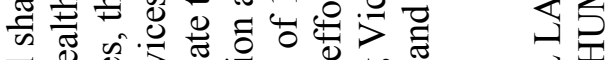

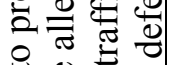

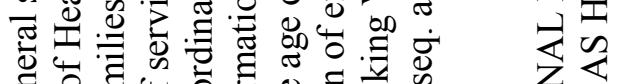

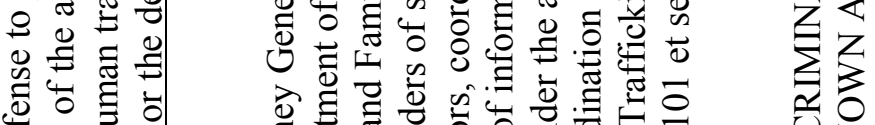

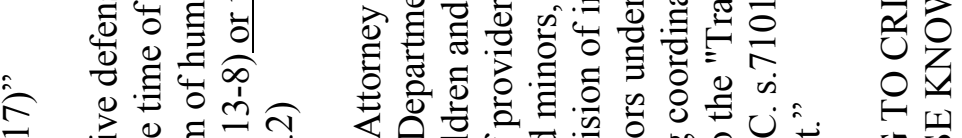

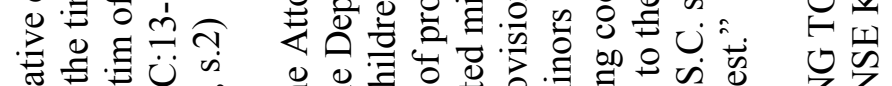

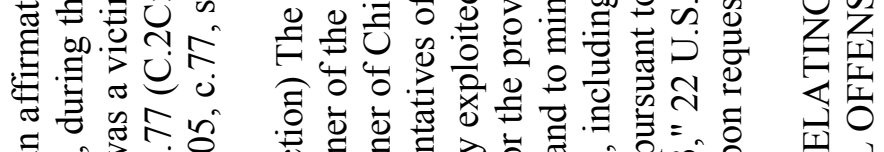

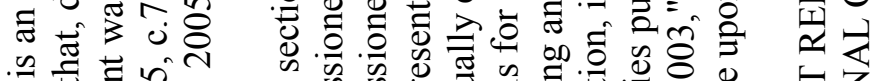

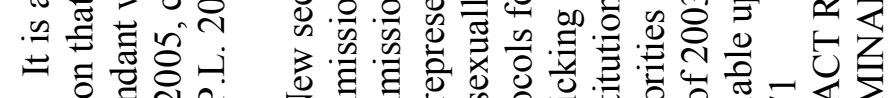

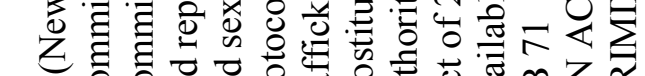

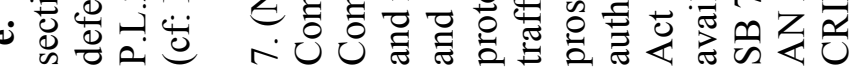

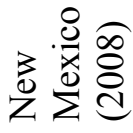




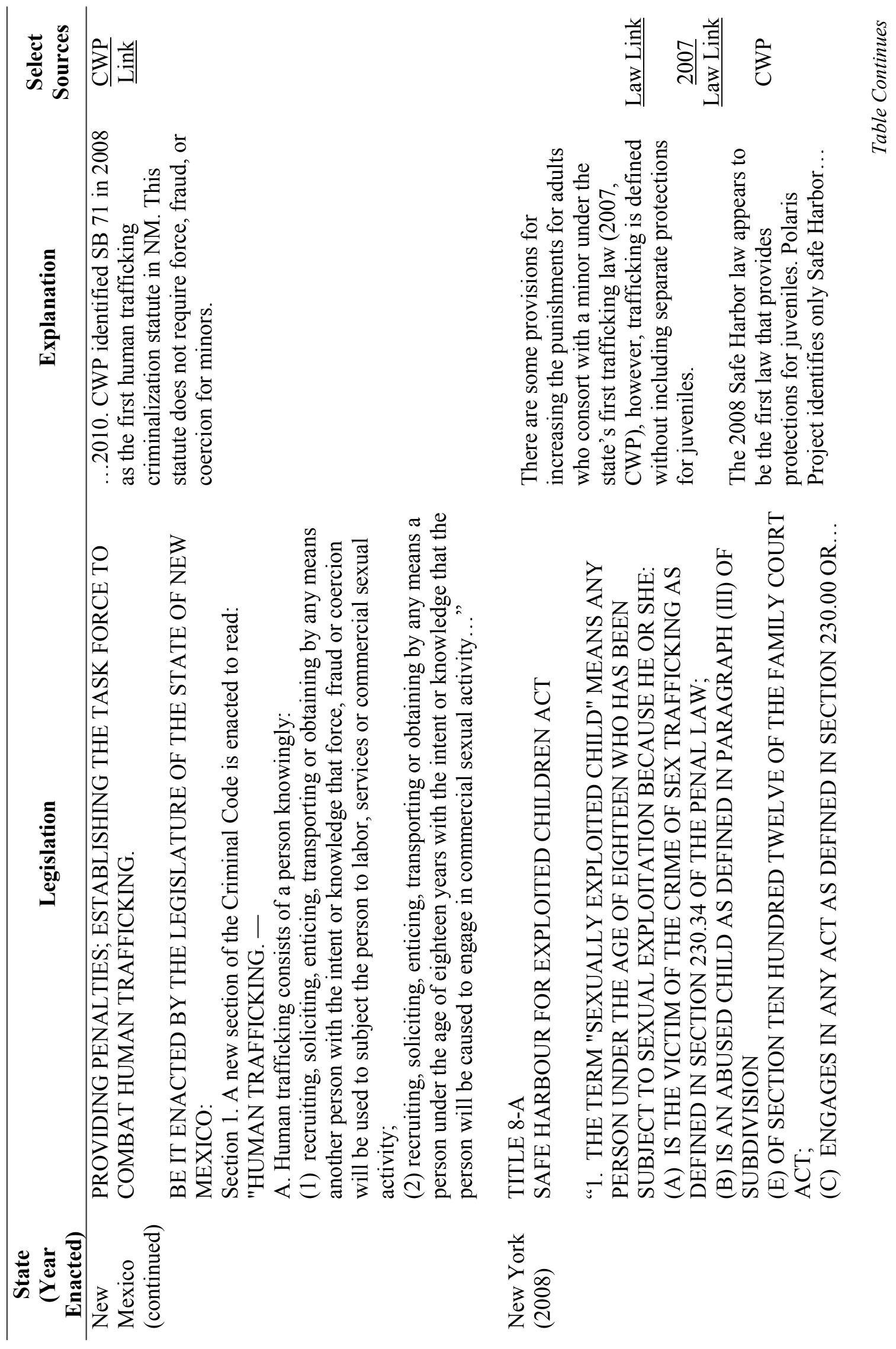




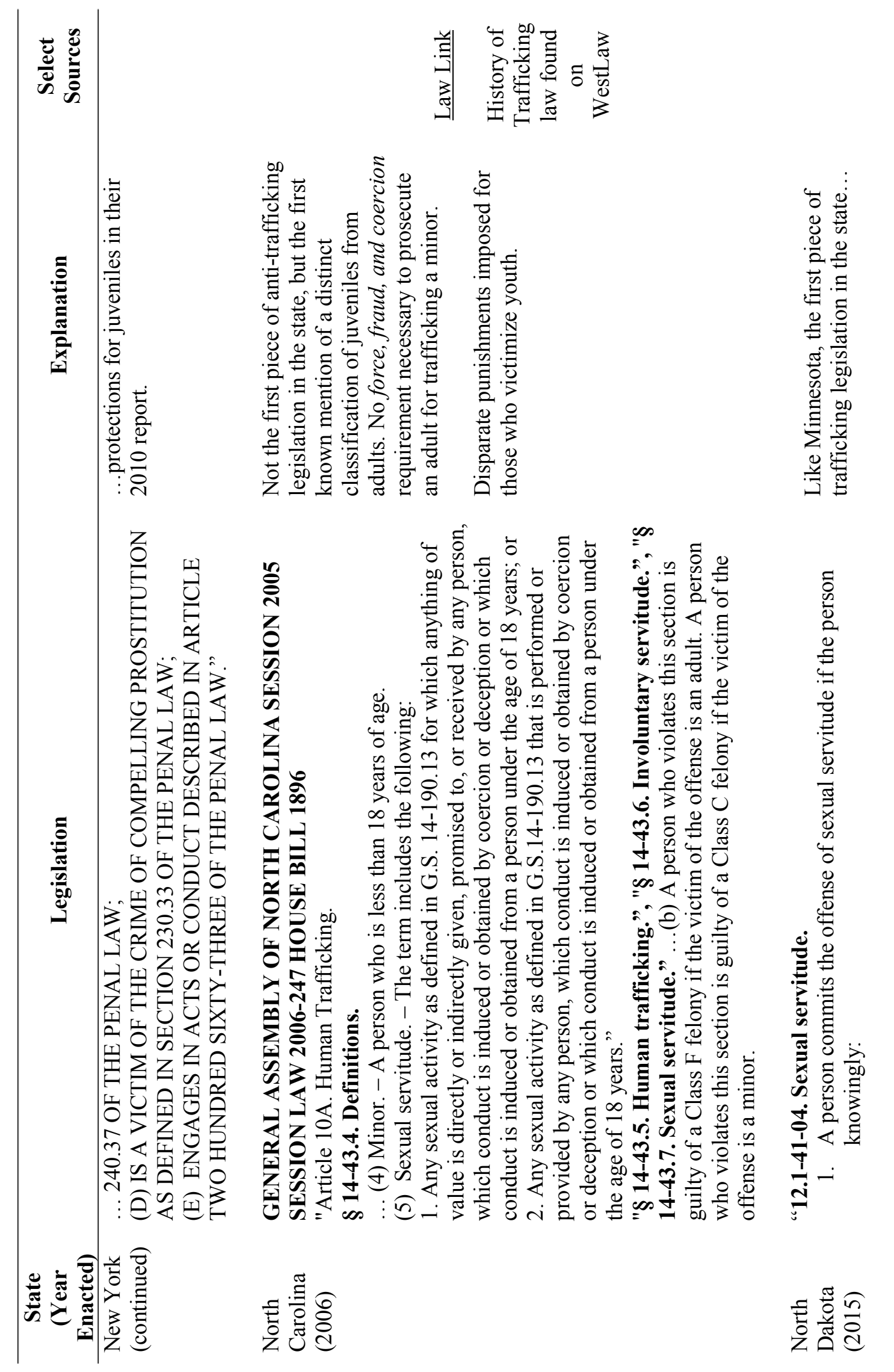




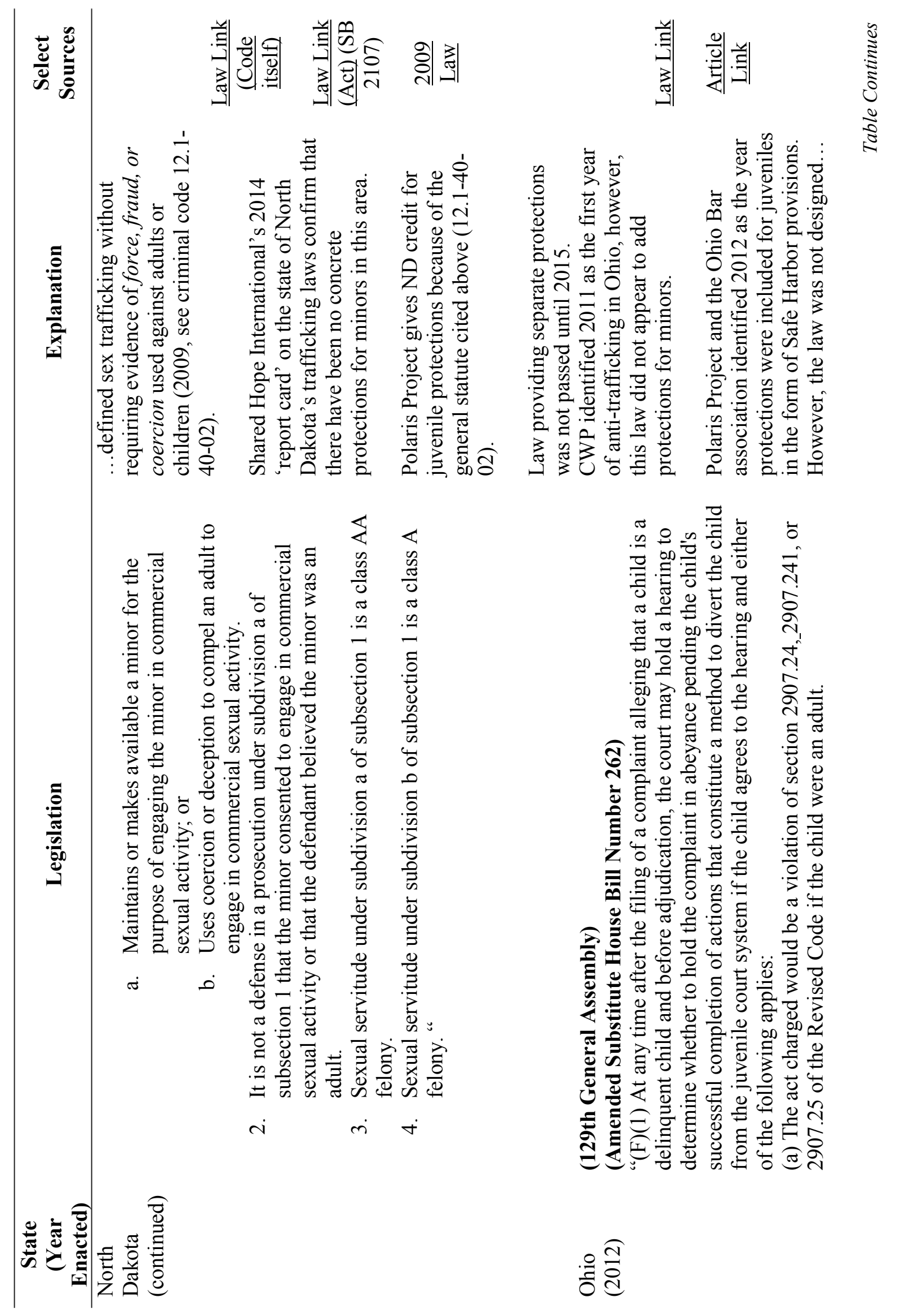




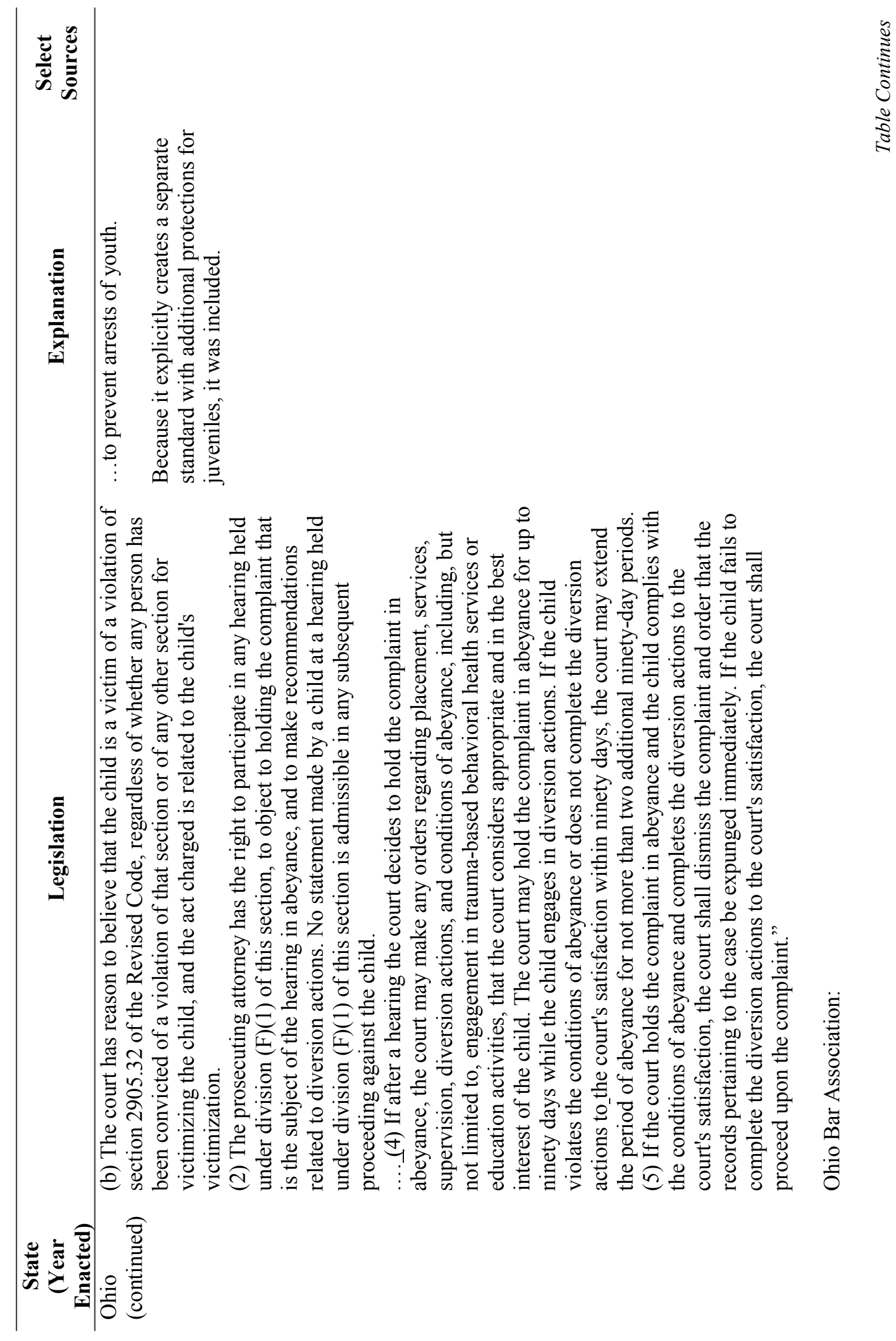




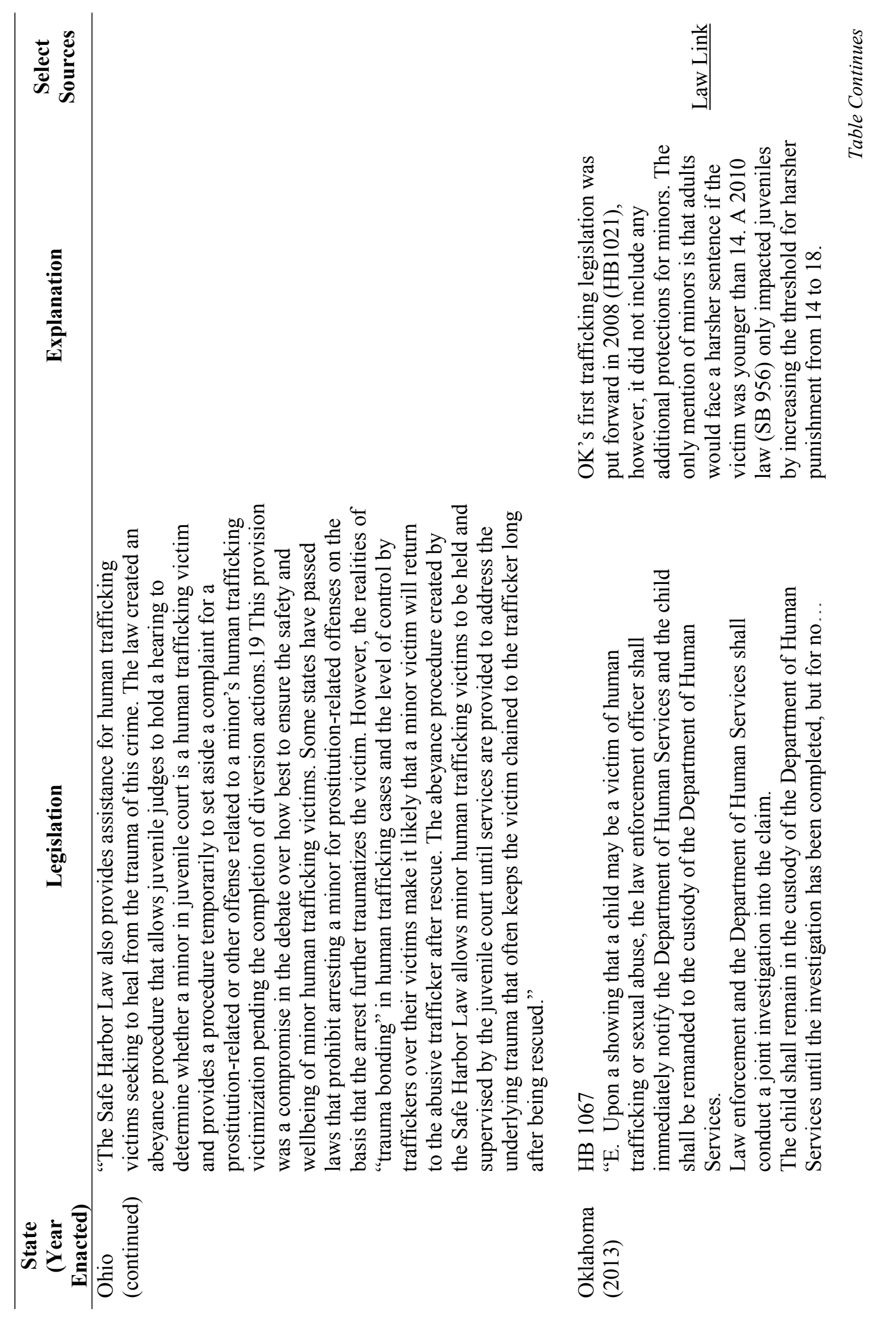



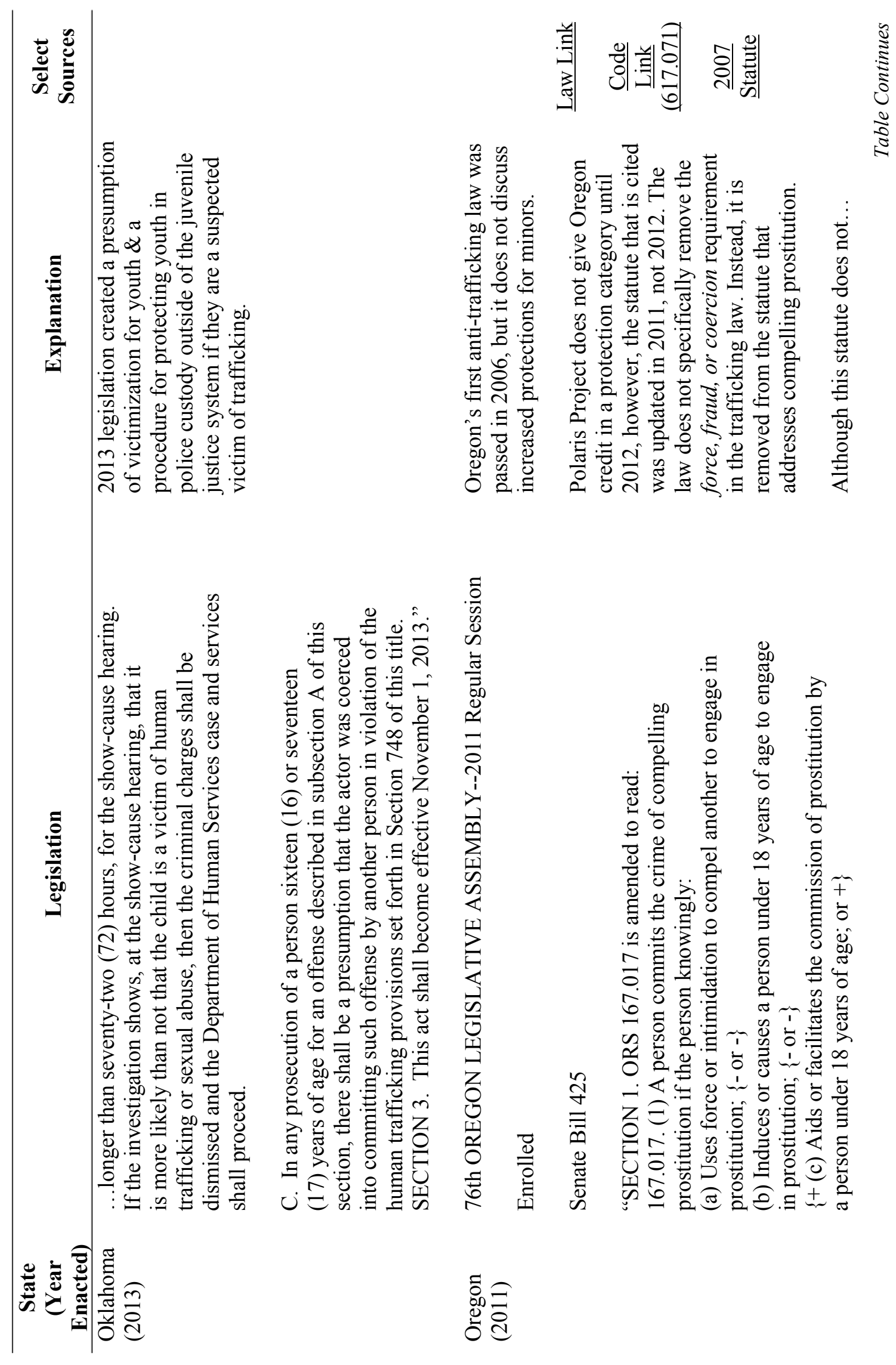

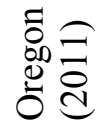




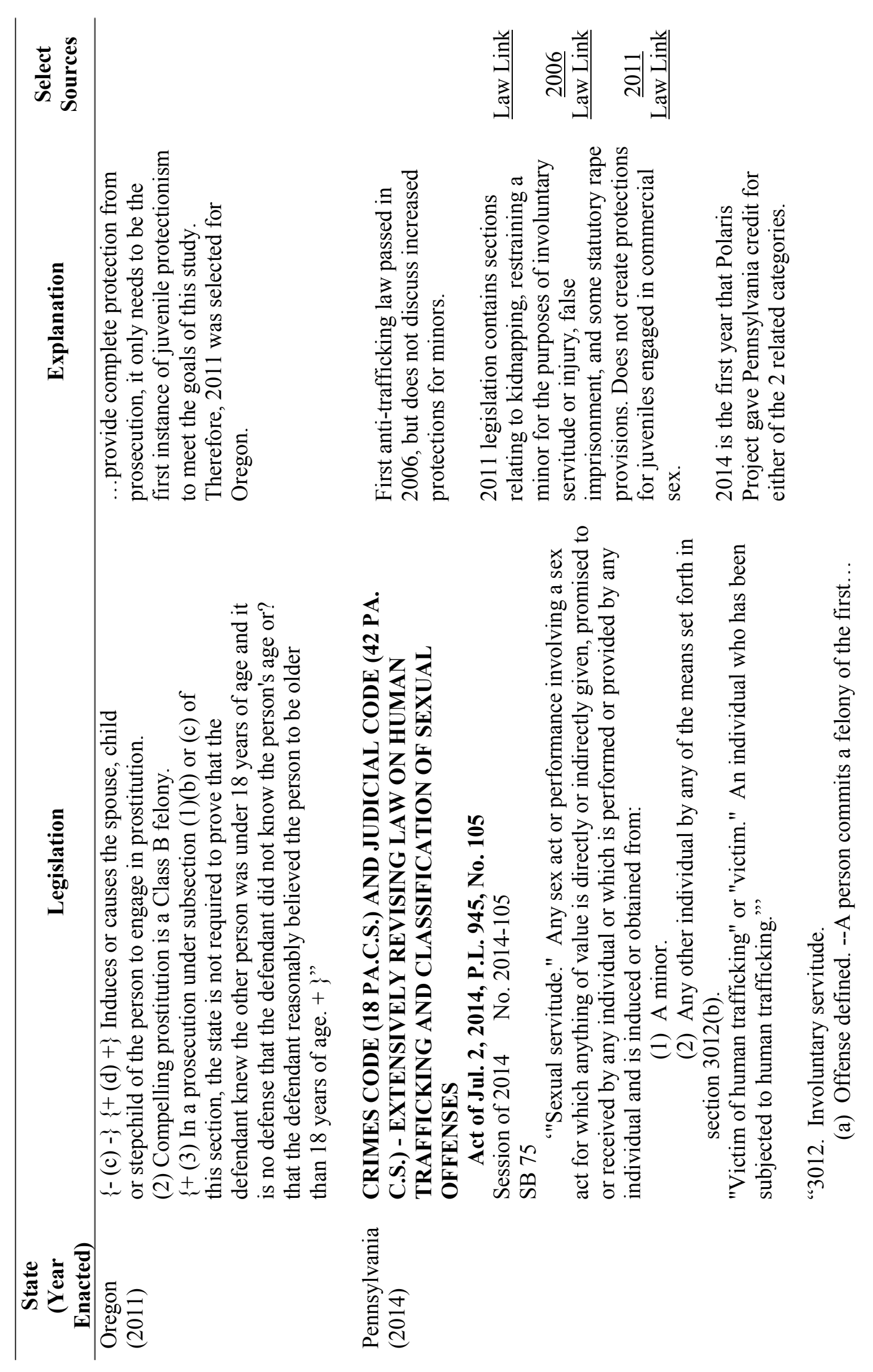




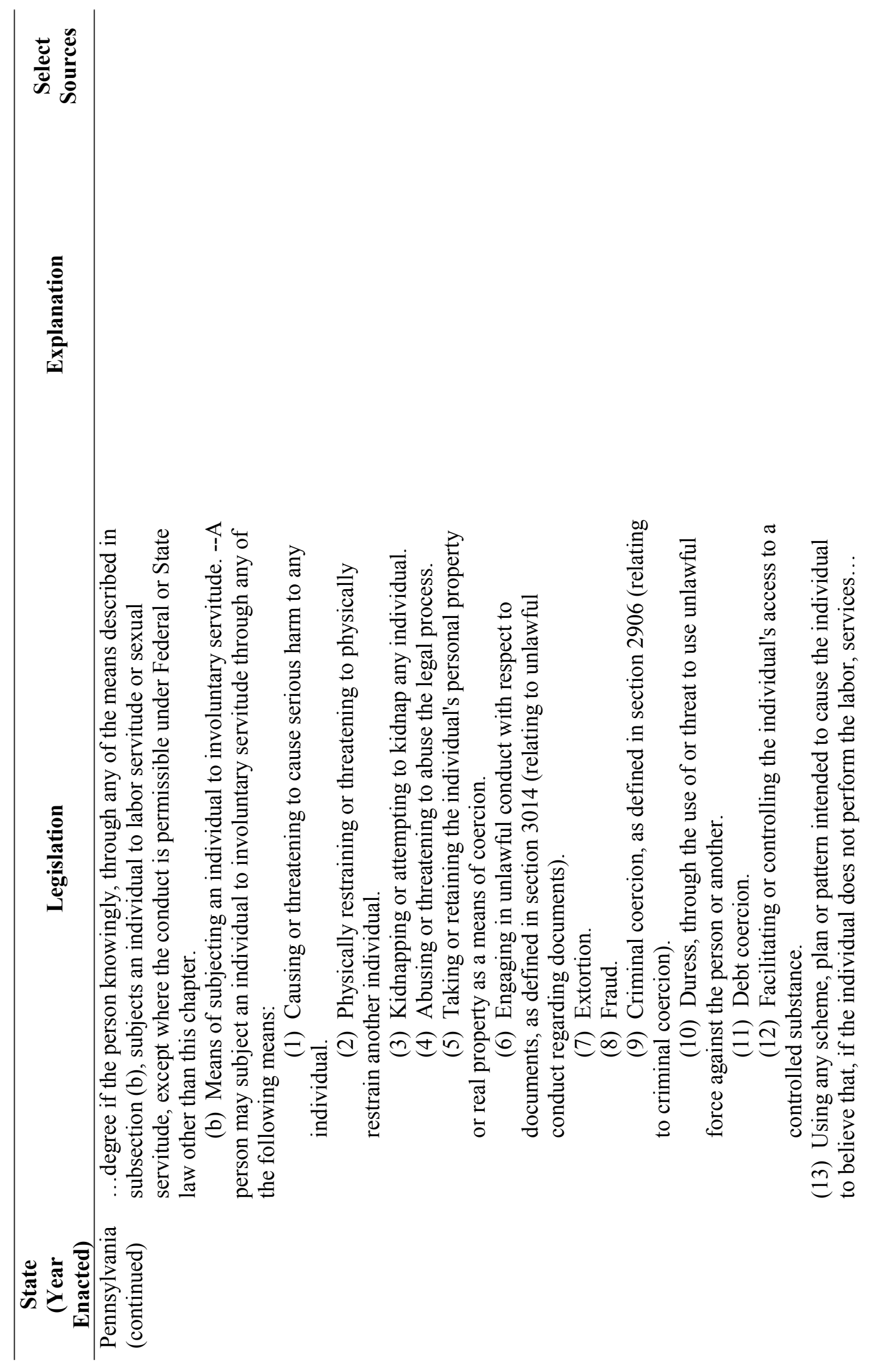




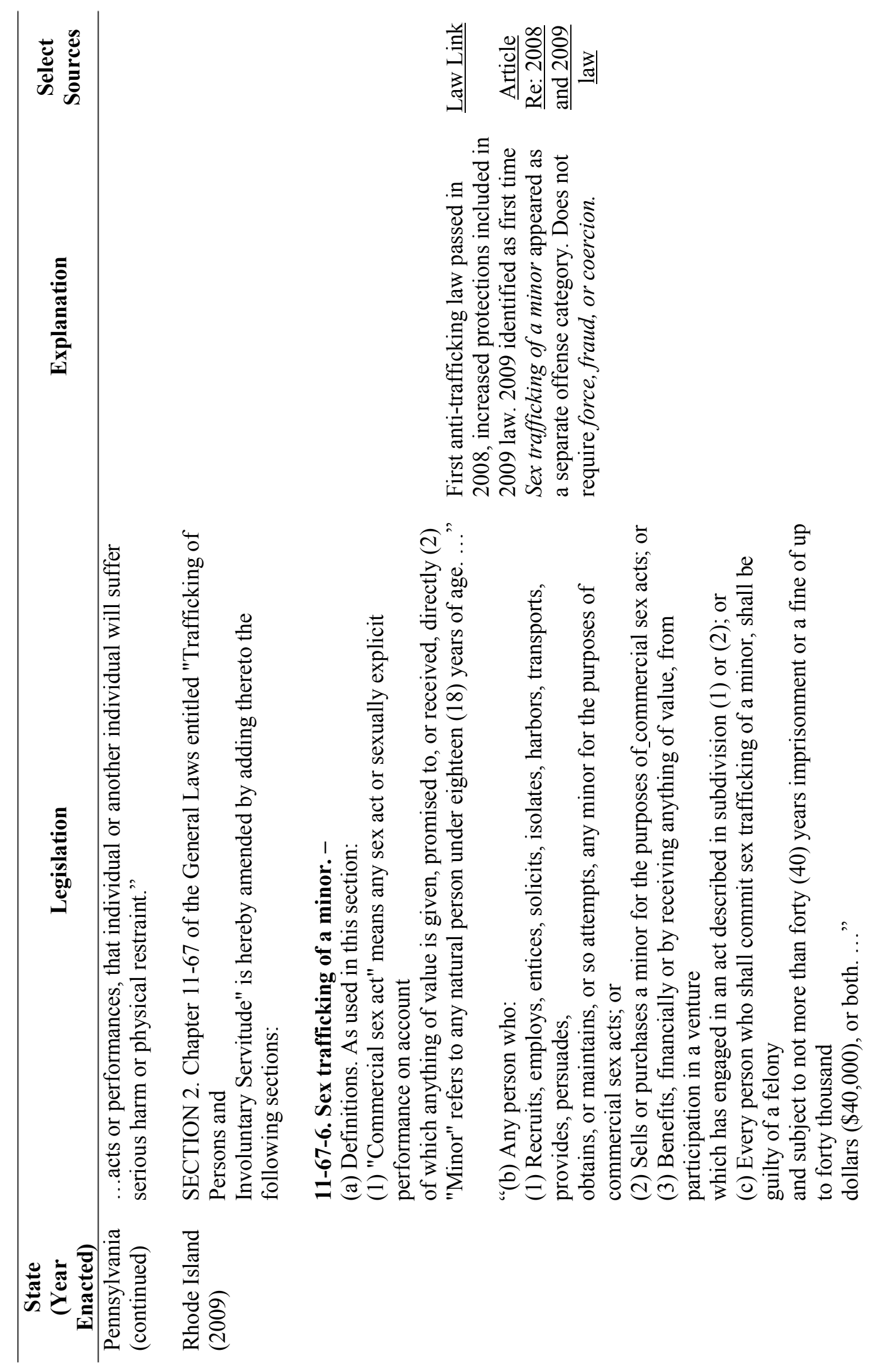

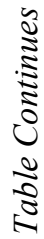




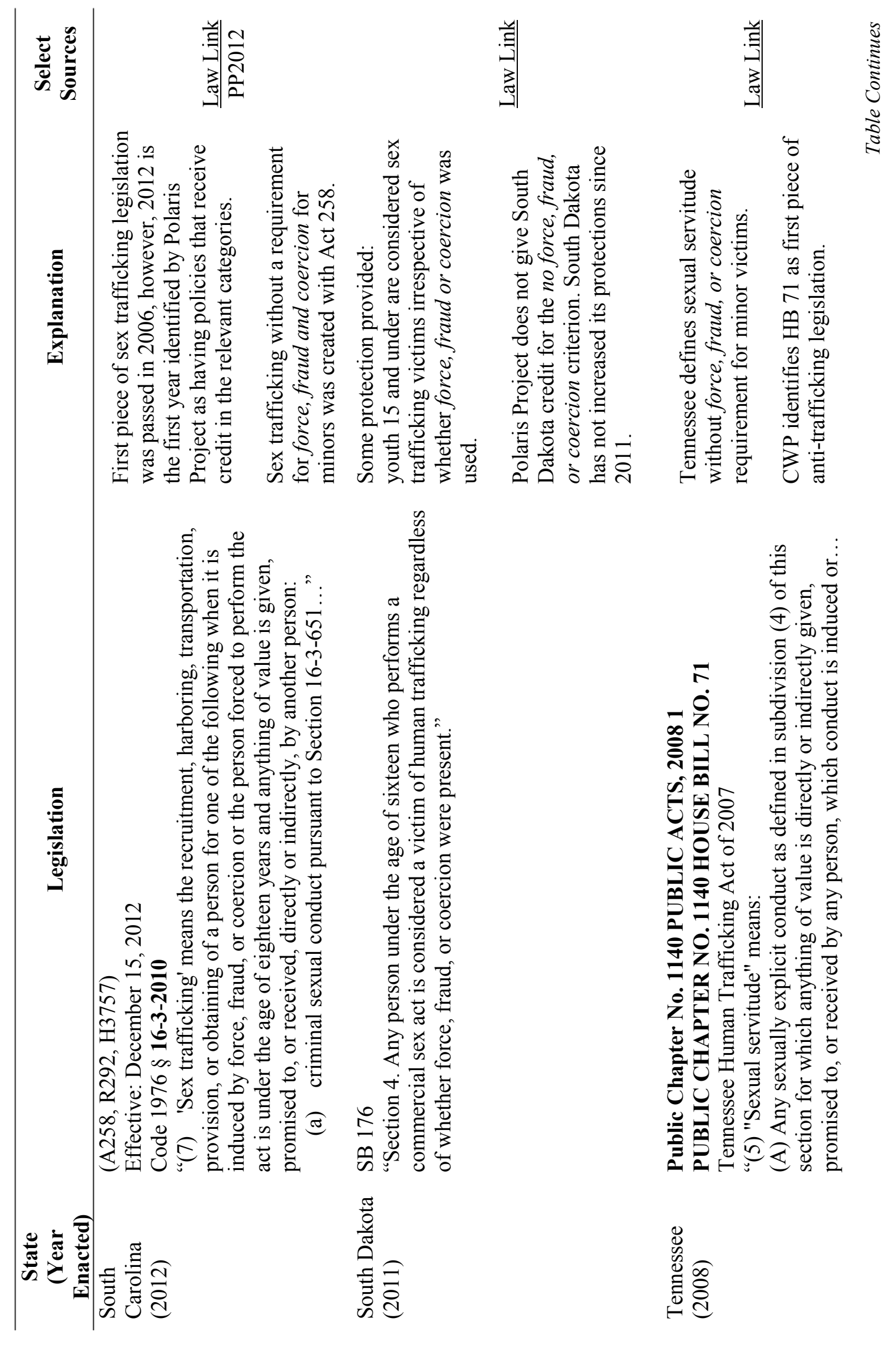




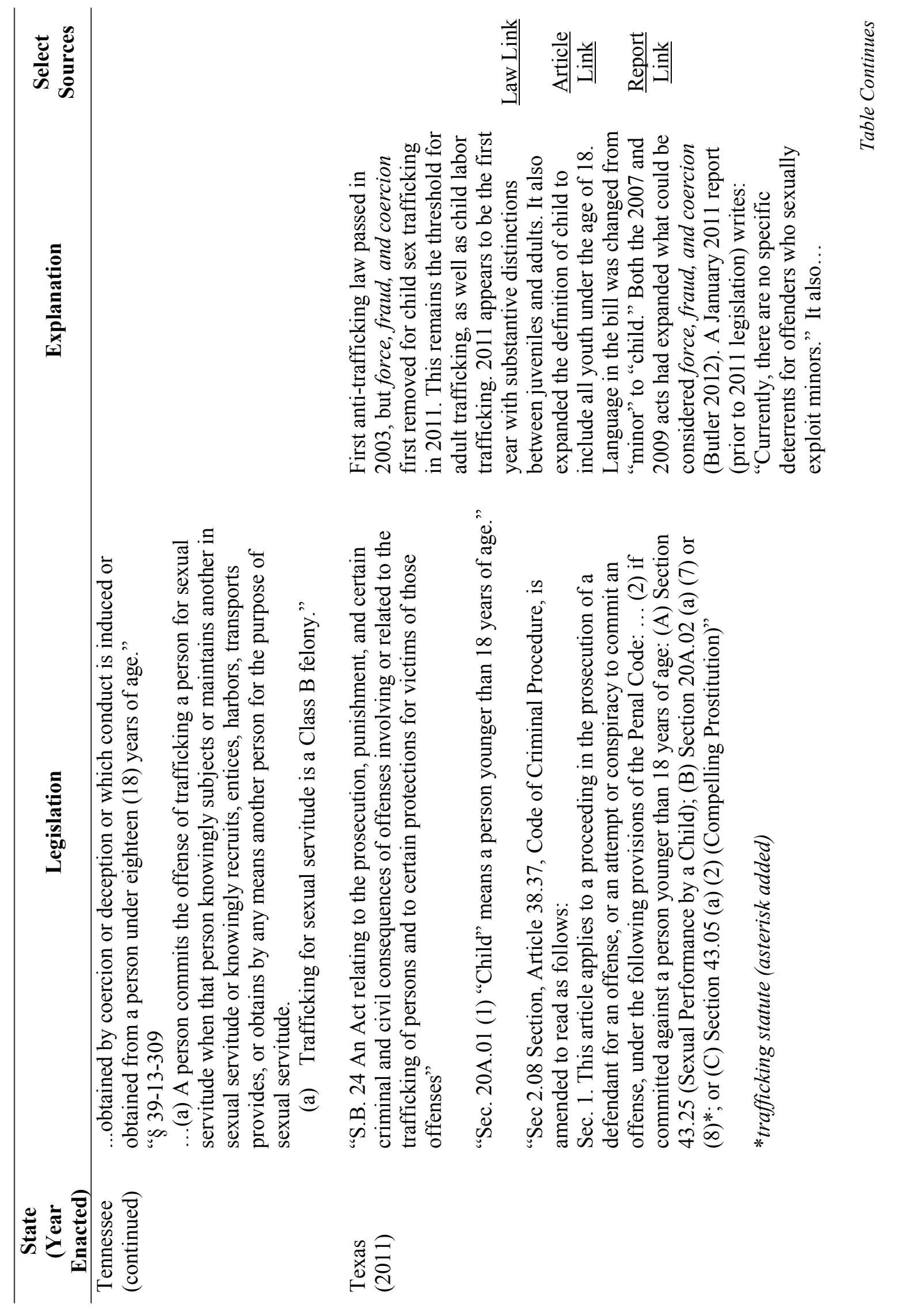




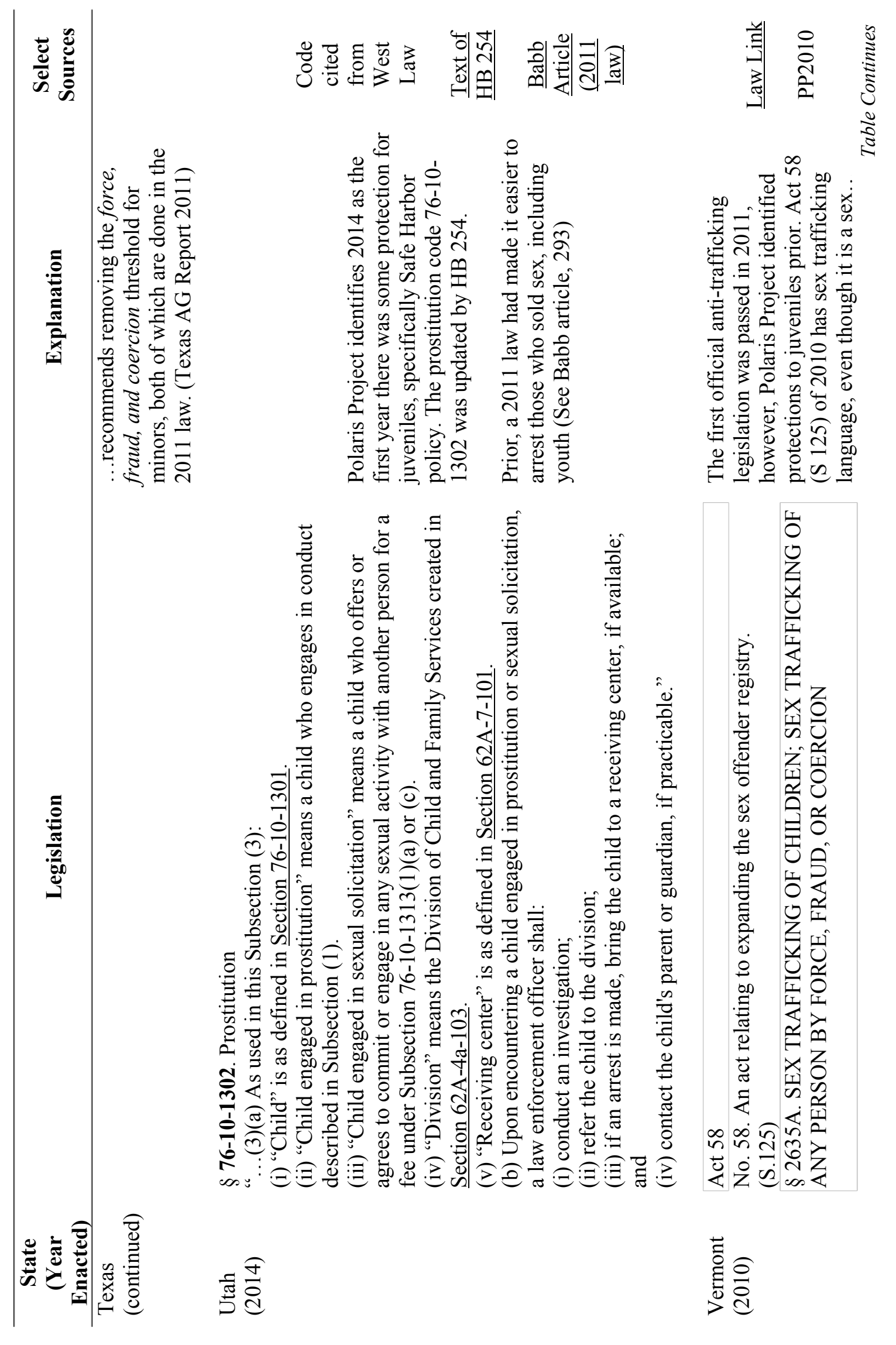



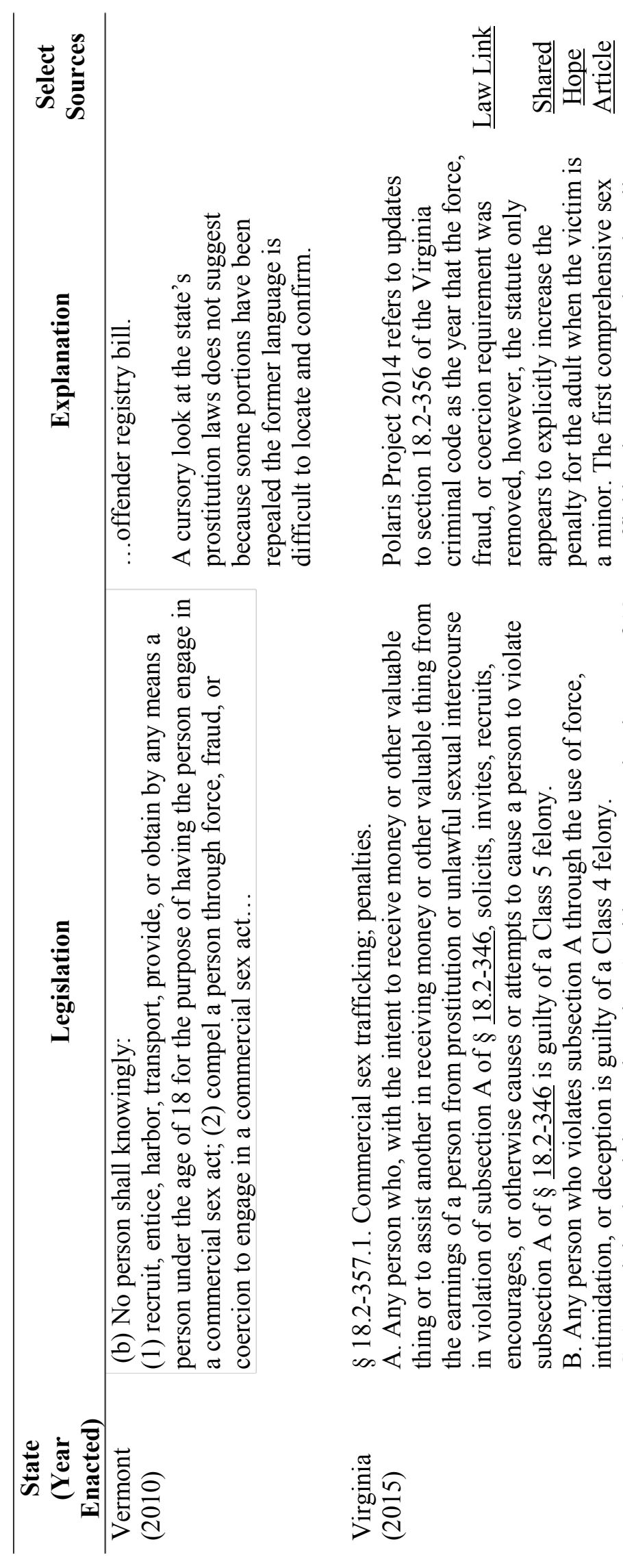

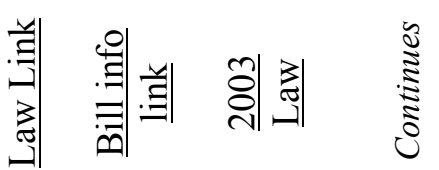

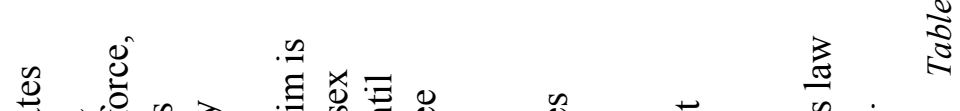

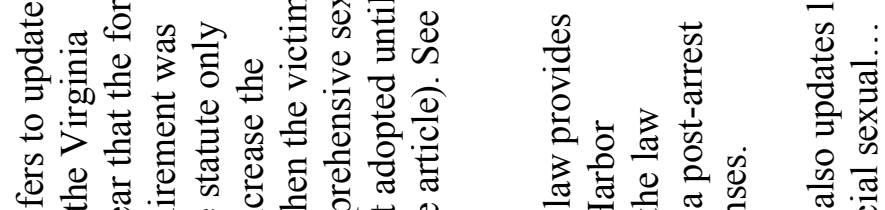
屯

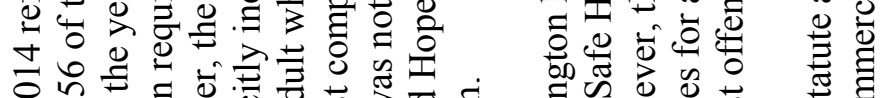

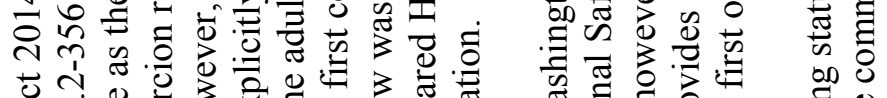
芯

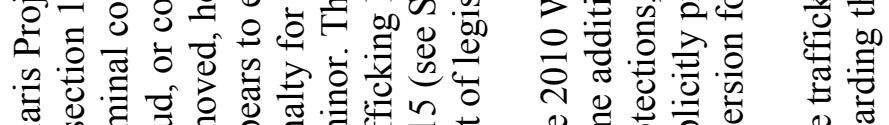

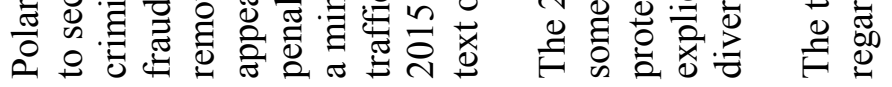

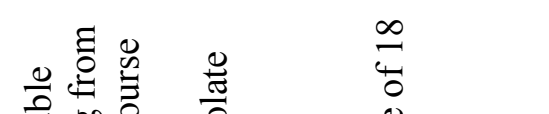

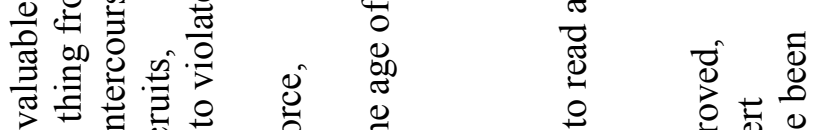

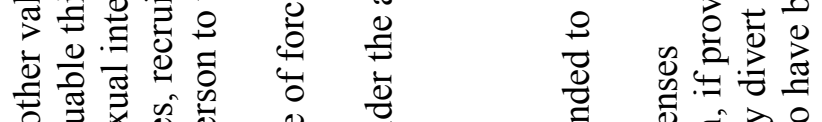

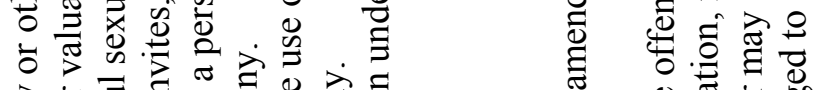

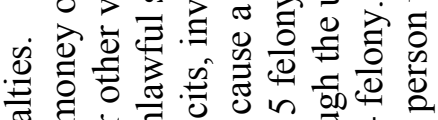

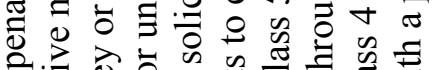

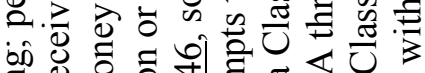

ดी

苛 0 ○

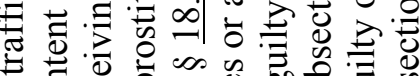

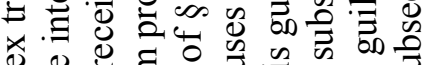

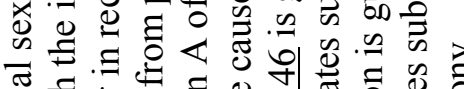

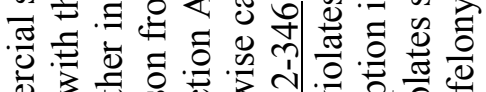

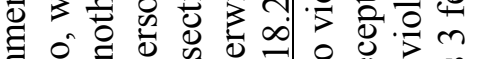

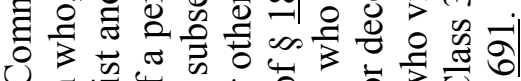

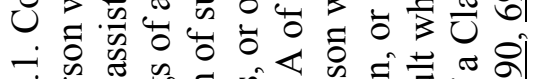

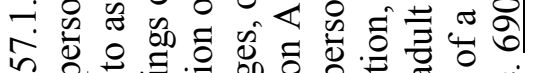

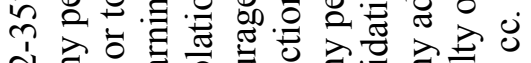

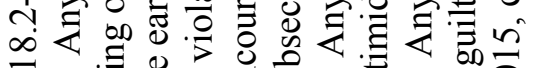

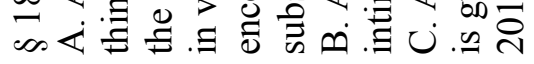

융

范

可 $\frac{0}{\bar{\sigma}} \overline{\mathrm{J}}$

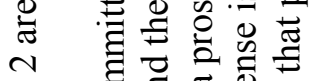

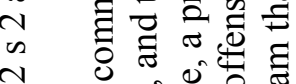

กิ

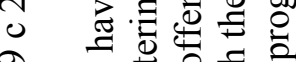

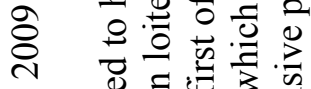

$\exists \quad 800.00$

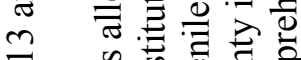

入 $\triangleq$ एँ

+ $\stackrel{0}{=}$

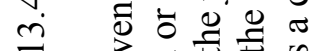

$3 \quad \stackrel{0}{0}$.

乙. .

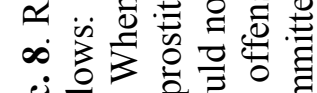

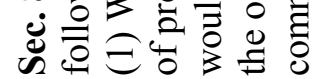

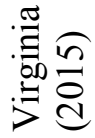

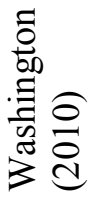




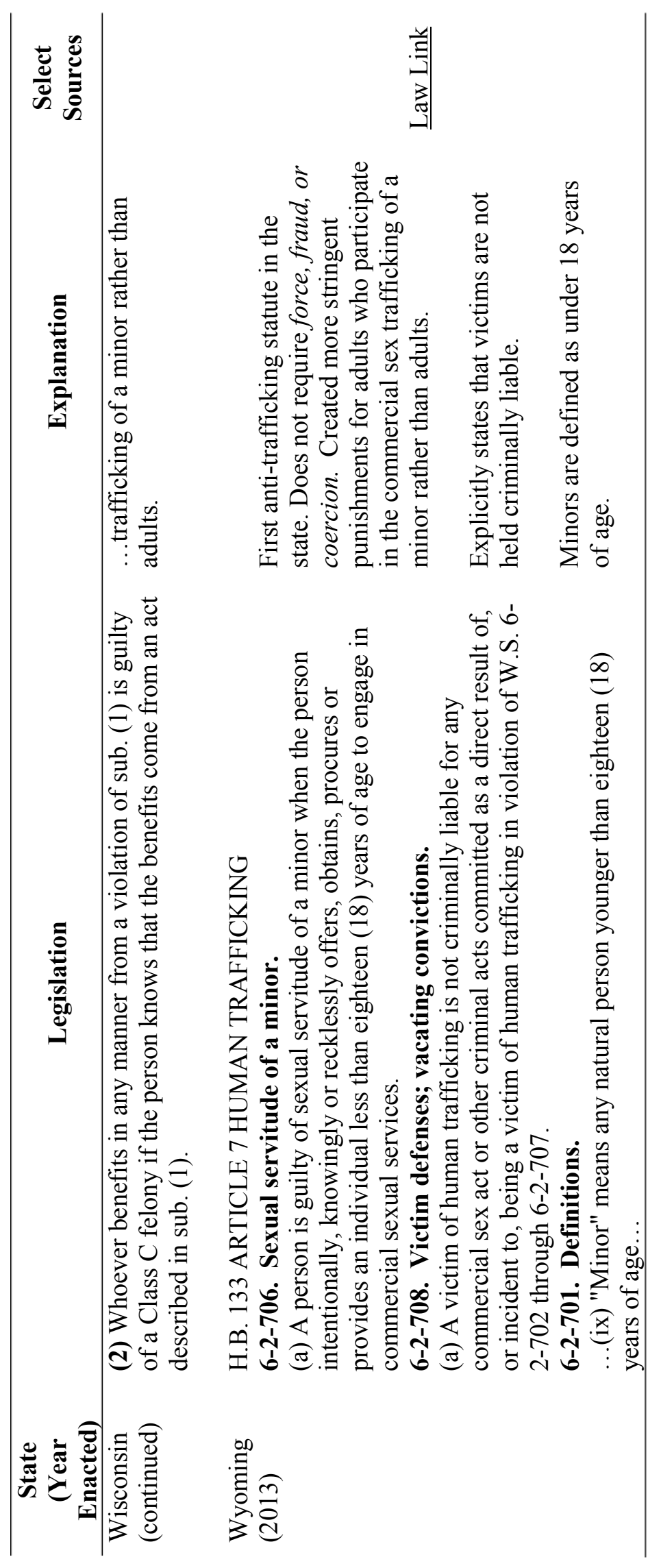




\section{APPENDIX C \\ DISCUSSION OF CIUS DATASET AND POTENTIAL LIMITATIONS}

Like all datasets, the CIUS has several limitations that must be considered in context of this study. First, the CIUS definition of Prostitution and Commercialized Vice, as stated earlier, contains counts of juveniles arrested for prostituting, as well as potential arrests of juveniles buying or facilitating the exchange of sex for money. The non-specific or heterogeneous nature of other offense categories has been discussed by other researchers, albeit few (Steffensmeier et al. 2015). An attempt was made to look at this offense category in a disaggregated way using data available under NIBRS; however, due to such low reporting it is was difficult to draw meaningful conclusions from the numbers. In addition, the NIBRS data currently available only divides the category into two sections, prostitution and assisting prostitution. The 'assisting' subcategory could encompass a wide range of behaviors including some who may be legally classified as victims and some who may not.

Although the precise proportion of these different sub-categories is unknown in the CIUS data used in the model, the study is concerned with seeing a decrease in arrests for an individual state over time. This study makes the assumption that non-victim proportions within each state do not vary in a systematic way over time. However, if a pattern to the variability in non-victim arrests did exist, it is most plausible that these arrests would increase under new anti-trafficking lws that create harsher sanctions for 
facilitating child prostitution. This is unlikely, given that the literature frequently discusses the low frequency of demand-side arrests of johns and traffickers, even following changes to policy (see Spohn 2014; Farrell et al. 2013). Therefore, the most plausible but unlikely consequence of using this collapsed category is that non-victim arrests may dampen the true effect that this study is trying to measure. It is also important to emphasize that a state may have a nonzero number of arrests in this category and be successfully providing full immunity to trafficking victims.

A second limitation of the CIUS dataset is a lack of consistency in the proportion of the state's population the reporting covers. While the proportion of the U.S. population covered by this dataset has increased over time, year-to-year state reporting often fluctuates. In addition, recent years have seen a downturn in the number of agencies reporting. One study looked at the characteristics of the agencies failing to report for a very similar FBI dataset with a similar reporting structure to the CIUS arrest data. The study found that the percentage of the population not covered through agency reporting had grown from 10 percent in 1992 to just over 12 percent by 2003 . More importantly, it found that agencies that are less likely to report share certain characteristics, they are disproportionately: from rural or suburban counties, from New England or South Atlantic regions, and are less likely to have a UCR program (Lynch and Jarvis 2008). In a footnote, the study briefly mentions that non-reporting agencies for arrest data appear to have the same characteristics, but the percentage of the population not covered by reporting is approximately 10 to 20 percent larger. It is clear that the data from this study will face some inconsistencies in agencies that report on a yearly basis, but it must operate under the assumption that non-reporting agencies do 
not have arrest trends that vary in a way that differs from those that report.

Inconsistency in reporting is the most pressing data problem facing this study and future study on the extent of the variation would be beneficial. The model accounts for this limitation by using only the proportion of the state's population that is covered by the FBI data to calculate the arrest rates.

The broad nature of the offense categories and incomplete reporting are among the most commonly discussed methodological issues with FBI crime data. There are a few others that do not pose a challenge in the current study but should be explained. One frequently raised concern with the UCR is its inability to ascertain the true amount of crime occurring in an area; however, the arrest data used for this study does not attempt to draw these types of estimates. A second related concern is that the data are vulnerable to policy and law enforcement shifts. This, again, is a relevant concern for researchers who are attempting to use FBI data to show the level of crime in an area irrespective of whether it is reported, not the level of arrest. In this instance, the identified 'limitation' is precisely what makes CIUS data appropriate for this study. An additional methodological issue considered in other research is inconsistency in the procedures, definitions, and completeness or honesty of agency level reporting (Loftin and McDowall 2010, Steffensmeier et al. 2015). Similar to the discussion above, a benefit of this analysis is that it is concerned with intrastate changes in arrest rate. While different agencies may have significantly different reporting procedures or definitions, it is not likely that individual agencies are drastically changing their own processes year to year. The study must operate under the assumption that if agencies are reporting in an inaccurate or dishonest way, that they are doing so consistently. 
APPENDIX D

\section{JUVENILE ARREST RATE MAPS}

Figure D-1

Juvenile Arrest Rate Maps

2001
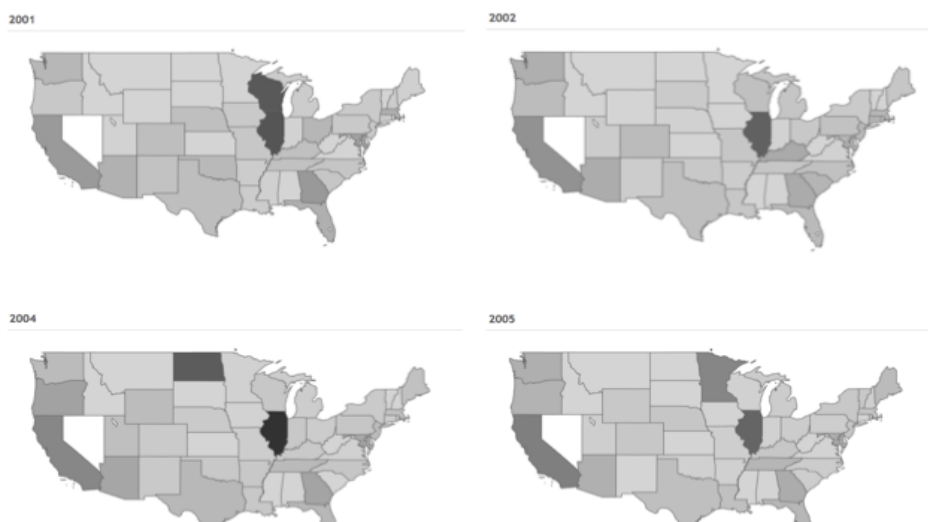

2005

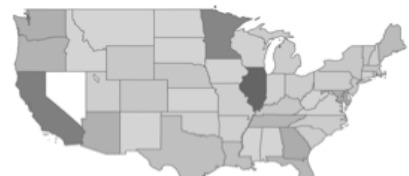

2007

2000

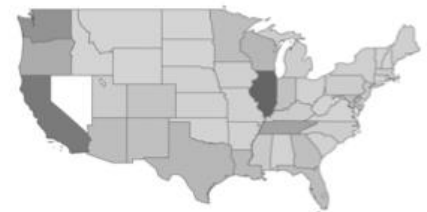

2010
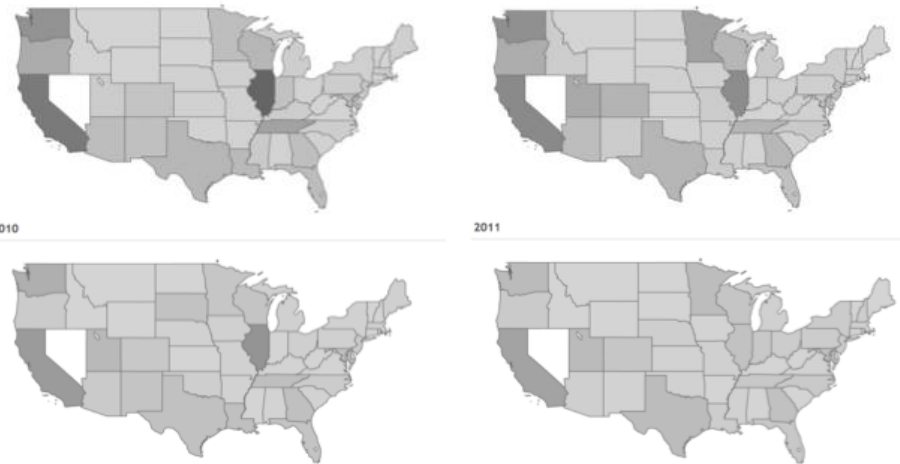

2011
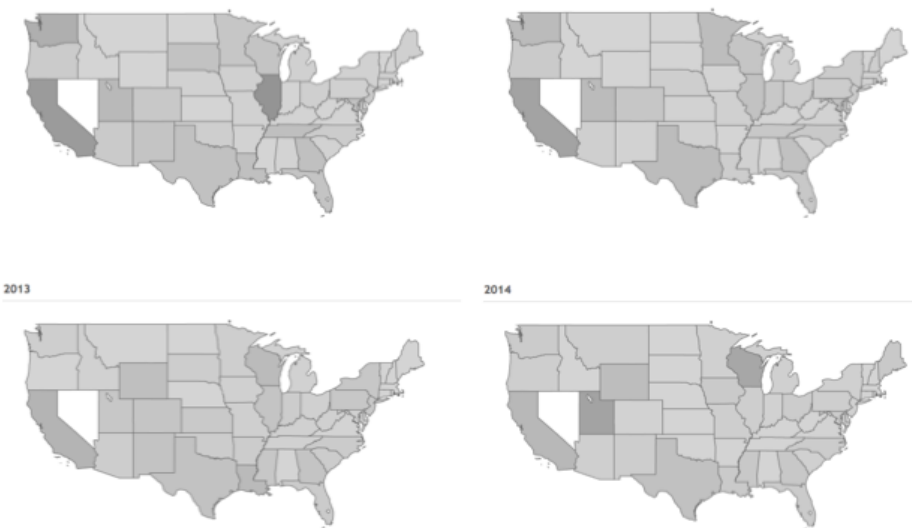

2003

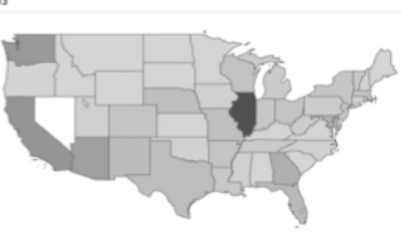

2006

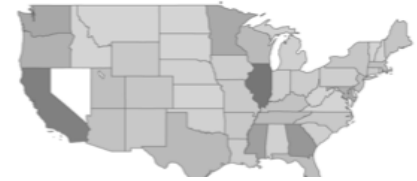

2009

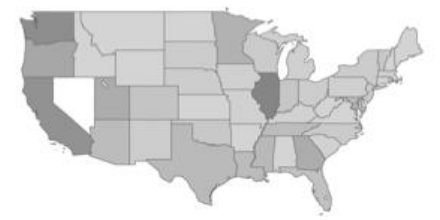

2012

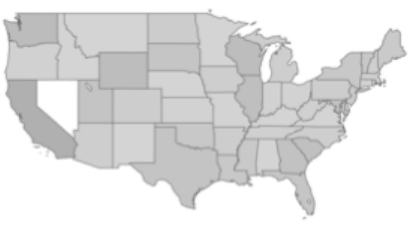

